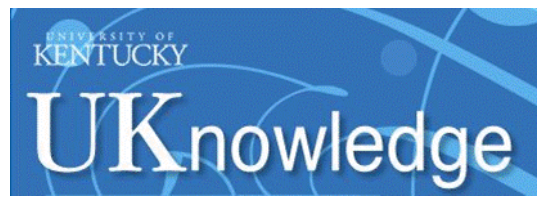

University of Kentucky

UKnowledge

Theses and Dissertations--Educational, School, and Counseling Psychology

Educational, School, and Counseling

Psychology

2016

\title{
THE ROLE OF ADULT ATTACHMENT IN INTERNATIONAL STUDENTS' ACCULTURATION PROCESS
}

\author{
Miao Li \\ University of Kentucky, miao.li@uky.edu \\ Digital Object Identifier: http://dx.doi.org/10.13023/ETD.2016.028
}

Right click to open a feedback form in a new tab to let us know how this document benefits you.

\section{Recommended Citation}

Li, Miao, "THE ROLE OF ADULT ATTACHMENT IN INTERNATIONAL STUDENTS' ACCULTURATION PROCESS" (2016). Theses and Dissertations--Educational, School, and Counseling Psychology. 42. https://uknowledge.uky.edu/edp_etds/42

This Doctoral Dissertation is brought to you for free and open access by the Educational, School, and Counseling Psychology at UKnowledge. It has been accepted for inclusion in Theses and Dissertations--Educational, School, and Counseling Psychology by an authorized administrator of UKnowledge. For more information, please contact UKnowledge@lsv.uky.edu. 


\section{STUDENT AGREEMENT:}

I represent that my thesis or dissertation and abstract are my original work. Proper attribution has been given to all outside sources. I understand that I am solely responsible for obtaining any needed copyright permissions. I have obtained needed written permission statement(s) from the owner(s) of each third-party copyrighted matter to be included in my work, allowing electronic distribution (if such use is not permitted by the fair use doctrine) which will be submitted to UKnowledge as Additional File.

I hereby grant to The University of Kentucky and its agents the irrevocable, non-exclusive, and royalty-free license to archive and make accessible my work in whole or in part in all forms of media, now or hereafter known. I agree that the document mentioned above may be made available immediately for worldwide access unless an embargo applies.

I retain all other ownership rights to the copyright of my work. I also retain the right to use in future works (such as articles or books) all or part of my work. I understand that I am free to register the copyright to my work.

\section{REVIEW, APPROVAL AND ACCEPTANCE}

The document mentioned above has been reviewed and accepted by the student's advisor, on behalf of the advisory committee, and by the Director of Graduate Studies (DGS), on behalf of the program; we verify that this is the final, approved version of the student's thesis including all changes required by the advisory committee. The undersigned agree to abide by the statements above.

Miao Li, Student

Dr. Jeff Reese, Major Professor

Dr. Kenneth Tyler, Director of Graduate Studies 
THE ROLE OF ADULT ATTACHMENT IN INTERNATIONAL STUDENTS' ACCULTURATION PROCESS

\author{
DISSERTATION \\ A dissertation submitted in partial fulfillment of the \\ requirements for the degree of Doctor of Philosophy in the \\ College of Education \\ at the University of Kentucky \\ By \\ Miao Li \\ Lexington, Kentucky \\ Director: Dr. Jeff Reese, Professor of Counseling Psychology \\ Lexington, Kentucky \\ 2016 \\ Copyright @ Miao Li 2016
}




\section{ABSTRACT OF DISSERTATION}

\section{THE ROLE OF ADULT ATTACHMENT IN INTERNATIONAL STUDENTS' ACCULTURATION PROCESS}

International students face a variety of challenges in their acculturation process. The acculturation process is a highly variable process that is influenced by the mediating and moderating effects of individual factors that exist prior to, or arise during, acculturation (Berry, 1997). Among the moderating personal factors existing prior to acculturation, adult attachment has received heightened attention as an important variable impacting the acculturation process and adaptation outcomes. Wang and Mallinckrodt (2006a) suggested that successful adaptation involves exploration of unfamiliar social situations that resemble the infants' exploration of their physical surroundings. The acculturation process can be challenging and stressful because individuals going through this process often encounter disparities in various situations. Similar to infants, whose attachment system tends to be activated particularly in a distressing situation, threatening events or situations in one's adult life also activate the attachment behavioral system of seeking proximity to attachment figures for security and support. Limited research has investigated the relationship between adult attachment and the acculturation processes (e.g., Brisset, Safdar, Lewis, \& Sabatier, 2010; Sochos \& Diniz, 2011). Previous research has highlighted a link between adult attachment (e.g., attachment styles and attachment security) and psychological adaptation. However, the relationship between adult attachment and international students' other acculturation outcomes (e.g., sociocultural adaptation) remains unclear in the existing literature due to inconsistent previous findings. The current study addressed the gaps in the literature by focusing on international students' acculturation processes and examined how adult attachment contributes to, or influences, their adaptation. Data was collected from 228 international students that are enrolled in higher education institutions in different geographic locations in the United States. Hierarchical multiple regressions were conducted for data analysis. The results suggest that attachment anxiety was a significant predictor of international students' psychological adaptation. Attachment avoidance significantly moderated the effect of acculturation to the U.S. culture on international students' psychological distress, while attachment anxiety was a marginally significant moderator for the effect of acculturation to the U.S. culture on sociocultural adaptation. Attachment avoidance also moderated the effects of physical assault and behavioral discrimination on international 
students’ self-esteem. Study limitations and future directions are discussed.

Keywords: International students, acculturation, adult attachment, adaptation outcomes, perceived discrimination

Miao Li

Student Signature

$01 / 22 / 2016$

Date 


\section{THE ROLE OF ADULT ATTACHMENT IN INTERNATIONAL STUDENT'S}

\section{ACCULTURATION PROCESS}

By

Miao Li

Jeff Reese, Ph.D.

Director of Dissertation

Kenneth Tyler, Ph.D.

Director of Graduate Studies

$01 / 22 / 2016$ 


\section{ACKNOWLEDGEMENTS}

I would like to express my sincerest gratitude to Dr. Jeff Reese, who served as the chair of my dissertation committee, for his unconditional support, encouragement and patience during the completion of this project. I would also like to thank Dr. Xin Ma for providing his expertise and guidance throughout the data analysis process. Thank you to other members of my doctoral committee: Dr. Pamela Remer, Dr. Marie Sossou, and my outside examiner Dr. Nathan Wood for the time and valuable feedback that they provided to me. I would also like to thank Dr. Keisha Love for introducing me to attachment theory, her guidance for the development of this project and her support for the recruitment process.

Completion of any research project is never possible without the cooperation of the participants. I would like to thank all the international students who participated in my study for their time and dedication, University of Kentucky International Center, and Boston College International Student Office, Dr. Jamie Hopkins. Specifically, Ms. Karen Slaymaker at University of Kentucky International Center, for the her incredible help with the recruitment process.

Finally, I would like to thank my parents, Yahe Li and Xiaoqun Zhong, who have always supported my dream and provided unconditional love through my life. My partner, Jeremy Walters for his love, support, and encouragement. My friends, who have been supportive and understanding of the trials and tribulations of completing a doctoral degree. Thanks to each of you for making this possible and for believing in me. 


\section{TABLE OF CONTENTS}

Acknowledgements..................................................................................................... ii

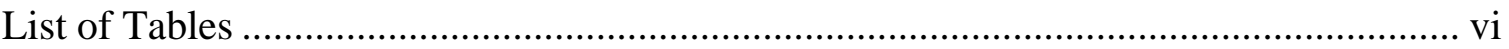

List of Figures ................................................................................................. vii

Chapter One: Introduction and Literature Review ……….......................................... 1

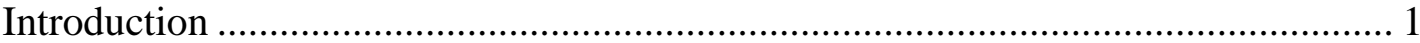

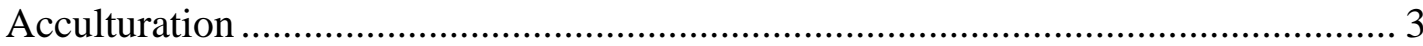

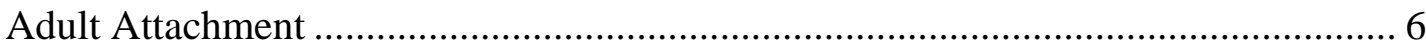

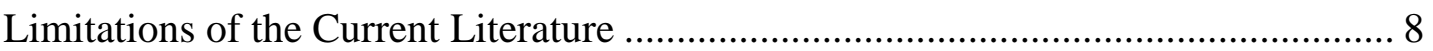

The Current Study ……………………………………..................................... 10

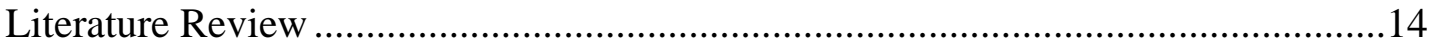

Berry's Multidimensional Acculturation Model .................................................. 14

Critique to Berry's Model and Existing Studies................................................. 20

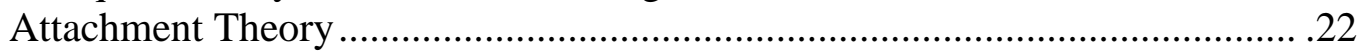

Ainsworth's Empirical Sudies.................................................................. 24

Hazan and Shaver's Three-Dimensional Conceptualization...................... 26

Other Conceptualizations of Adult Attachment ......................................... 28

Cross-cultural applicability of attachment theory..................................... 31

The Influence of Adult Attachment on Adjustment Outcome ............................. 33

The Impact of Adult Attachment on Acculturation............................................... 36

The Link between Attachment Seucrity and Capacity to Explore.............. 39

Empirical Studies on Adult Attachment and Acculturation ....................... 40

The Impact of Cultural Distance............................................................... 42

Attachment Styles and Acculturation Attitudes......................................... 44

Summary and Critique of Existing Studies ....................................................... 45

Research Questions and Hypotheses of the Current Study ................................ 47

Operational Definitions ................................................................................... 50

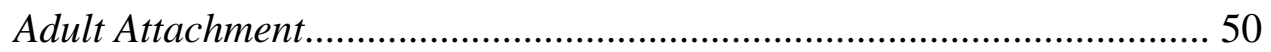

Acculturation..................................................................................... 50

Acculturative Stress ............................................................................ 50

Psychological Adaptation ................................................................... 51

Sociocultural Adaptation ....................................................................... 51

Perceived Discrimiation ...................................................................... 51

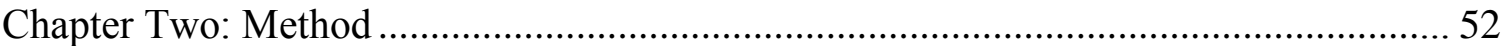

Participants and Recruitment............................................................................. 52

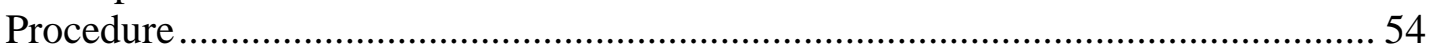

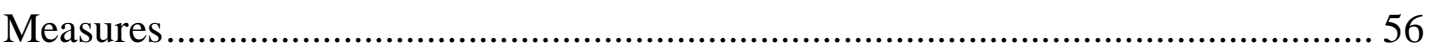

Demographic Questionnaire........................................................................... 56

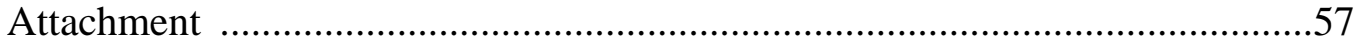

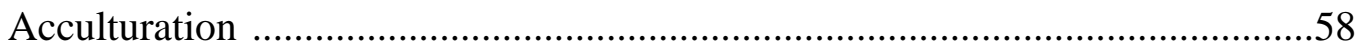


Acculturative Stress ………………………………….................................59

Psychological Adaptation ..............................................................................59

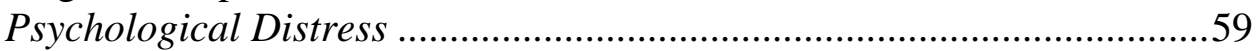

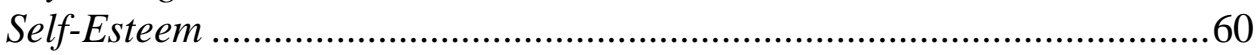

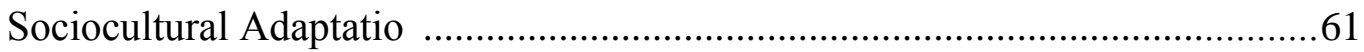

Perceived Discrimination ...............................................................................62

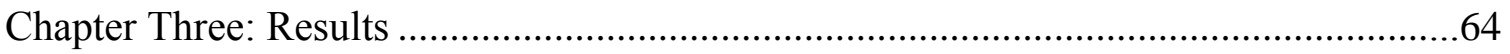

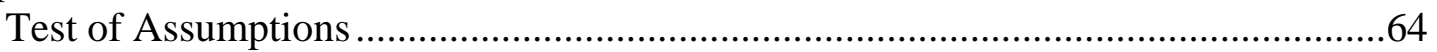

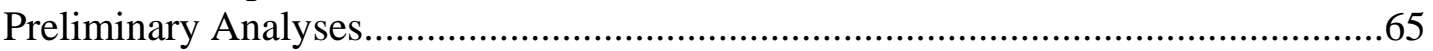

Primary Analyses..........................................................................................69

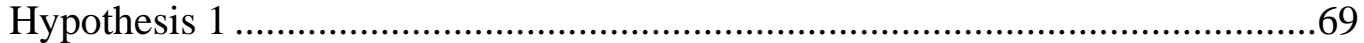

Hypothesis 2 .......................................................................................

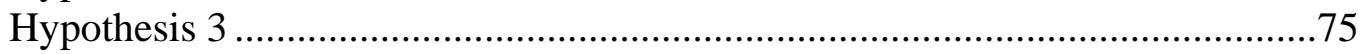

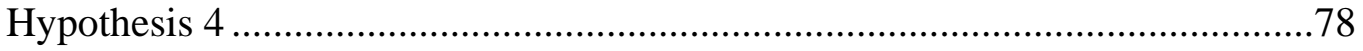

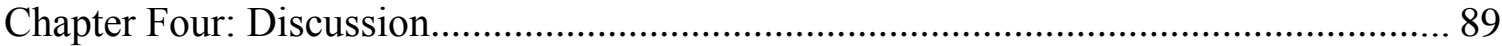

Adult Attachment, Acculturation, and Adaptation Outcomes..................................... 92

Adult Attachment, Discrimination, and Psychological Adaptation ........................... 97

The Effect of Control Variables.............................................................................. 100

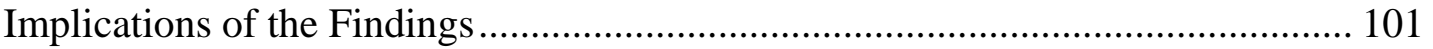

Limitations and Future Directions.......................................................................... 108

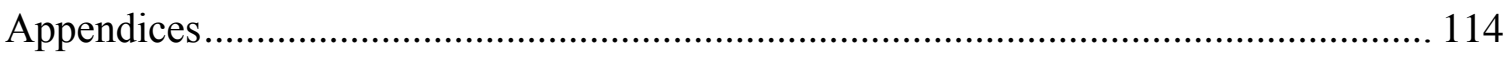

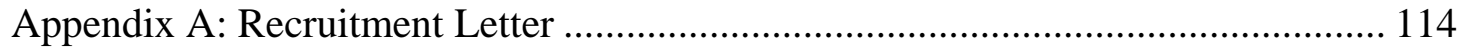

Appendix B: Survey Cover Letter ......................................................................... 116

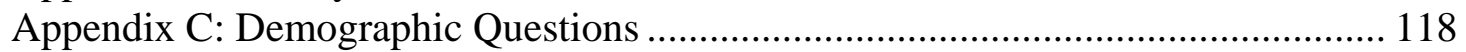

Appendix D: Experience in Close Relationship Scale-Short Form............................. 122

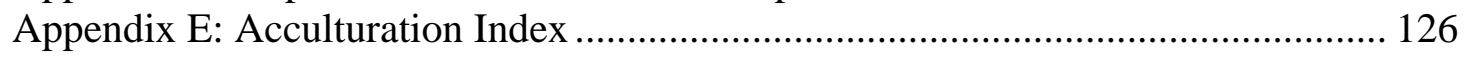

Appendix F: Revised Sociocultural Adaptation Scale................................................ 128

Appendix G: Acculturative Stress Scale for International Students ........................... 131

Appendix H: Center for Epidemiologic Studies Depression Scale Revised............... 135

Appendix I: Rosenberg Self-Esteem Scale .............................................................. 139

Appendix J: Items of the Experience of Discrimination Scale ................................... 141

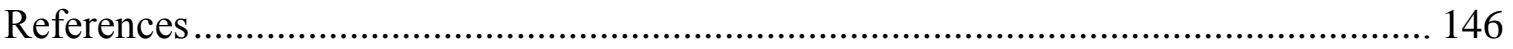

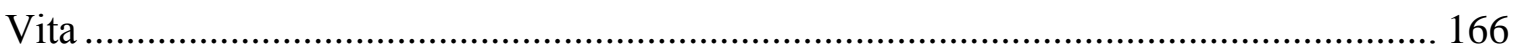




\section{List of Tables}

Table 1, One-Way Analysis of Variance Summary Table for Categorical

Demographic and Study Variables

Table 2, Correlations of Demographic, Attachment, Acculturation, and

Adaptation Variables .......................................................................67

Table 3, Correlations of Ethnicity, Acculturation, and Adaptation Variables ...................68

Table 4, Hierarchical Regression Analysis of Acculturation ..........................................70

Table 5, Hierarchical Regression Analysis of Psychological Distress,

Acculturative Stress, and Sociocultural Adaptation ...............................73

Table 6, Hierarchical Regression Analysis of Psychological Distress ..........................82

Table 7, Hierarchical Regression Analysis of Self-Esteem ............................................83

Table 8, Hierarchical Regression Analysis of Sociocultural Adaptation .........................84

Table 9, Moderation Analysis of Psychological Distress ............................................85

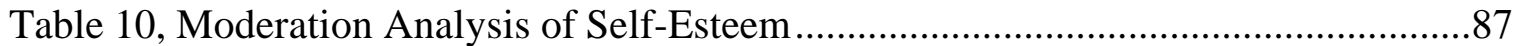




\section{List of Figures}

Figure 1, Acculturation Strategies in Ethnocultural Groups and the Larger Society ....... 15

Figure 2, Two-dimensional Four-category Model of Adult Attachment ........................ 30

Figure 3, A Framework for Acculturation Research ................................................... 37 
The Role of Adult Attachment in International Students' Acculturation Process

\section{Chapter One: Introduction and Literature Review}

According to the Institute of International Education’s (IIE) Open Doors Report

(2014), the number of international students in the United States is currently the highest it has ever been, at 886,052 in 2013-2014. International students face a variety of pressures when adapting to their new environment. For instance, students need to adapt to the American education system and meet certain academic requirements and expectations to maintain their visa status that allows them to study in the United States. This adaptation may be difficult because classroom requirements and expectations, class participation in particular, may be very different from the education system from which the students come (Mori, 2000). Another hurdle that international students often face is a language barrier. Limited English fluency, the presence of an accent, and the use of inaccurate expressions may negatively influence international students' ability to communicate and make friends with members of the host culture, which is vital to their adaptation (Barratt \& Huba, 1994). In addition, negative experiences with prejudice, discrimination, and racism have been found to be some of the most frequently reported hurdles for international students (Johnson \& Sandhu, 2007). The oppressive stereotypes associated with their race, ethnicity, religious beliefs or cultural background can be extremely stressful for international students. The process of overcoming these hurdles and adjusting to a new cultural environment is known as acculturation. Researchers have identified a variety of individual variables that influence the acculturation process; however, adult attachment as one of these variables has not been fully examined. 
What role does adult attachment play in international students' acculturation process? Researchers have raised this question in recent years. In Berry’s (1997) theoretical framework of acculturation, he stated that the acculturation process is a highly variable process that is influenced by the mediating and moderating effects of individual factors that exist prior to, or arise during, acculturation. Individuals begin the acculturation process with a number of personal characteristics based on their demographic, psychological, and social nature. These characteristics include age, gender, education, socioeconomic status, reason for migration (i.e., motivation and expectations), cultural distance from the host culture, and other personal factors such as locus of control and personality traits such as attachment behaviors.

Among the moderating personal factors existing prior to acculturation, adult attachment style has received increased attention as an important variable influencing the acculturation process and adaptation outcomes. According to Wang and Mallinckrodt (2006a), “the acculturation process involves exposure to unfamiliar and potentially frightening social situations” (p. 423). Individuals going through the acculturation process often encounter disparities in various situations including language, social structure, and value systems. This process can be stimulating, challenging, confusing, and stressful. Events that occur during the acculturation process may resemble the threatening events that activate one's attachment behavioral system. Similar to infants, whose attachment system tends to be activated particularly in an alarming or distressing situation, threatening events or situations in one's adult life also activate the attachment behavioral system of seeking proximity to attachment figures for security and support. Therefore, examining attachment behaviors as a factor in international students' 
acculturation process is warranted (Ainsworth, Blehar, Waters, \& Wall, 1978; Mikulincer \& Shaver, 2008). The current study examined the influence of adult attachment on international students' acculturation process and adaptation.

A few researchers have empirically studied the relationship between adult attachment and the acculturation processes (e.g., Brisset, Safdar, Lewis, \& Sabatier, 2010; Polek, Wöhrle, \& van Oudenhoven; Sochos \& Diniz, 2011; Wang \& Mallinckrodt, 2006a). A link between adult attachment (e.g., attachment dimensions, attachment styles and attachment security) and psychological adaptation was commonly found in these studies. However, the relationship between adult attachment and other outcomes of international students’ psychological acculturation (e.g., sociocultural adaptation) remains unclear in the existing literature due to inconsistent findings from studies.

\section{Acculturation}

The concept of acculturation provides a practical framework for understanding the adjustment process of international students. According to Redfield, Linton, and Herskovits (1936), “ acculturation comprehends those phenomena which result when groups of individuals having different cultures come into continuous firsthand contact, with subsequent changes in the original culture patterns of either or both groups” (p. 149). According to this definition, acculturation encompasses all changes that arise following any contact between individuals and/or groups of different cultures. These changes may result from direct cultural transference, which refers to the transmission of one autonomous cultural system, or may be the consequence of non-cultural events such as demographic or ecological changes caused by an invading culture. Acculturation can occur both at individual or group levels. Psychological acculturation, which refers to 
acculturation at the individual level, denotes changes in behaviors, beliefs, attitudes, values, and preference in individuals because of acculturation (Graves, 1967). Ward (2001) suggested that psychological acculturation often involves affective (A), behavioral (B), and cognitive (C) changes in the individual, in what she has termed the ABCs of acculturation. These changes are viewed as short-term acculturation outcomes, while the long-term outcomes of acculturation changes were referred to as adaptation (Sam, 2006). Ward and her colleagues (Searle \& Ward, 1990; Ward, 2001; Ward \& Kennedy, 1993) proposed and validated two kinds of adaptation: psychological and sociocultural adaptation. Psychological adaptation generally refers to psychological well-being and satisfaction in a specific cultural milieu, while sociocultural adaptation relates to the acquisition of skills to negotiate or "fit into" a new cultural context (Ward, 2001).

Although some aspects of the acculturation process are similar across groups, acculturating groups (e.g., immigrants, indigenous groups, refugees, sojourners) differ in their experience of the acculturation process due to the distinctive conditions or reasons for their acculturation. Compared to other groups undergoing acculturation, international students experience unique stressors and concerns such as social isolation, academic problems, financial concerns, and uncertainty (Johnson \& Sandhu, 2007). Many international students report feelings of loneliness and isolation due to being physically distant from their families in their home country, and due to having limited social support in the United States (Mori, 2000). They also tend to experience more academic obstacles because of language barriers and differences in academic systems between the U.S. system and the system in their culture of origin, which tends to distinguish them from other acculturating groups. Financial concern is another common stressor for 
international students. Substantial cost and restricted work opportunities due to visa status often contribute to difficult financial situations among international students. Moreover, international students are often forced to live in a state of uncertainty because they do not know how long they will be in the United States, whether they will be able to succeed academically, when they will be able to return home, and how they will fit back into their culture of origin (Johnson \& Sandhu, 2007). This uncertainty may cause a significant amount of worry about their future.

Another major factor that influences international students' acculturation process is the host society's attitudes, primarily negative attitudes such as prejudice and discrimination, towards international students. In Berry's (1997) model, the host society's attitudes were identified as one of the several moderating factors that arise during the acculturation process. Perceived prejudice and discrimination, as the manifestation of negative attitudes towards international students, are the most frequently reported predictors of international students' psychological symptoms, and play a significant role on their adaptation outcomes (Johnson \& Sandhu, 2007; Zhang \& Goodson, 2011). Berry et al. (2006) suggested that perceived discrimination is an important predictor of the psychological and sociocultural adaptation for immigrant youth. Perceived discrimination has been found to predict adjustment difficulties for Turkish international students in the United States (Duru \& Poyrazli, 2011). A study in the United Kingdom indicated that international students who were identifiable as foreigners by their appearance reported more perceived discrimination, and their positive contacts with host nationals were associated with lower levels of perceived discrimination (Krahe, Abraham, Felber \& Helbig, 2005). 
To facilitate international students' psychological and sociocultural adaptation, it is imperative that researchers examine key factors to the acculturation process. As referenced previously, a variety of individual factors that influence international students' acculturation and their psychosocial adjustment have been identified (Smith \& Khawaja, 2011; Zhang \& Goodson, 2011). Adult attachment has recently become an emerging area as one of these individual factors in studies about international students' acculturation process (Smith \& Khawaja, 2011).

\section{Adult Attachment}

Attachment theory was originally developed by Bowlby $(1969 / 1982,1988)$, who proposed attachment as an ethological approach to understand the nature of the motherchild's tie. Bowlby (1988) argued that an attachment figure can serve as a secure base for the attached individual, so that the presence of the attachment figure fosters social behaviors such as exploration or play. He suggested that this phenomenon could be observed throughout the lifespan, especially in situations in which individuals' attachment behaviors are activated, such as during emergencies or during times of distress. Similar to infants, whose attachment system tends to be activated particularly in an alarming or distressing situation, threatening events or distressing situations in one's adult life also activate the attachment behavioral system of seeking proximity to an attachment figure (Ainsworth et al., 1978; Mikulincer \& Shaver, 2008). Events that occur during the acculturation process may resemble the threatening events that activate one's attachment behavioral system. Ainsworth and colleagues (Ainsworth \& Bell, 1969; Ainsworth et al., 1978) provided empirical support of Bowlby’s conceptualization of attachment and expanded his theory by developing the Strange Situation, a laboratory 
procedure investigating infants' attachment behaviors upon separation and reunion with their mothers, to examine the concept that infants use their attachment figures as a secure base from which to explore the environment. She identified three patterns of attachment behavior (i.e. secure, avoidant, and anxious-ambivalent) through the Strange Situation studies. Ainsworth’s findings were expanded to adult romantic relationships by Hazan and Shaver (1987). They developed a three-category model of adult attachment styles originally based on Ainsworth's three-category model of infant attachment. Later, Bartholomew (1990) proposed a four-category classification for adult attachment based on Bowlby’s (1969/1982, 1973) conception of internal working models and Hazan and Shaver's conceptualization of adult attachment. I will provide more details about the three and four-category models of adult attachment in the literature review section later.

Young children use their attachment figures as a secure base from which to explore, but if they do not expect their attachment figure to be responsive and available in threatening situations, the exploratory system will likely be deactivated. Infants and children form internal, cognitive working models of themselves and others based on their interactions with their attachment figures that serve as a template for their behavior throughout life. Bowlby referred to these models as "internal working model.” The contemporary adult attachment literature has conceptualized these internal working models as two underlying dimensions of adult attachment patterns: one corresponding to avoidance (discomfort with dependency and closeness) and the other corresponding to anxiety (about abandonment or insufficient love; see Collins \& Read, 1990; Levy \& Davis, 1988; Simpson, 1990). Bartholomew and Horowitz (1991) explained these two dimensions using Bowlby's (1988) internal working model, and suggested that the 
anxiety dimension is related to positivity of an internal model of self, while the avoidant dimension is associated with a positive or negative model of others. The positivity of internal working models of self and others affect individuals' ability to explore unfamiliar surroundings, develop relationships in the new environments, and regulate their ability to adapt or cope with the distress associated with the unfamiliarity of situations (Mikulincer, Shaver, Sapir-Lavid, \& Avihou-Kanza, 2009; Weinfield, Sroufe, Egeland, \& Carlson, 2008). Therefore, it is highly probable that attachment avoidance and anxiety are significant contributors to international students' acculturation process.

Researchers have begun to consider adult attachment as a psychological factor that influences international students' acculturation processes and adaptation in recent years (e.g., Brisset, Safdar, Lewis, \& Sabatier, 2010; Chen, Mallinckrodt, \& Mobley, 2003; Wang \& Mallinckrodt, 2006). Wang and Mallinckrodt (2006a) examined adult attachment and acculturation as predictors of Chinese international students' psychological distress and sociocultural adjustment problems. The results suggested that Chinese international students with high levels of attachment anxiety were unlikely to engage in the exploration of the new cultural milieu completely because they were experiencing enhanced feelings of loneliness and distress. These findings were similar to infants in Ainsworth's Strange Situation study who were high in attachment anxiety. The inability to engage in exploration also resulted in lower acculturation to the host culture and high acculturative stress.

\section{Limitations of the Current Literature}

The majority of studies that have examined adult attachment in relationship to acculturation have used the traditional three-category or four-category models of adult 
attachment (e.g. Brisset et al., 2010; Polek et al., 2010; Sochos \& Diniz, 2011; van Oudenhoven \& Hofstra, 2006). However, current research using the two-dimensional model of adult attachment has demonstrated that it is the best conceptualization for adult attachment because it encompasses both the behavioral and cognitive facets of the attachment behavioral system (Crowell, Fraley, \& Shaver, 1999; Fraley \& Waller, 1998). Furthermore, empirical evidence suggests that the cross-cultural validity of threecategory and four-category attachment models with international students is limited. For instance, in a cross-cultural study involving international participants from 62 cultural regions, researchers found only one or two dimensions of the three or four category attachment models demonstrated validity cross culturally (Schmitt, 2008, 2010; Schmitt et al., 2004). In contrast, the two dimensional model demonstrated consistent crosscultural applicability in numerous studies (e.g., Conradi, Gerlsma, van Duijn, \& de Jonge, 2006; Mallinckrodt \& Wang, 2004). Therefore, to get a more accurate picture of this relationship, the conceptualization and operationalization of attachment must be appropriate and applicable for international students.

Although more studies have been conducted to examine the role of adult attachment in acculturation processes, the majority of these studies have focused on immigrant populations. Only three of these studies have investigated international students' attachment and their role in their acculturation process (Brisset et al., 2010; Chen, Mallinckrodt, \& Mobley, 2003; Wang \& Mallinckrodt, 2006). As mentioned previously, international students encounter unique stressors and concerns compared to other groups undergoing acculturation; therefore, it is important to address how adult attachment impacts their experience of acculturation. 
Moreover, studies have clearly demonstrated a moderating relationship between acculturation and adult attachment on international students' sociocultural adaptation (Brisset et al., 2010; Polek et al., 2010; Sochos \& Diniz, 2011; Wang \& Mallinckrodt, 2006). However, few studies have examined the moderating effect of adult attachment style on acculturation processes and psychological adaptation (Brisset et al., 2010; Sochos \& Diniz, 2011). Even though these studies provided support for the moderating effect of adult attachment style on the link between acculturation process and psychological adaptation (Brisset et al., 2010; Sochos \& Diniz, 2011), these limited results in both number and effect sizes are not strong enough to establish the moderating relationship between acculturation and adult attachment on international students' psychological adaptation. As such, further research needs to be conducted on the moderating effect of adult attachment style on acculturation processes and psychological adaptation.

\section{The Current Study}

In the current study, I focused on international students’ acculturation processes and examined how adult attachment contributes to, or influences, their adaptation for my dissertation. Especially, the study contributes to the literature on international students by addressing the following issues.

First, recent research has proven that the two-dimensional approach to conceptualizing and operationalizing adult attachment provides a better model regarding the underlying mechanisms of attachment behavior, especially among international students (Fraley \& Waller, 1998; Schmitt, 2010; Schmitt et al., 2004). Therefore, I used the two-dimensional model, which has been considered the most valid adult attachment 
model by researchers. I operationalized adult attachment using the Experiences in Close Relationships (ECR) scale (Brennan, Clark, \& Shaver, 1998). One benefit of using the two-dimensional conceptualization and operationalization of adult attachment is its crosscultural validity compared to a three-category or four-category conceptualization that has not demonstrated the same validity. This contemporary conceptualization and operationalization is a significant contribution to the international student literature.

The second issue that has remained unexplained is determining if adult attachment moderates the relationship between acculturation (which I operationalize as heritage culture maintenance and host culture participation) and the psychological and sociocultural adaptation of international students. Wang and Mallinckrodt (2006a) found that adult attachment did not moderate the effect of acculturation on Chinese international students' psychological and sociocultural adaptation. However, they also stated that this finding is possibly a result of a lack of sufficient statistical power with a small sample, thus, it is important to continue examining the relationships between moderators in Berry’s (1997) model. No other studies have re-examined Wang and Mallinckrodt's findings so far, and no sufficient empirical evidence supporting adult attachment as a moderator of international student's acculturation process has been provided. I replicated the procedure in Wang and Mallinckrodt's study with a larger sample size in order to provide more sufficient statistical power, as a way of re-investing the role of adult attachment as a moderator between acculturation and adaptation outcomes.

Third, I wanted to investigate the unique role that adult attachment plays in international students' psychological acculturation and its impact on international students' short-term outcomes (behavioral changes and acculturative stress) and long- 
term outcomes (psychological and sociocultural adaptation) of acculturation.

Corresponding to the two-dimensional model, research has demonstrated that low attachment anxiety and avoidance (i.e., attachment security) are related positively to selfefficacy, social competence, affection-regulation, and openness to outgroup members (Mikulincer \& Shaver, 2001; Mikulincer et al., 2009; Weinfield et al., 2008). A securely attached individual will be more open to outgroup members, more willing to explore the new cultural milieu, and more open to learn the social skills to thrive in the host societies. At the same time, he or she will be likely to have a positive mental representation of him or herself, and have a sense of security towards his or her culture of origin. Only one study among the existing literature using the two-dimension model has examined the link between adult attachment and international students' attitudinal dimensions of acculturation (heritage culture maintenance and host culture participation; Wang \& Mallinckrodt, 2006). This study revealed a negative association between attachment anxiety and international students' acculturation to the United States. In order to provide further understanding of the link between adult attachment and the two acculturation dimensions, I investigated the relationship between the two dimensions of adult attachment (attachment anxiety and avoidance) and the two attitudinal dimensions of acculturation.

Several studies have used psychological distress and stressful events, such as perceived racism or discrimination, as variables contributing to acculturation outcomes (e.g., Brisset et al., 2010; Chen, Mallinckrodt, \& Mobley, 2003; Polek et al., 2010; Wang \&Mallinckrodt, 2006a). However, stress due to the acculturation process, known as acculturative stress, as a distinct concept has not been examined in the existing literature. 
In terms of adaptation, although most of the existing literature provides evidence supporting the link between adult attachment style, conceptualized as the three or four category models, and psychological adaptation, the link between attachment style and sociocultural adaptation was found less consistently. In order to address the limitation in the existing literature, I also examined the impact of adult attachment on international students' acculturative stress level, psychological adaptation, and sociocultural adaptation. The fifth issue I address in the current study is if there is a link between perceived discrimination or prejudice, and adult attachment. No existing study has examined the relationship between perceived discrimination and prejudice and adult attachment. Even though perceived discrimination and racism have been found as significant predictors of international students’ psychological symptoms (Jung, Hecht, \& Wadsworth, 2007; Rahman \& Rollock, 2004; Wei, Ku, Russell, Mallinckrodt, \& Liao, 2008), there was no previous study examining the relationship between adult attachment and experience with perceived discrimination in international students' acculturation process. International students' attachment behavioral system may be activated when they experience perceived discrimination which are often threatening situations, so that adult attachment may also contribute to the acculturation outcomes of international students who has been exposed to perceived discrimination. The current study will assess if any link exists between adult attachment and international students' experience of perceived discrimination, and investigate how adult attachment influences the predictive relationship between perceived discrimination and international students’ psychological symptoms. 


\section{Literature Review}

In this section, I provide a historical overview of the major constructs in this dissertation, namely acculturation and attachment. I review Barry’s model of acculturation and review and critique studies that have utilized his model with international students. I also review the formulation of attachment theory, its evolution, and cross-cultural applicability. I end the chapter by discussing the need for researchers to examine the role of attachment behaviors in international students' acculturation process, and provide detailed descriptions of the research questions and hypotheses.

Berry’s multidimensional acculturation model. Berry’s (1970, 1974, 1980) multidimensional acculturation model was developed based on a distinction between the orientations toward one’s own group, and toward other groups, namely the host group. The orientation toward one's own group reflects a relative preference for maintaining an individual's heritage culture and identity, whereas the orientation toward other groups refers to a relative preference for participating in the larger host society. These two attitudinal dimensions, according to Berry (1980), are independent from each other. Therefore, it is possible for an individual to acquire or adapt to a new culture without losing one's heritage culture. Individual differences in orientations toward these two attitudinal dimensions are based on generally positive or negative views about these dimensions, which intersect and define four different acculturation strategies: integration, assimilation, separation, and marginalization (see Figure 1). The third dimension, which represents the dominant group's attitude towards the acculturating group (strategies of the larger society), is also depicted in this figure. I provide more information in the later section. 

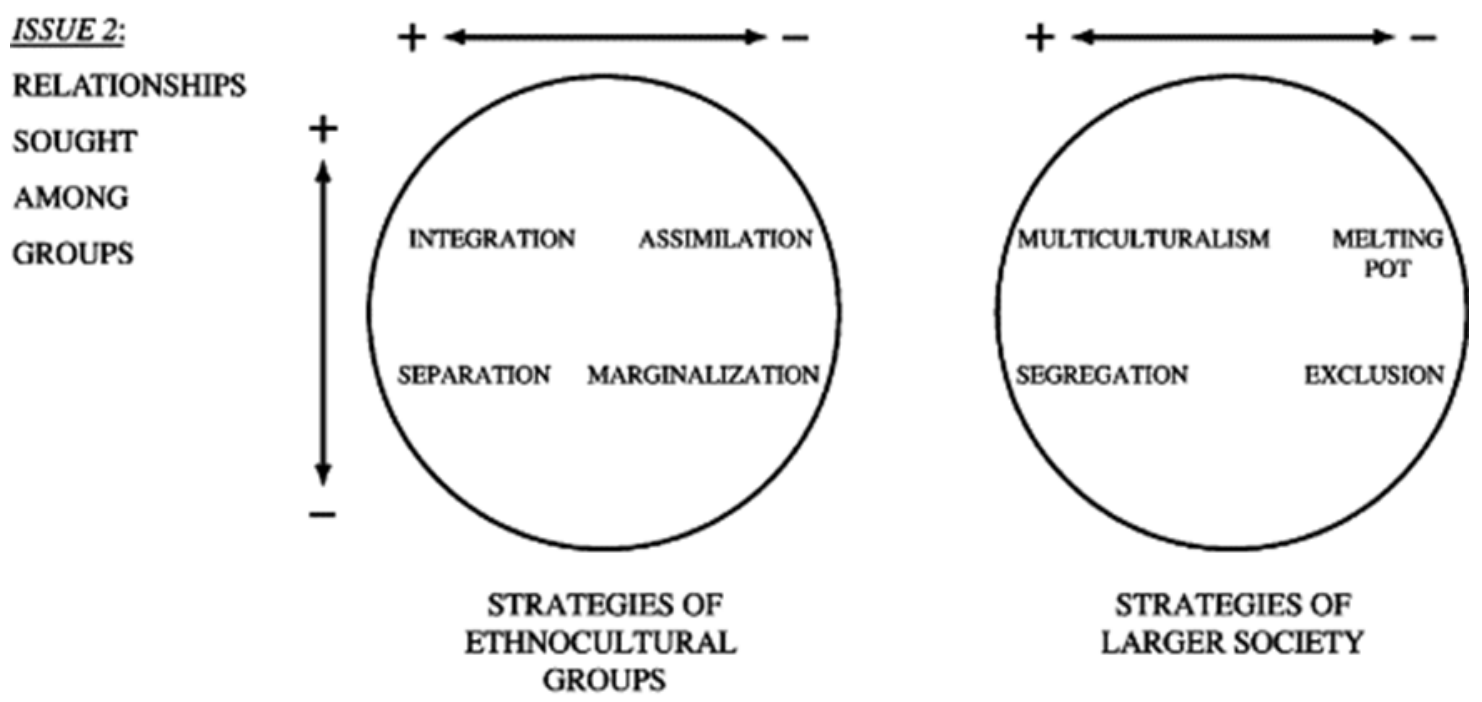

Figure 1. Acculturation strategies in ethnocultural groups and the larger society. Adapted from “Acculturation, Discrimination, and Adaptation Among Second Generation Immigrant Youth in Montreal and Paris,” by J. W. Berry and C. Sabatier, 2010, International Journal of Intercultural Relations, 34, p. 193. Copyright 2010 by the Elsevier Ltd. Reprinted with permission.

According to Berry (1997), individuals using an assimilation strategy wish to participate and interact with other cultures on a daily basis without maintaining their cultural identity. The integration strategy, in contrast, is defined as an interest in both maintaining one's heritage culture, and having daily contact with other cultural groups. Individuals with a separation strategy do not wish to seek daily interaction with other groups and focus on holding on to their culture of origin. Finally, if there is little interest or possibility in maintaining one's original culture, in addition to little interest in having daily interactions or relations with other cultural groups, one might qualify as having a marginalization strategy. 
Different acculturation strategies, in this model, may lead to distinct acculturation outcomes. However, individual members of non-dominant groups may not be able to choose how they want to approach intercultural contact (Berry, 1974). A third dimension was added by Berry (2003) to his model in order to address the significant role played by the dominant group (host culture) in influencing the way in which reciprocal acculturation would occur. Depending on how open and inclusive the dominant society is in its orientation towards cultural diversity, an individual may or may not be able to freely choose and successfully pursue an integration strategy (Berry, 1974, 2006a). Even though integration has been recognized as the most adaptive strategy with reduced risk for international students (Berry, 1997, 1998; Ward \& Kennedy, 1994, 1999), it may not be an option if the dominant group (host culture) is not prepared to adapt (e.g., education, health, immigration policy) to better meet the needs of international students. Berry also distinguished four acculturation strategies for the dominant group (host culture): melting pot refers to when the dominant group seeks and enforces assimilation, while the demand for separation leads to segregation; enforcing marginalization forms exclusion, and a society seeking integration and cultural diversity practices multiculturalism (see Figure 1). According to this model, the United States' orientation toward cultural diversity plays a powerful role in international students' acculturation process. Whether students can freely choose their acculturation strategy depends on how they perceive the expectations American society has for them.

The term acculturative stress is defined as a particular type of stress that results from the process of acculturation (Berry, Kim, Minde, \& Mok, 1987). Sandhu and Asrabadi (1994) identified some key sources of acculturative stress that contribute to 
international students' adjustment problems, including perceived discrimination, homesickness, perceived hate and rejection, fear, culture shock and stress due to change, and guilt related to being away from home. Berry, Kim, Minde, and Mok (1987) compared the acculturative stress levels for different groups undergoing acculturation, and found that international students showed the highest level of acculturative stress in the voluntary migrant group, likely due to the temporality of their contact with the new culture, their relatively young age, and their student status. Chavajay and Skowronek (2008) found that international students experienced stress due to feeling rejected and discriminated against by the host culture. One study with 336 international students in the United States found that participants' personal and multicultural strengths would partially reduce their experiences of acculturative stress, and lead to more positive adjustment (Yakunina, Weigold, Weigold, Hercegovac, \& Elsayed, 2013).

In Berry's multidimensional model, several important factors of the acculturation process are identified through research (Berry, 1997, 1998; Berry \& Kim, 1988). One’s acculturation strategy is found to be one factor affecting short-term outcomes of acculturation (Berry, 1980). Berry $(1997,2006 b)$ also discussed the mediating and moderating influence of individual factors, such as personal characteristics and migration motivation, that exist prior to or arise during acculturation. The operation of these factors may lead to the variance of individual acculturation processes, so that these moderating and mediating factors are important for both groups and individuals, and can become both risk and protective factors. Berry also emphasized the importance of examining the impact of these factors on the acculturation process.

Berry's multidimensional acculturation model conceptualizes adaptation as the 
"relatively stable changes that take place in an individual or group in response to external demands” (Berry, 2006b, p. 52). Adaptation, in his model, is an outcome that may or may not be positive in valence, which can range from a very positive to a very negative way of living in the new cultural setting. Berry (1997) adopted the distinction that Ward and colleagues (Searle \& Ward, 1990; Ward, 2001; Ward \& Kennedy, 1993) proposed between psychological and sociocultural adaptation. He suggested that predictors of positive psychological adaptation include personality variables, life-changing events, and social support. Positive sociocultural adaptation is predicted by positive inter-group attitudes, degree of contact, and cultural knowledge. Cultural distance (how different the two cultures are in language, religion, etc.) is one factor that Berry has identified that influences acculturation. General findings suggest that the greater the cultural dissimilarity, the less positive the adaptation (Berry, 2006b). This claim is consistent with findings in which Asian international students in the United States reported higher levels of acculturative stress and depression compared to European international students (Yeh \& Inose, 2003).

Berry's model also emphasizes the impact of acculturation strategies on adaptations, especially the consistent finding that integration is related to positive adaptation while marginalization is related to negative adaptation, whereas assimilation and separation strategies are intermediate. This pattern, according to Berry, is present for all types of acculturating groups (Berry, 1980; Berry, Phinney, Sam \& Vedder, 2006; Berry \& Sam, 1997). Both psychological and sociocultural adaptations were found to be predicted by the successful application of the integration strategy, and by minimal cultural distance (Ward, 1996; Ward \& Kennedy, 1993). Furthermore, the critical role 
the host society plays is also emphasized in this model of individuals' acculturation process. According to Berry (2006a), factors related to the acculturation strategy of the host culture that facilitate individuals' positive adaptation to a new culture include: widespread acceptance of cultural diversity, relatively low levels of prejudice or discrimination, positive mutual intergroup attitudes, and a sense of identification with the larger society by all individuals and groups.

International students' experiences of prejudice and discrimination are important factors that impact their acculturation process and their adaptation outcomes (Johnson \& Sandhu, 2007; Mori, 2000). Asian international students reported experiencing discrimination in the United States in previous studies (e.g., Constantine, Kindaichi, Okazaki, Gainor, \& Baden, 2005). The stress related to be a target of racism and discrimination has a negative effect on African international students (Klonoff, Landrine, \& Ullman, 1999). Surprisingly, I could only locate limited published studies that examined the role perceived discrimination plays in international students' mental health outcomes. Among the existing studies, some of them indicated that prejudice and perceived discrimination are predictors of international students' mental health (e.g., Atri, Sharma, \& Cottrell, 2006), and three of these studies found a predictive relationship between perceived prejudice/ discrimination and depression (Jung, Hecht, \& Wadsworth, 2007; Rahman \& Rollock, 2004; Wei, Ku, Russell, Mallinckrodt, \& Liao, 2008). Jung, Hecht, and Wadsworth (2007) found that social undermining (i.e., the counter concept of social support, negative product of relationships) exacerbates the relationship between perceived discrimination and depression levels among international students. In a sample with Asian international students, Wei, Ku, Russell, Mallinckrodt, and Liao (2008) found 
that both coping strategies and self-esteem were significant moderators of the relationship between perceived discrimination and depressive symptoms. Specifically, this relationship was strengthened for students who tended to use suppressive coping (i.e., a tendency to avoid coping activities and deny problems), but only for students with relatively high self-esteem..

Critique to Berry's model and existing studies. As pioneers of acculturation research, John Berry and his colleagues have developed and elaborated on a model that conceptualizes acculturation phenomenon systematically, and provides a stress and coping framework to depict the cross-cultural transition as a series of stress-provoking life changes that draw on adaptive resources and require coping responses (Ward, Bochner, \& Furnham, 2001). Unlike the traditional medical models of cross-cultural transition that emphasize a pathological reaction to cross-cultural contact, the stress and coping approach places a greater emphasis on the coping process and on a positive adaptation to a new environment. Moreover, the attention is not solely directed toward the individuals, but is also directed toward the broader sociocultural context. Successful adaptation to a new culture not only depends on personal characteristics and factors, but also involves a range of contextual factors including characteristics of both heritage and host cultures (Berry, 1997). This approach, exemplified by Berry in his work on acculturation and acculturative stress, offers a more comprehensive view of cross-cultural transition. Considering the changes in immigration policies, and United States' societal acceptance of migrants in the last 50 years, especially post 9/11, Berry’s framework offers an advantage in adding a third dimension, the host culture's acculturation strategy, to the conceptualization of the acculturation process. 
Many concepts about acculturation that are widely utilized and studied are proposed and defined by Berry and his colleagues, such as acculturative stress, acculturation strategies, and adaptation (Berry, 1970, 1997; Berry, Kim, Minde, \& Mok, 1987). The distinction between the two independent dimensions of acculturation attitudes, and the four categories of acculturation strategies, allowed researchers to obtain a more comprehensive picture of the acculturation process. In addition to his effort in elaborating on the concept of acculturation strategies, Berry also suggested an empirical method to examine and classify individuals into the different categories he proposed. Berry (2006b) also identified a number of mediating and moderating factors that exist prior to, or arise during acculturation, and he argued that these individual-level factors significantly affect one’s psychological acculturation process. His model has been widely used and tested on the international student population, and many of his studies are conducted in the United States (Berry, 2003; Berry, Kim, Minde, \& Mok, 1987; Zheng \& Berry, 1991). In a meta-analysis of 64 studies on international students in the United States, which were published in peer-reviewed journals between 1990 and 2009, Berry and colleagues’ acculturation model was the most frequently utilized among acculturation models (Zhang \& Goodson, 2011). The multidimensional model of individual acculturation attitudes received support from these empirical studies, and many others have developed bidimensional or multidimensional models since then (e.g. LaFramboise, Coleman, \& Gerton, 1993; Ryder, Alden, \& Paulhus, 2000; Sanchez \& Fernandez, 1993). As one of the most widely accepted and influential models, Berry’s acculturation model has laid the foundation, inspired, and contributed to many theorists' conceptualization of the acculturation process. 
Critics of Berry's model have stated that the measurement issues of this model remained unresolved, with arguments about what methodology can accurately assess the two dimensions (Arends-Tóth \& van de Vijver, 2006). Berry’s approach has also been criticized for failing to adequately capture the particular characteristics of the four acculturation strategies (Ryder, Alden, \& Paulhus, 2000). Although integration was found to relate to the most positive adaptation outcomes in many studies, some studies have found separation or assimilation to be positively related to adaptation (Nguyen, 2006). These issues, however, are often related to the use of different adaptation indicators, disparities in the conceptualization of acculturation, and different contexts in which individuals or groups reside.

Attachment theory. Bowlby $(1969 / 1982,1988)$ proposed attachment as an ethological approach to understand the nature of the mother-child's bond. He suggested that infants naturally seek proximity to their caregivers through attachment behaviors as an evolutionary strategy to increase the likelihood of protection and their chance of survival. Attachment is not exclusively a human phenomenon, but is considered to be shared among other non-human primates and species (Fraley, Brumbaugh, \& Marks, 2005; Suomi, 2008). The attachment behaviors, such as body movement and crying, can be organized into an attachment behavioral system (Bowlby, 1969/1982; Cassidy, 2008). Bowlby emphasized that the concept of an attachment behavioral system involves inherent motivation so that the system is not the by-product of any fundamental process or "drive." Findings supported that an attachment system is not driven by pleasurable associations, because infants are even attached to abusive mothers (Bowlby, 1956). This assertion distinguished Bowlby's attachment theory from Freud's secondary-drive 
theories (Freud, 1910/1957). Bowlby considered attachment behaviors as "goalcorrected," that is, flexible to environmental changes while attempting to attain proximity to one's mother. The goal of attachment behavior is to seek proximity to the caregiver in order to attain a survival advantage, so that children are predisposed to activate their attachment behavioral system and seek their parents in times of distress. Considering attachment is an outcome of evolution and a shared phenomenon in nonhuman species, Bowlby (1988) suggested that the activation of attachment behavior in these circumstances is universal and normative, regardless of a specific cultural context.

According to Bowlby (1988), an infant who is aware that an attachment figure is responsive and available experiences a pervasive feeling of security. In other words, an attachment figure serves as a secure base for the attached individual, and the presence of this individual fosters social behaviors such as exploration or play (Bretherton \& Munholland, 2008). Attachment phenomenon is a normal and healthy characteristic of humans, and can be observed throughout the lifespan, especially during times of distress. Bowlby discussed the impact of attachment relationships beyond infancy by providing the concept of an internal working model. He claimed that an attached individual develops mental representations that reflect the experienced interaction patterns with his or her attachment figure, and these mental representations in one's internal world eventually form working models of the self and of the attachment figure(s). For instance, if the context of an individual's working model of the attachment figure as being emotionally available and supportive of exploratory activities is present, the attached person develops a working model of self as valued and competent (Bretherton \& Munholland, 2008). Individuals can operate using internal working models to generate 
predictions about the way an attachment figure may respond to their attachment behaviors, which enables the individual to evaluate the potential outcomes of alternative behaviors and determine which behaviors are best. Furthermore, these self-other representations allow infants to understand that attachment figures continue to exist even when they are out of sight, so that infants can feel secure without the physical presence of the figures. If caregivers respond to an infant's needs consistently and are available when the infant is distressed or anxious, the infant learns that he or she can count on others when needed and develops a sense of trust towards others (Fraley \& Waller, 1998). The interactions between a caregiver-infant dyad play a critical role in the development of an internal working model, which has a substantial impact on the goals and strategies the infant adopts to control his or her emotions and social behaviors.

Ainsworth's empirical studies. Bowlby's theoretical conceptualization of attachment provided the foundation for the development of later conceptual models of infant and adult attachment. However, attachment theory may not be widely regarded and supported as it is today without Ainsworth's pioneer empirical studies on attachment behavior both in Africa and in the United States (Ainsworth, 1963, 1967; Ainsworth et al., 1978). Mary Ainsworth expanded Bowlby's attachment theory by empirically studying individual differences in the quality of attachment relationships. She developed the Strange Situation, a laboratory procedure investigating infants’ attachment behaviors upon separation and reunion with their mothers, to examine the concept that infants use their attachment figures as a secure base from which to explore the environment (Ainsworth \& Bell, 1969; Ainsworth et al., 1978). In her studies conducted in Uganda and Baltimore, she found three patterns of attachment behavior in samples of both 
Ugandan and American infant-mother dyads: insecure-avoidant (Group A), secure (Group B), and insecure resistant or anxious-ambivalent (Group C). Securely attached infants explored freely in the caretaker's presence and checked on the caretaker periodically, but restricted their activities in her absence. They exhibited varying degrees of distress during the caretaker's absence, but quickly reverted to exploration following her return. Insecure-avoidant infants, on the other hand, displayed little interest in their caretaker's presence, exhibited only slight distress over her departure, and ignored the caretaker upon her return. Anxious-ambivalent infants exhibited extreme distress upon separation from their caretakers and displayed impoverished activity during their absence. These infants wanted immediate contact, but when picked up by the returning mother, they did not settle down easily. Main and Solomon (1986) identified a fourth category, disorganized/disoriented attachment (Group D), for dyads that were difficult to classify with the original three category system. The infants in Group D did not appear to have any coping strategy for separation from their caretakers, and they would not even approach the caretaker upon her return, as if frightened or confused. In the small sample of 23 mother-infant dyads from which Ainsworth developed the A-B-C criteria, 57\% of the infants were securely attached to their mother, $26 \%$ avoidant, and $17 \%$ resistant (Ainsworth et al., 1978). About 15\% of the normative samples, and a much higher portion of high-risk samples, fell into the category of disorganized/disoriented (Main \& Solomon, 1986). Ainsworth's findings provided empirical support for Bowlby’s argument that an infant's organization of attachment behavior at 12 months of age is significantly associated with the sensitivity of maternal behavior and consistency of maternal responsiveness (Ainsworth et al., 1978). 
Ainsworth’s tripartite classification system of attachment relationships offers a typological conceptualization of attachment theory. Numerous studies have been conducted to replicate the results and investigate the classification system since Ainsworth’s original studies (van Ijzendoorn \& Sagi-Schwartz, 2008). The three category model of attachment relationships has become the most influential model for research studies to examine attachment in infancy and in early childhood (Sroufe, 1990). The fourth category, disorganized/disoriented, has not been prevalent and well-used in previous studies comparing to the other three categories. Recent studies suggested that serious family risk factors (e.g., child maltreatment, parental mental disorder, and parental substance use) have been correlated with significant increase in the occurrence of disorganized attachment patterns among infants (Lyons-Ruth \& Jacobvits, 2008). However, most existing cross-cultural studies have used the three category model (van Ijzendoorn \& Sagi-Schwartz, 2008).

\section{Hazan and Shaver's three-dimensional conceptualization of adult attachment.}

Bowlby stated that "attachment behavior [characterizes] human-beings from the cradle to the grave” (1979, p. 129). He believed that remaining within easy access of a familiar individual who could come to one's help in an emergency was a good "insurance policy" regardless of one’s age. Hazan and Shaver (1987) expanded Bowlby and Ainsworth’s attachment theory to adult romantic relationships. The characteristics of infant-caregiver bonds were considered applicable to the affectionate bonds in adult romantic relationships: the tendency of seeking security from partners; desire of closeness especially under distress; and protest or distress when threatened with separation or loss (Weiss, 1982, 1986). Hazan and Shaver suggested that romantic love is an attachment 
process, in which individual differences exist due to differences in attachment histories. The attachment experience in early childhood impacts the formation of the internal working model of the interaction pattern with the attachment figure. According to Bowlby (1973), the working models and behavior patterns are central components of personality. Hazan and Shaver proposed that adult relationship styles of romantic love are associated with the internal working model of self and social life. The specific characteristics of infant-caregiver interaction patterns were assumed to cause differences in adult romantic attachment styles, similar to Ainsworth’s typology of attachment patterns.

To test their hypothesis about the relationship between infant and adult romantic attachment patters, Hazan and Shaver developed a single-item, self-report attachment measure in which they applied Ainsworth's three categories of infant attachment patterns to adult attachment styles. This forced-choice measure consisted of three paragraphs that were written to translate Ainsworth et al.'s (1978) description of infant attachment patterns into expressions corresponding to adult love. Participants were asked to think about the most important love relationship they have ever had and then complete questionnaires assessing their attitudes, beliefs about close relationships in general, and their specific experiences with their most important relationship. Their early childhood relationships with parents and the parents' marital relationship were also assessed to provide information about their childhood attachment relationships and internal working model. The results of the adult attachment typology measure revealed a similar frequency of the three attachment patterns found in infants. Approximately $56 \%$ of the participants identified themselves as secure, approximately $24 \%$ as avoidant, and 
approximately $10 \%$ as anxious/ambivalent (Hazan \& Shaver, 1987). The three attachment groups differed in their experiences of love, their working models of self and relationship, and early childhood relationships with parents, which were related to their attachment security in adult romantic relationships. Moreover, the insecure group, especially among anxious/ambivalents, reported greater trait and state loneliness.

Hazan and Shaver (1987) succeeded in translating and applying Ainsworth’s attachment classification system and conceptualization of infant-caregiver attachment relationships into adult romantic love. They provided a conceptual model of adult attachment that accounted for individual differences in adult relationship styles, and suggested that adult romantic love is associated with early attachment experiences and the internal working model of self and relationships.

Other conceptualizations of adult attachment. Two important developments occurred after Hazan and Shaver’s (1987) publication. First, the effort to transform the categorical measure developed by Hazan and Shaver to a multi-item continuous rating scale led to the discovery of two underlying dimensions of adult attachment: one corresponding to avoidance (discomfort with dependency and closeness) and the other corresponding to anxiety (about abandonment or insufficient love; Collins \& Read, 1990; Levy \& Davis, 1988, Simpson, 1990). Ainsworth et al. (1978) conducted a discriminant function analysis predicting infant attachment styles from the continuous rating scales, which were used by coders in the Strange Situation procedure to classify infant behavior (e.g. exploratory behavior, crying, resistance). This analysis suggested that a two-factor description can reproduce the A-B-C classifications of Ainsworth et al.’s classificatory system. Brennan, Clark, and Shaver (1998) argued that these two factors corresponded to 
the two dimensions derived from the adult attachment typology. One factor distinguished ambivalent attachment (crying, angry resistance) from secure and avoidant attachment, hence reflecting the anxiety dimension. The other factor distinguished avoidant (distance interaction, avoiding contact) from secure and anxious-ambivalent attachment, therefore reflecting the avoidance dimension. The discovery of these two dimensions supported a two-dimensional model of adult attachment.

Second, Bartholomew (1990) proposed a four-category classification for adult attachment based on Bowlby's $(1969,1973)$ conception of internal working models. The four attachment patterns were defined in terms of two underlying dimensions: positivity of one's model of self and positivity of one's model of others. The model of self described whether the self is viewed as worthy or unworthy of love and support, and the model of others described whether others are expected to be available and supportive. A positive model of self is, therefore, associated with less anxiety and dependency on other's approval, and a positive model of others is associated with less avoidance towards closeness and seeking out more comfort in close relationships. Researchers later found that Bartholomew's (1990) four categories of adult attachment can be placed into the two-dimensional attachment style space of attachment avoidance and attachment anxiety (see Figure 2; Brennan, Clark, \& Shaver, 1998; Mikulincer \& Shaver, 2007). Feeney (1995) suggested that avoidance is linked to the model of others, whereas anxiety is linked to the model of self. 


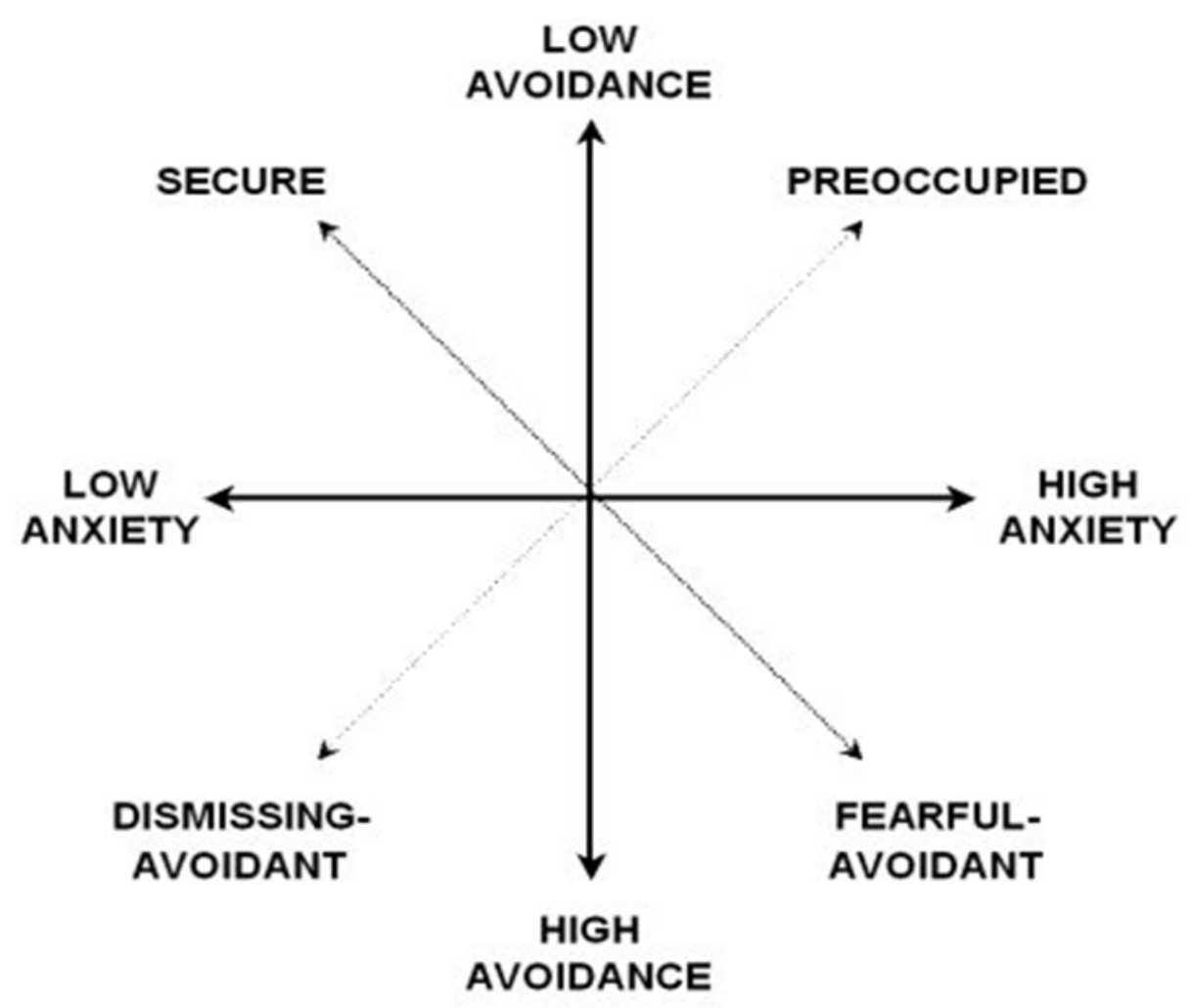

Figure 2. Two-dimensional four-category model of adult attachment. Adapted from Attachment in Adulthood: Structure, Dynamics, and Change (p. 89) by M. Mikulincer, and P. R. Shaver, 2007, New York: Guilford Press. Copyright 2007 by the Guilford Press. Reprinted with permission.

In Bartholomew’s conceptual model of adult attachment (Bartholomew, 1990; Bartholomew \& Horowitz, 1991), secure attachment is characterized by the combination of a positive model of self and a positive model of others. Individuals classified in this category are comfortable with intimacy in close relationships and have an internalized sense of self-worth. Individuals with a negative model of self and a positive model of others are classified in a preoccupied attachment category, and readily rely on others and seek to gain acceptance or validation from others. The avoidant category is split into two 
attachment styles: avoidant-fearful and avoidant-dismissing. These models have been mapped onto attachment avoidance and attachment anxiety, the two dimensional conceptualization of attachment (Mikulincer \& Shaver, 2007). Bartholomew’s studies bridged the gap between different methods of assessing adult attachment, and provided a more elaborate approach in applying Bowlby's conceptualization of the internal working model to the two-dimension model of adult attachment.

Cross cultural applicability of adult attachment theory. The categorical classification of secure and insecure attachment has been criticized for its limited validity to non-Western cultures due to the fact that the original conceptualization was developed and examined based on Western White middle-class samples. Cross-cultural studies have provided evidence supporting the applicability of the two-dimension conceptualization of adult attachment (e.g., Schmitt, 2008; Schmitt et al., 2004). Bartholomew’s conceptualization explained the corresponding relationship between Bowlby’s (1973) internal working model of self and others with the two underlying dimensions of anxiety and avoidance. Although the findings of one cross-cultural study questioned the applicability of the two-dimension model of adult attachment(Csóka et al., 2007), most of the cross-cultural studies provided general support of the two dimensions as fundamental components of human psychology (e.g. Schmitt, 2008; Schmitt et al., 2004). The universality of the four-categories, on the other hand, was not as evident cross-culturally as the two-dimension model. In many cultures, classification of the four-category model did not correlate in the predicted directions, and factor analyses demonstrated that the four categories of romantic attachment do not align as predicted within the twodimensional space in some regions such as South America, Western Europe, Eastern 
Europe, the Middle East, Africa, and East Asia (Schmitt, 2010).

The cross-cultural studies I reviewed also indicated insufficient support for the normativity of secure attachment (Schmitt, 2008; Schmitt et al., 2004). Bartholomew (1990) conceptualized secure attachment with the combination of a positive model of self and other. Individuals classified in this category in the Western samples are characterized by low attachment anxiety and avoidance, are comfortable with intimacy in close relationships and have an internalized sense of self-worth. However, higher rates of preoccupied attachment, compared to the Western samples, have been consistently found in East Asian cultures, and higher levels of avoidance and anxiety were evident in other non-Western cultures (Schmitt et al., 2004; Wang \& Mallinkcrodt, 2006b; You \& Malley-Morrison, 2000). Demographic statuses including age, sexual orientation, gender, and socioeconomic status have also been found to associate with adult attachment styles. Belsky et al. (1991) discussed the relationship between social context and attachment security from an evolutionary perspective. Overall, there is insufficient evidence supporting the cross-cultural normativity of secure attachment, and that the conceptualization of secure attachment needs to take culture-specific norms and ideologies into consideration in order to provide a more applicable definition of attachment security or insecurity across cultures.

The measurement issues related to Hazan and Shaver's three-category model, which contributes to the reason for the decrease of research using this model shortly after its development, facilitated the development of the more elaborate two-dimension model. Both Ainsworth's and Hazan and Shaver's conceptual model suffered from one common issue of their validity: the typological conceptualization. Fraley and Waller (1998) 
discussed the disadvantages of using typological models through taxometric techniques in assessing individual differences in adult attachment. They concluded that the dynamic conception of attachment does not require individuals to be distributed into categories, but rather along dimensions, and that the use of the typological model "seriously undermines reliability, validity, and statistical power” (p. 105). The dimensional approach provided a better model to think about underlying mechanisms. The large number of cross-cultural studies that have been conducted based on the dimensional model provide a near universal validity of the two-factor structures (e.g., Alonso-Arbiol, Balluerka, \& Shaver, 2007; Conradi, Gerlsma, van Duijn, \& de Jonge, 2006; Lin, 2010; Schmitt, 2008; Schmitt et al., 2004). The model of self and the model of other, corresponding to attachment anxiety and avoidance, were found to be the two underlying dimensions in studies that consistently applied the model to international populations. Insufficient evidence was found for the four-category model cross-culturally (Schmitt, 2010; Schmitt et al., 2004; Wang \& Mallinkcrodt, 2006b; You \& Malley-Morrison, 2000), which further confirmed that the dimensional model is more appropriate than the typology model. A few recent studies on the role of adult attachment in acculturation have also endorsed the conceptual model of two dimensions (Sochos \& Diniz, 2011; Wang \& Malinkrodt, 2006a). In order to capture the individual difference in adult attachment and its impact on social-psychological adjustment of a diverse population (i.e., international students), the two-dimension conceptual model of adult attachment seems best suited and was used for the current study.

The influence of adult attachment on adjustment outcomes. During the challenge of adapting to unfamiliar social situations, individuals are required to explore 
new cultural contexts in order to learn the environment and navigate the cultural differences in their life in their new culture. The exploratory requirement is similar in respect to the ways infants learn about the environment through exploration as a survival advantage (Wang \& Mallinckrodt, 2006a). Young children use their attachment figures as a secure base from which to explore, but if they do not expect their attachment figure to be responsive and available in threatening situation, the exploratory system will likely be deactivated. This model has been extended to adult attachment, and conceptualized as two underlying dimensions of individual difference in attachment patterns: attachment anxiety and attachment avoidance (Mikulincer, Shaver, Sapir-Lavid, \& Avihou-Kanza, 2009; Weinfield, Sroufe, Egeland, \& Carlson, 2008). If an individual undergoing acculturation has access to a secure attachment figure or internal working model, the person may be more open to members of other cultures and more capable of regulating negative emotions provoked by threatening situations. The research conducted by Mikulincer and his colleagues provided an understanding of the cognitive bases of secure people’s affect-regulation strategies and behaviors in social relationships by considering situations that activate their attachment systems. Securely attached individuals are characterized by both low attachment anxiety and low attachment avoidance. Mikulincer and Shaver (2001) suggested that activating one's sense of a secure base reduces the cognitive appraisal of an out-group as threatening and eventually leads to less negative reactions to out-groups. A sense of being supported and loved by surrounding others allows people to be open to alternative worldviews and to be more accepting of members who are not from one's own group. Secure individuals have a more accessible and richer secure-base script (working models of procedural knowledge of distress management), 
can reach out to supportive others, and can use attachment figures to provide a safe haven which shapes their processing of attachment-related information (Mikulincer et al., 2009). Secure attachment histories were found to predict an individual's later self-reliance, efficacy, affect regulation, and social competence (Weinfield et al., 2008). These dimensions of behavioral and personal characteristics were also studied by researchers as predictors of acculturation outcomes (Safdar, Lay, \& Struthers, 2003; Zhang \& Goodson, 2011). Some researchers suggested that attachment styles are better predictors of adjustment than other personality characteristics such as the Big Five Personality traits (Bakker, van Oudenhoven, \& van der Zee, 2004) and demographic variables (Polek, van Oudenhoven, \& ten Berge, 2008).

Attachment avoidance and anxiety were also found to contribute to negative moods and interpersonal problems through different affect regulation strategies (i.e., emotional cutoff or emotional reactivity), while emotional cutoff and emotional reactivity mediated the association between negative moods, interpersonal problems, and attachment anxiety or avoidance distinctively (Wei, Vogel, Ku, \& Zakalik, 2005). In a survey study of 430 undergraduate students in the United States, both social self-efficacy and emotional awareness were found to be significant mediators for the influence of attachment anxiety and avoidance on psychological distress and perceived social support (Mallinckrodt \& Wei, 2005). The authors suggested that people with high attachment avoidance and anxiety tend to perceive themselves as relatively helpless in forming new friendships or making progress in improving their social support network. Further investigation on the link between adult attachment and affect regulation problems revealed that attachment avoidance was related to both suppressive coping (suppressing 
negative affects) and reactive coping strategies (attend to distress, being expressive about it), while attachment anxiety was related to reactive coping strategies (Lopez, Mauricio, Gormley, Simko, \& Berger, 2001). With a small sample size of 55 college students, Lopez et al.’s study indicated that students' problem coping styles significantly mediated the ability of insecure attachment styles to predict psychological distress. Another study conducted by Shaffer, Vogel, and Wei (2006) found that the association between high attachment avoidance and less intent to seek help appeared to be mediated by higher anticipated risks, less positive attitudes toward seeking help, and lower anticipated benefits. The link between higher attachment anxiety and greater intent to seek help, however, was mediated by higher anticipated risks, more positive attitudes toward seeking help, and higher anticipated benefits. High levels of attachment anxiety and avoidance appeared to be consistently associated with psychological distress, difficulty in affection regulation, interpersonal problems, and less social support. Adaptation to a new culture requires individuals to cope effectively with psychological distress associated with the acculturation process, regulating emotional reactions, and actively building social support through interpersonal interactions. Individuals with high attachment anxiety and avoidance, therefore, may experience more difficulties in this process and report higher levels of psychological distress, compared to those with low anxiety and avoidance.

The impact of adult attachment on acculturation. In Berry's (1997) theoretical framework, acculturation phenomenon consists of two sets of variables: group-level (situational variables) and individual-level (person variables; see Figure 3). 


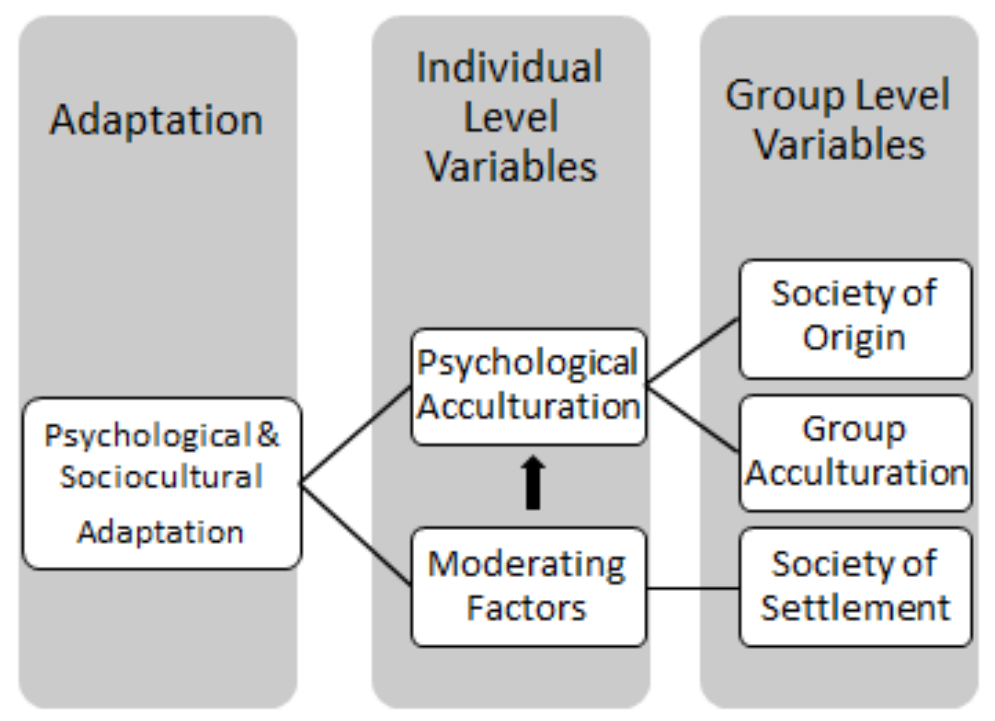

Figure 3. A framework for acculturation research. Adapted from “Immigration, Acculturation, and Adaptation,” by J. W. Berry, 1997, Applied Psychology: An International Review, 46, p. 15. Copyright 1997 by the International Association of Applied Psychology.

Figure 3 shows the framework that was developed by Berry to illustrate the acculturation process. On the right side of Figure 3 are group-level variables, which are expected to flow from right to left to influence individuals experiencing acculturation. Berry suggested that the central portion flowing from group acculturation to adaptation through individual acculturation is a process that takes place over time, and there are factors that influence this process, which provides structure by which acculturation occurs. This process is highly variable, and depends on specific characteristics of the group-level factors, but is also influenced by the mediating and moderating effect of individual factors that exist prior to, or arise during, acculturation. Berry claimed that 
individuals begin the acculturation process with a number of personal characteristics based on their demographic, psychological, and social nature. These characteristics include age, gender, education, socioeconomic status, reason for migration (i.e., motivation and expectations), cultural distance, and other personal factors such as locus of control and personality traits. The moderating factors that arise during acculturation are: contact discrepancy, social support, societal attitudes (appraisal and reaction), coping strategies and resources, and acculturation strategies (attitudes and behaviors).

Among the moderating personal factors existing prior to acculturation, I believe that adult attachment style may be considered an important variable influencing the acculturation process and predicting adaptation outcomes. Bowlby (1988) argued that an attachment figure can serve as a secure base for the attached individual, so that the presence of the attachment figure fosters social behaviors such as exploration or play. He suggested that this phenomenon can be observed throughout the lifespan, especially in situations in which an individual's attachment behaviors are activated, such as during emergencies. The concept of the internal working model was developed to explain the transition of infant attachment to adult attachment and details how early attachment experiences affect one's view of self and others, which eventually leads to individual difference in attachment styles. According to Wang and Mallinckrodt (2006a), "the acculturation process involves exposure to unfamiliar and potentially frightening social situations” (p. 423). Individuals going through the acculturation process often encounter disparity in various situations including language, social structure, and value systems. This process can be stimulating, challenging, confusing, and stressful. Events that occur during the acculturation process may resemble the threatening events that activate one's 
attachment behavioral system. Similar to infants, whose attachment system tends to be activated particularly in an alarming or distressing situation, threatening events or situations in one's adult life also activate the attachment behavioral system of seeking proximity to external or internal attachment figure (Ainsworth et al., 1978; Mikulincer \& Shaver, 2008).

The link between attachment security and capacity to explore. Mikulincer and his colleagues showed that securely attached individuals are able to access an internalized secure sense of their own self-worth, and expectation that others are generally available and supportive. Therefore, they are more likely to explore the unknown patterns of social interaction, learn about novel social environments and culture values, and cope effectively with the stress associated with intercultural contact. Those without secure attachment, on the other hand, may lack the capacity to engage in exploration of the unfamiliar situations and draw on personal or interpersonal resources to adapt or adjust to their new milieu.

Berry’s (1997) stress and coping model conceptualized the acculturation process as a series of stress-provoking life changes that require individuals to draw on personal and interpersonal resources and to develop coping responses. The culture learning approach, influenced by Berry’s conceptual framework, also addressed the learning component in acculturation (Ward, Bochner, \& Furnham, 2001). This approach suggests that intercultural problems arise because individuals undergoing cross-cultural transitions (e.g., immigrants, sojourners, and refugees) experience difficulties managing daily social contacts and interactions. Adaptation can be reached through learning the culturespecific skills that are demanded to negotiate the new cultural context. Socially skilled 
individuals with a flexible behavioral repertoire respond appropriately in different social situations, but people newly arrived in a disparate culture will be in a similar position to socially inadequate individuals who lack the social and behavioral skills used to navigate the rules that regulate interpersonal contact (Ward, Bochner, \& Furnham, 2001). In order to communicate effectively with people from the host culture, individuals need to explore the unfamiliar rules of social behavior that regulate interpersonal communication in a new culture. Lacking the capacity to be involved in exploration of new social rules and communication patterns creates barriers for one's adaptation of cross-cultural transition.

Both the culture learning approach and the stress and coping model emphasize the importance of one's capacity to engage in exploration, to draw on resources to overcome the challenges associated with cross-cultural transition, and to develop social competence in a new cultural milieu. Attachment anxiety and attachment avoidance, as two dimensions of adult attachment styles, are viewed as critical factors that influence an individual's ability to explore the new environment and cope with the threatening unfamiliar situations. Consequently, low levels of attachment anxiety and attachment avoidance (i.e., attachment security), may moderate the effect of international students' acculturation process and predict their adaptation outcomes in an unfamiliar cultural milieu.

Empirical studies on adult attachment and acculturation. Researchers began to consider adult attachment as a psychological factor influencing acculturation processes and adaptation outcomes in recent years; however, research is still extremely limited on the role of adult attachment in the individual acculturation process. One pioneer study was conducted by Wang and Mallinckrodt in 2006. They conceptualized international 
students' acculturation as a continuing process that may be affected by their adult attachment patterns. Wang and Mallinckrodt examined adult attachment and acculturation as predictors of Chinese international students' psychological distress and sociocultural adjustment problems. The result of this study revealed a negative association between attachment anxiety and international students' acculturation to the U.S., while higher attachment anxiety and attachment avoidance predicted more sociocultural adjustment problems and psychological distress. Although acculturation to U.S. culture was found to be a significant predictor for sociocultural adjustment and psychological distress for international students, cultural identification to one's home culture did not significantly predict the adjustment outcomes. Furthermore, the findings indicated that there was no significant moderating effect between attachment and acculturation on students’ psychological adjustment outcome. However, Wang and Mallinckrodt argued that the findings may be a result of a lack of sufficient power within the sample, rather than an indication of the true relationships of the variables. According to Wang and Mallinckrodt, the separation that international students experience from their significant others in their home countries resemble the features of Ainsworth et al.'s (1978) Strange Situation protocol, and is likely to activate international students' adult attachment systems. They argued that Chinese international students with high levels of attachment anxiety were unlikely to completely engage in exploration of the new cultural milieu, similar to the anxiously attached infants in Ainsworth’s Strange Situation, because international students were experiencing enhanced feelings of loneliness and distress. The inability to engage in exploration also resulted in lower acculturation to the host culture, and high acculturative stress. 
Individuals undergoing the acculturation process, who report low attachment avoidance and anxiety (classified as having a secure attachment style) tend to report greater perceived social support and less psychological distress. Chen, Mallinckrodt, and Mobley (2003) conducted a survey study of East Asian international students including students from mainland China, Hong Kong, Japan, Korea, and Taiwan. They found a positive association between attachment security and perceived social support from both new friends in the United States and family and friends from home cultures, and a negative association between attachment security and both psychological symptoms of distress and stressful life events (including the experience of racism). Sochos and Diniz (2011) argued that attachment styles moderate the acculturation process. They found that secure and dismissing attachment styles significantly moderated the effect of sociocultural adaptation difficulties on psychological distress with a sample of 172 Brazilian immigrants in the United Kingdom; while preoccupied attachment styles moderated both the effects of previous immigration experiences on psychological distress and the effects of duration of stay with regard to terrorism concerns.

\section{The impact of cultural distance between the host culture and culture of origin.}

The significance of attachment styles in the adaptation process when adjusting to a new environment may depend on how far away one is from home. Polek (2007) found that the link between attachment styles and psychological well-being was stronger for immigrants than for nonimmigrant participants. Chataway and Berry (1989) compared personalities, coping styles, and psychological and physical health of Hong Kong Chinese international students in Canada with French-Canadian and English Canadian students. Their findings indicated that Chinese students experienced higher trait-anxiety, 
more prejudice, lower perceived social support, and more adaptation and communication problems than the other two groups. A comparison of the elements facilitating or impeding adaptation to a new environment between Vietnamese international students in France, and French college freshman, revealed differences in the significance of attachment issues in these two groups' adaptation outcomes (Brisset, Safdar, Lewis, \& Sabatier, 2010). Brisset et al. (2010) argued that attachment issues appeared to be of greater significance for Vietnamese international students because they were further away from home compared to the French students, whose distress was produced by factors other than attachment issues. They also suggested that the sociocultural adaptation for Vietnamese students is predicted by co-national identification.

Polek, Wöhrle, and van Oudenhoven (2010) claimed that attachment styles appeared to be more related to the psychological adjustment of immigrants than to their sociocultural adjustment. In their study on German and Eastern European (Russian, Hungarian, and Polish) immigrants in the Netherlands, secure attachment was positively related to psychological and sociocultural adjustment, and was negatively related to perceived discrimination among Eastern European participants. A negative relation was found between fearful attachment style and both psychological and sociocultural adjustment for all sample groups. Preoccupied attachment was negatively related to psychological adjustment, but not for other measures of sociocultural adjustment, with the exception of perceived discrimination. Finally, dismissing attachment was not found to be related to either psychological or sociocultural adjustment, except for in the Russian sample. When examining the influence of cultural distance on psychological and sociocultural adjustment, Polek et al. suggested that the more similar the home culture is 
to the host culture, the less significant the relation between attachment style and sociocultural adjustment. However, the measurement for the sociocultural adjustment variable was self-developed by Polek et al. and the content appeared to be more similar to instruments assessing acculturation attitudes, rather than sociocultural adjustment. Therefore, the limited construct validity of the measurement may have impacted the findings of this study.

Attachment styles and acculturation attitudes. Attachment styles were also found to predict Berry's (2003) classification of acculturation attitudes in both immigrants and members of the host culture (van Oudenhoven \& Hofstra, 2006). Both securely attached immigrants and host society members displayed positive attitudes toward Berry's classification of integration strategy, whereas persons with a dismissing attachment style did not show positive feelings to integration strategy. Immigrants with dismissing attachment styles preferred separation attitudes, but members of the host society did not show significant preference. Immigrants and host culture members with a preoccupation or fearful attachment style, reacted significantly different to different acculturation attitudes. Immigrants with preoccupied attachment styles showed positive attitudes toward separation but host society members did not. Immigrants were found to have distinct attitudes toward all four acculturation strategies depending of their attachment style, and the authors concluded that attachment style plays an important role in immigrants' attitudes toward adaptation to the host culture and culture maintenance. Limitations of this study include that both measurement of acculturation attitude and attachment styles were self-developed measures created by the authors, and that the acculturation attitude measurement consisted of participants rating their reaction after 
listening to a scenario. Both content and construct validity remained questionable for these two measurements.

Summary and critique of existing studies. In most of the existing empirical studies on adult attachment and acculturation process, researchers frequently found a link between adult attachment (e.g., attachment dimensions, attachment styles and attachment security) and psychological adaptation outcomes. The sociocultural adaptation outcome, though conceptualized and measured very differently in the existing empirical studies on adult attachment and acculturation process, was another common variable that was found to be related to adult attachment (Brisset et al., 2010; Polek et al., 2010; Sochos \& Diniz, 2011; Wang \& Mallinckrodt, 2006a). Even though a few of these studies provided evidence for the moderating effect of adult attachment style on the relationship between acculturation process and psychological adaptation outcome (Brisset et al., 2010; Sochos \& Diniz, 2011), others did not (Polek et al., 2010; Wang \& Mallinckrodt, 2006a). Therefore, the moderating effect of the adult attachment style on the acculturation process was not consistently supported by the existing literature. Adult attachment styles were also found to be predictors of acculturation orientations (one's orientation towards one's own cultural group, and toward the host culture), though the pattern of predictive relationships also varied in different studies (e.g., van Oudenhoven \& Hofstra, 2006; Wang \& Mallinckrodt, 2006a). The significance of the relationship between adult attachment style and adaptation outcomes differed depending on the cultural distance between the acculturating group and the host culture; the more different the culture of origin and the host culture are, the more important attachment issues are on an individual's adaptation outcomes. This finding is consistent with the theory that if the 
host culture is very different from one's culture of origin, individuals may experience more challenges and feel that their identity or values are more threatened by the host culture. If this is the case, one's attachment system is more likely to be activated in such situations.

The majority of studies that examined adult attachment in relationship to acculturation have used the three-category or four-category model of adult attachment (e.g. Brisset et al., 2010; Polek et al., 2010; Sochos \& Diniz, 2011; van Oudenhoven \& Hofstra, 2006). However, current research using the two-dimensional model of adult attachment has demonstrated that it is the best conceptualization for adult attachment because it encompasses both the behavioral and cognitive facets of the attachment behavioral system (Fraley \& Waller, 1998; Crowell, Fraley, \& Shaver, 1999). Furthermore, empirical evidence suggests that the cross-cultural validity of threecategory and four-category attachment models with international students is limited. For instance, in a cross-cultural study involving international participants from 62 cultural regions, researchers found only one or two dimensions of the three or four category attachment models were demonstrated cross culturally (Schmitt, 2008, 2010; Schmitt et al., 2004). In contrast, the two dimensional model has demonstrated consistent crosscultural applicability in numerous studies (e.g., Conradi, Gerlsma, van Duijn, \& de Jonge, 2006; Mallinckrodt \& Wang, 2004). Therefore, to get a more accurate picture of this relationship, the conceptualization and operationalization of attachment must be appropriate and applicable for international students.

The majority of the previous studies have been conducted to examine the role of adult attachment in acculturation processes of immigrant populations. Only three of 
these studies have investigated international students' attachment and their role in their acculturation process (Brisset et al., 2010; Chen, Mallinckrodt, \& Mobley, 2003; Wang \& Mallinckrodt, 2006a). International students encounter unique stressors and concerns compared to other groups undergoing acculturation, therefore it is important to address how adult attachment impacts their experience of acculturation as a personal factor.

Research questions and hypotheses of the current study. In the current study, I focused on international students' acculturation processes and examined how adult attachment contributes to, or influences, their adaptation for my dissertation. Specifically, I had four research questions:

1. What is the relationship between adult attachment (attachment anxiety and avoidance) and acculturation (heritage cultural maintenance and host culture participation)?

a. I hypothesize that a negative association exists between both attachment anxiety and avoidance and international students' host culture participation (i.e., acculturation to the United States).

b. I hypothesize that a negative association exists between both attachment anxiety and avoidance and international student's heritage cultural maintenance (i.e., identification to their heritage cultures).

2. Does adult attachment predict international students' acculturative stress level, psychological adaptation and sociocultural adaptation?

a. I hypothesize that a positive association exists between both attachment anxiety and avoidance and international students’ acculturative stress level. 
b. I hypothesize that a positive association exists between both attachment anxiety and avoidance and international students' depression level (i.e., negative indicator of psychological adaptation).

c. I hypothesize that a negative association exists between both attachment anxiety and avoidance and international students' self-esteem (i.e., positive indicator of psychological adaptation).

d. I hypothesize that a negative association exists between both attachment anxiety and avoidance and international students' and sociocultural adaptation (i.e. factors related to cultural learning and social skills acquisition).

3. Is there a moderating effect between adult attachment and acculturation on international students' psychological and sociocultural adaptation?

a. I hypothesize that a moderating effect exists between attachment anxiety and international student's heritage cultural maintenance (i.e., identification to their heritage cultures) on international students’ depression level and selfesteem (i.e., psychological adaptation).

b. I hypothesize that a moderating effect exists between attachment avoidance and international student's heritage cultural maintenance (i.e., identification to their heritage cultures) on international students' depression level and selfesteem (i.e., psychological adaptation).

c. I hypothesize that a moderating effect exists between attachment anxiety and international student's host culture participation (i.e., acculturation to the U.S) on international students' depression level and self-esteem (i.e., psychological adaptation). 
d. I hypothesize that a moderating effect exists between attachment avoidance and international student's host culture participation (i.e., acculturation to the U.S) on international students' depression level and self-esteem (i.e., psychological adaptation).

e. I hypothesize that a moderating effect exists between attachment anxiety and international student's heritage cultural maintenance (i.e., identification to their heritage cultures) on international students’ sociocultural adaptation.

f. I hypothesize that a moderating effect exists between attachment avoidance and international student's heritage cultural maintenance (i.e., identification to their heritage cultures) on international students’ sociocultural adaptation.

g. I hypothesize that a moderating effect exists between attachment anxiety and international student's host culture participation (i.e., acculturation to the U.S) on international students' sociocultural adaptation.

h. I hypothesize that a moderating effect exists between attachment avoidance and international student's host culture participation (i.e., acculturation to the U.S) on international students’ sociocultural adaptation.

4. Is there a moderating effect between adult attachment and perceived discrimination on international students’ depression level and self-esteem (i.e., psychological adaptation)?

a. I hypothesize that attachment anxiety will moderate the effect of perceived discrimination on international students’ depression level and self-esteem (i.e., psychological adaptation). 
b. I hypothesize that attachment avoidance will moderate the effect of perceived discrimination on international students' depression level and self-esteem (i.e., psychological adaptation).

c. I hypothesize that attachment anxiety will moderate the effect of perceived discrimination on international students’ sociocultural adaptation.

d. I hypothesize that attachment avoidance will moderate the effect of perceived discrimination on international students' sociocultural adaptation .

\section{Operational definitions.}

Adult attachment. Adult attachment will be operationalized using the Experiences in Close Relationships Scale-Short version (ECR-S; Wei, Russell, Mallinckrodt, \& Vogel, 2007). The ECR-S is a 12 item, self-report measure that assesses two dimensions of adult attachment: avoidance and anxiety.

Acculturation. Acculturation will be operationalized using Acculturation Index (AI; Ward \& Kennedy, 1994). The AI was developed based on Berry et al.’s (1987) twodimensional acculturation model, which assesses two fundamental dimensions of acculturation: relationship to members of host culture and identification with heritage culture.

Acculturative stress. Acculturative stress will be operationalized using the Acculturative Stress Scale (ASSIS; Sandhu \& Asrabadi, 1994). The ASSIS is a 36-item scale that was developed to identify and assess the seven factors that contribute to acculturative stress of international students: Perceived Discrimination, Homesickness, Perceived Hate, Fear, Stress Due to Change/ Culture Shock, Guilt, Miscellaneous concerns. 
Psychological adaptation. Psychological adaptation is operationalized by three different factors: (a) psychological distress, and (b) psychological well-being. Psychological distress was operationalized using the Center of Epidemiological StudiesDepression Scale Revised (CESD-R; Radloff, 1977). The CESD-R is a 20-item selfreport scale developed to assess depressive symptoms. Psychological well-being was operationalized using the Rosenberg (1965) Self-Esteem Scale (RSES). The RSES is a 10-item scale that has been widely used as a measure of global self-esteem.

Sociocultural adaptation. Sociocultural adaptation was operationalized using the 21-item version of Socio-Cultural Adaptation Scale (SCAS; Ward \& Kennedy, 1999). The SCAS was developed based on Ward \& Kennedy’s (1994) definition of sociocultural adaptation that is more strongly impacted by factors related to cultural learning and social skills acquisition.

Perceived discrimination. Perceived discrimination was operationalized using the Experience of Discrimination Scale (EDS; Krahe, Abraham, Felber, \& Helbig, 2005). EDS was developed as a 22-item scale that assesses perceived discrimination for international students in Germany and the United Kingdom, which consisted of four subscales: Assault, Discrimination, Avoidance, and Antilocution. 


\section{Chapter Two: Method}

\section{Participants and Recruitment}

The participants for this study were recruited from multiple higher education institutions in different geographic locations in the United States via email and asked to complete multiple measures (see Measures section) using Qualtrics, a web-based survey software tool. Participants were international students who are holders of an F-1, student visa or a J-1, temporary educational exchange visitor visa, and were at least 18 years old. According to the Institute of International Education (IIE, 2014), the number of international students in the U.S was 886,052 in 2013-2014. China, India, and South Korea are the top three places of origin for international students (IIE, 2014). Other countries represented by a large number of international students include Saudi Arabia, Canada, Taiwan, Japan, Vietnam, Mexico, Turkey (IIE, 2014). Approximately 41\% of the international students are pursuing undergraduate degrees, 38\% are seeking graduate degrees, $12 \%$ are in the status of Optional Practical Training, while $9 \%$ are non-degree seeking students. Based on an a-priori power analysis, approximately 107 students were needed for the study using a .80 power level, a .05 Type I error rate, and anticipating a medium effect size $(w=.15)$ to adequately power the study according to Cohen's (1992) statistical power analysis table.

A total of 316 participants began the Qualtrics survey. However, 88 participants withdrew from the study during the demographic questionnaires and the first instrument by closing the browser. These participants were excluded from the data analysis because no data were available to analyze. The final sample contained 228 participants who met 
the criteria to be included into the final analysis (i.e., completed at least the first instrument of adult attachment).

The final sample of 228 participants included 98 (43\%) male and 127 (56\%) female, while 3 participants identified as “other." In terms of ethnicity, the sample included 8 (3.5\%) participants who identified as “Arab/Middle East,” 138 (60.3\%) as “Asian,” 10 (4.4\%) as “African/Black,” 43 (18.8\%) as “Caucasian/White,” 24 (10.5\%) as "Hispanic/Latino,” 3 (1.3\%) as “Multiracial," and 2 as “Other” who entered “Turkish” as their ethnicity (see Table 1). Four ethnicity categories included 10 or less participants, which may impact the validity of the final analysis due to the imbalanced sample size of each category. Furthermore, a correlation analysis using dummy variables suggested that these four categories were not significantly correlated with the outcome variables of the study. Therefore, I decided to combine the categories of "Arab/Middle East," “African/Black,” "Multiracial,” and "Other” into one category as “Other.” Dummy variables were created using “Other” as the baseline category. Three dummy variables, "Asian," "Caucasian/White," and "Hispanic/Latino" were included in the final analysis. The participants ranged in age from 18 to 45 years $(M=25.08, S D=5.24)$. The length of stay in the United States ranged from less than a year to 20 years $(M=3.3, S D$ $=2.71)$. The final sample contained 97 (42.4\%) undergraduate students, 39 (17\%) master’s level graduate students, 83 (36.2\%) doctoral level graduate students, 1 (0.4\%) student enrolled for English as a Second Language (ESL) program, 2 (0.9\%) visiting scholars, and 6 (2.6\%) identified as "Other.” The participants were enrolled in 16 different higher education institutions across the United States. The three institutions with the largest number of participants were the University of Kentucky (165; 72.1\%), 
Boston College (29; 12.7\%), and Kennesaw State University (5; 2.2\%). There was one participant for each of the other 13 institutions: Indiana University, University of Tennessee, Southern Illinois University, University of Delaware, Purdue University, University of Florida, University of Louisville, University of Maryland, Indiana University-Purdue University, University of Missouri- Kansas City, University of Missouri-Columbia, University of Denver, and University of California-Santa Barbara. Seventeen participants did not provide the name of the institution they are enrolled in. The participants were from 58 countries and regions over the world. The three countries with the largest number of participants were: China (55; 24\%); India (22; 10\%), and South Korea (16; 7\%). The nationality of other participants were listed below: Argentina, Australia, Bangladesh, Brazil, Bulgaria, Burkina Faso, Canada, China, Colombia, Czech Republic, Denmark, Egypt, Ethiopia, Finland, France, Germany, Ghana, Haiti, Honduras, Hong Kong, Hungary, India, Indonesia, Iran, Ireland, Italy, Japan, Jordan, Malaysia, Mexico, Nepal, Niger, Nigeria, Norway, Oman, Pakistan, Panama, Paraguay, Peru, Philippines, Portugal, Romania, Russia, Saudi Arabia, Singapore, Slovakia, South Korea, Spain, Sri Lanka, Taiwan, Thailand, Turkey, Uganda, Ukraine, United Arab Emirates, United Kingdom, Venezuela, and Vietnam.

\section{Procedure}

In the current study, a cross-sectional, correlational design was employed to answer each of the aforementioned research questions and address the proposed hypotheses. Participation in the study consisted of completing a demographic form and several self-report questionnaires online through a Qualtrics-hosted website. This site contained the informed consent page that outlined the purpose of the study and addressed 
all portions of research ethics in accordance with the American Psychological Association (APA) guidelines involving conducting research with human subjects and the institution’s Office of Research Integrity (ORI). Participants were specifically provided with the logistics of the study including information about the reasons for being invited to participate, the purpose of the study, how long it would last, what they would be doing in the study, the possible risks and benefits, incentives to participate, and voluntary termination of participation in the study. Participants were also informed that the research study was anonymous, in that their identifying information would not match their responses in any presentation of the study's findings thereby maintaining anonymity. Participants had the opportunity to ask questions prior to agreeing to participate by emailing the primary investigator any questions.

Once Institutional Review Board (IRB) approval was granted, the recruitment email with a link to the survey site in Qualtrics was sent to potential participants. Participants were recruited via email from the listserv of the International Students Office at the University of Kentucky and Boston College. Further recruitment was conducted via email from the listservs of the International Section of the American Psychological Association’s Counseling Psychology Division 17 and the Council of Counseling Psychology Training Programs. The recruitment email was also distributed to personnel at Kennesaw State University. Students who successfully completed the survey were given an opportunity to be entered into a raffle to win one iPad Mini. Participants were given an option to enter their email address if they want to be entered into the raffle after they completed the survey on Qualtrics and then were randomly assigned a number for the purpose of raffle. The assigned number was entered into the raffle using raffle 
software to randomly choose the winners of the raffle. The number was used to connect the winner to the person's email address, and the winner was contacted via email and asked to provide a mailing address. The iPad Mini was mailed to "Research Participant" at the address that the winner provided.

\section{Measures}

Demographic questionnaire. The participants completed a brief survey requesting background information, including age, gender, ethnicity, country of origin, religious affiliation, type of visa, number of years resided in the U.S., field of study, program of study, degree of study, year in their program, institution of study, relationship history, first language, other languages spoken, education history in the United States, relatives in the United States, highest education level, self-reported English fluency, GPA, reasons for studying in the United States, planned time remaining in the United States, intent to stay in the United States, and relationship status. Students were asked to write in their age, country of origin, religious affiliation, years resided in the United States, field of study, institution of study, first language, other languages spoken, GPA, and planned length of stay in the United States. Students were asked to choose the category that represents their gender (e.g., male, female, or other), ethnicity, type of visa, program of study, degree of study, year in their program, relationship history, education history in the United States, relatives in the United States, highest education level, reason to come to the United States, intent to stay in the United States, and relationship status. They were asked to rate their English fluency on a 4-point, Likert-type scale in the following areas: reading proficiency, writing proficiency, speaking fluency, listening ability, and overall English ability. 
Attachment. Adult Attachment was measured using the Experiences in Close Relationships Scale-Short version (ECR-S; Wei, Russell, Mallinckrodt, \& Vogel, 2007). The ECR-S is a 12 item, self-report measure that assesses two dimensions of adult attachment: avoidance and anxiety. Each dimension is measure by a subscale consisted of 6 items. Respondents use a 7-point, Likert-type scale ranging from 1 (disagree strongly) to 7 (agree strongly) for each item. Of the 12 items, 4 are reverse-keyed (1 item from the Anxiety subscale and 3 items from the Avoidance subscale). Participants rate how well each statement describes their typical feelings in romantic relationships. The average score of the items for each subscale were calculated to create subscale scores. High scores on the Anxiety and Avoidant subscales indicate high levels of attachment anxiety and attachment avoidance, respectively. Wei, Russell, Mallinckrodt, and Vogel (2007) reported Cronbach’s alphas ranged from .77 to .86 for scores on the Anxiety subscale, and ranged from .78 to .88 for the Avoidance subscale scores across studies with 2,136 undergraduate college students, including 1-3\% percent of the sample who were non-U.S. citizens. The Cronbach’s alphas for the current sample were .75 for scores on the Avoidance subscale, and .67 for the Anxiety subscale. They also reported testretest reliabilities were adequate $(r=.80$ and .82 [Anxiety] and $r=.83$ and .86 [Avoidance]) respectively, over a 1-month period. Confirmatory factor analyses suggested a model with two oblique factors (i.e., Anxiety and Avoidance) along with two orthogonal response set factors, which provided a good model fit for both the short and original versions of ECR (Wei et al., 2007). Wei et al. discussed that participants completing the ECR-S showed consistent patterns of responding to the item as a function 
of the direction of item wording, and they concluded that the items of ECR-S represent two oblique underlying factors of attachment anxiety and attachment avoidance.

Acculturation. Acculturation Index (AI; Ward \& Kennedy, 1994) was used to measure participants' acculturation. The AI is based on Berry et al.'s (1987) twodimensional acculturation model, which assesses two fundamental dimensions of acculturation: identification with heritage culture and relationship to members of host culture. The AI contains 21 cognitive and behavioral items (e.g., food, language, recreational activities, social customs, pace of life, religious beliefs). Respondents are asked to consider two questions about their current life style in two cultures, "How similar are your experiences and behaviors to members of your culture of origin?” and “How similar are your experiences and behaviors to the members of American culture?" The instrument uses a 7-point, partly anchored, Likert-type scale ranging from 1 (not at all similar) to 7(very similar). The AI yields two independent scores for the two dimensions: identification toward the heritage culture and identification toward the host (American) culture. Scores of both cases range from 0 to 126 with higher scores indicating stronger identification. Previous research studies suggested that internal reliabilities (coefficient alpha) for heritage culture scores range from .91 to .94 and for host culture scores, from .89 to .97 , with sojourns from New Zealand and Chinese immigrant population in Singapore (Ward \& Kennedy, 1994; Ward \& Rena-Deuba, 1999). Moreover, the coefficient alpha was .95 for the heritage culture scores and .92 for the American culture scores in a study with 104 Chinese international students in the U.S (Wang \& Malinckrodt, 2006a). The Cronbach’s alphas for the current sample were .94 for scores on the heritage culture subscale, and .93 for the American culture scores. 
Validity of the AI is supported by significant correlations in expected directions with other measures of acculturation process and stress (Ward \& Kennedy, 1994).

Acculturative Stress. Acculturative stress was measured using the Acculturative Stress Scale (ASSIS; Sandhu \& Asrabadi, 1994). The ASSIS was developed to identify and assess the acculturative stress of international students. The ASSIS is a 36-item scale that consisted of seven factors: Perceived Discrimination (8 items), Homesickness (4 items), Perceived Hate (5 items), Fear (4 items), Stress Due to Change/ Culture Shock (3 items), Guilt (2 items), Miscellaneous concerns (10 items). Respondents use a 5-point Likert scale ranging from 1 (strongly disagree) to 5 (strongly agree) to answer each question. The sum of all seven factors represented a total score (ranging from 36-180). Higher scores reflect greater acculturative stress perceived by the respondents. Sample items include "Many opportunities are denied to me” and "I feel guilty that I am living a different lifestyle here.” The coefficient alpha for total scale scores ranged from .92 to .94 for international students (Constantine et al., 2004; Sandhu \& Asrabadi, 1994). In the current study, the coefficient alpha for total scale scores is .96. The principal components analysis indicated six factors accounting for $70.6 \%$ of the total explained variance. The 10 Miscellaneous concerns items are included because they contributed to the unexplained variance and did not fall under any particular factors.

\section{Psychological Adaptation.}

Psychological distress. Psychological distress was measured using the Center of Epidemiological Studies-Depression Scale Revised (CESD-R; Radloff, 1977). The CESD-R is a 20-item self-report scale developed to assess depressive symptoms. 
Respondents use a 4-point Likert scale ranging from 0 (rarely or none of the time) to 3 (most or all of the time) to answer each item, based on how frequently participants have experienced each symptom during the previous week. Total score of CESD-R can range from 0 to 60, with higher score suggesting higher levels of depression. Score of 16 or higher imply a possible risk for clinically significant depression symptoms. The CESD-R was found to provide sound psychometric properties and has been used previously to assess depressive symptoms in Asian international students (e.g., Constantine et al., 2004; Rahman \& Rollock, 2004, Wei et al., 2008; Wei et al., 2007). The coefficient alpha for total scale scores was .85 for the general population and .90 for a psychiatric population in the original validity study (Radloff, 1977). The coefficient alpha was .86 for total scores with a sample of 354 Asian international students (Wei et al., 2008). The coefficient alpha for total scale scores in the current study is .94. The construct validity of the CESD-R has been evidenced by the positive association with acculturative stress (Constaintine et al., 2004; Wei et al., 2007), and negative association with social selfefficacy (Constaintine et al., 2004) and intercultural behaviors (Rahman \& Rollock, 2004) among Asian international students.

Self-esteem. The Rosenberg Self-Esteem Scale (RSES; Rosenberg, 1965) was chosen to assess self-esteem. The RSES has been widely used as a measure of global self-esteem. This 10-item scale asks the respondents to rate statement such as "I feel that I have a number of good qualities" using a 4-point Likert scale ranging from 1 (strongly disagree) to 4 (strongly agree). Total scores range from 10 to 40, with higher scores indicating greater self-esteem. Coefficient alphas for the total self-esteem scale scores ranged from .78 to .92 for Asian international students (Chinese, Korean, Taiwan, and 
Indian international students) and Asian college students (Korean American and Taiwanese students ) in previous studies (Lee, 2005; Wang, Slaney, \& Rice, 2007; Wei et al., 2008). Furthermore, a cross-cultural study administered the RSES to 16,998 participants across 53 nations and indicated Cronbach’s alphas ranging from .70 to.90 for most of the nations (Schmitt \& Allik, 2005). The Cronbach’s alpha for total scale scores is .9 in the current study. Structure equivalence was evident in the same study by the findings of the factor structure that was largely invariant across nations, cross-cultural equivalence of the RSES was also supported by the correlation among RSES and neuroticsm, extraversion, and romantic attachment styles within nearly all nations. A negative association between the RSES and depressive symptoms has also been found for Korean college students (Lee, 2003) and Taiwanese college students (Wang et al., 2007), which provides support for construct validity of the scale.

Sociocultural Adaptation. The Socio-Cultural Adaptation Scale (SCAS; Ward \& Kennedy, 1999) was selected to assess participants’ sociocultural adaptation. The SCAS was inspired by Furnham and Bochner’s (1982) 40-item Social Situations Questionnaire (SSQ), and developed based on Ward \& Kennedy’s (1994) definition of sociocultural adaptation that is more strongly impacted by factors related to cultural learning and social skills acquisition. The SCAS asks respondents to indicate the amount of difficulty they have experienced in a variety of areas such as relationships by using a 5-point Likert scale ranging from 1 (Not at all competent) to 5 (Extremely competent). The SCAS is a flexible instrument and can be easily modified depending on the characteristics of the sample. Most versions contain 20-23 items. The total scores range from 21-105. 
Previous studies have used this instrument with international students studying in a variety of nations (e.g., Malaysian students in Singapore and Singaporean and Japanese students in New Zealand). The items have been found to generate reliable scores with coefficient alphas ranging from .84 to .91 (Ward \& Kennedy, 1999). According to Ward \& Kennedy (1999), construct validity was evident by the consistently significant correlations between sociocultural and psychological adaptation as measured by the Zung Self-rating Depression Scale (Zung, 1965). In the current study, I included all 40 items of the survey (e.g., making friends with local people, using the transport system, adapting to the local accommodations) with the current sample and conducted an Exploratory Factor Analysis to examine the factor structure. The result suggested a two-factor structure which the first two factors explained $49.61 \%$ of the cumulated variance. I decided to use the 20 items that loaded the highest on these two factors for our data analysis. There were 15 items that loaded higher than .4 for the first factor, which explained $43.09 \%$ of the cumulated variance. The other 5 items loaded higher than .4 for the second factor, which explained $6.51 \%$ of the cumulated variance. Unlike the original scale, higher scores indicate greater adaptation in different areas to the host culture. In the current study, the coefficient alpha was .95.

Perceived Discrimination. Perceived discrimination was assessed by using the Experience of Discrimination Scale (EDS; Krahe, Abraham, Felber, \& Helbig, 2005). EDS is a 22-item scale that consisted of four subscales: Physical Assault, Discrimination, Avoidance, and Antilocution (i.e., verbal discrimination). The four subscales represent increasingly severe experiences of discrimination. The EDS was developed as a measure of perceived discrimination for international students in Germany and the United 
Kingdom. In the current study, the wording of the original scale was adapted for international students in the United States. Respondents were asked to answer questions (e.g., "How often have you felt that you were treated unfairly by people who work in public services because you are not American?”) using a 5-point Likert scale ranging from 1 (never) to 5 (very often). The mean score is calculated for each subscale. A mean score of less than 2 indicates "no experience" with the level of discrimination represented by the subscale. If the mean scores of all four subscales are below 2, a final score of "0" is allocated. A score of "1" suggested experience of antilocution (mean $<2$ on avoidance, discrimination and assault scales but $\geq 2$ on the antilocution scale). A score of "2" suggested experience up to avoidance (mean $<2$ on discrimination and assault scales but $\geq 2$ on the avoidance scale). A score of " 3 " suggested experience up to the level of behavioral discrimination (mean $<2$ on assault scales but $\geq 2$ on the discrimination scale). A score of " 4 " suggest experience or fear of physical assault (mean $\geq 2$ on the assault scale) with the possibility of experience with other levels of discrimination. Scores have generated coefficient alphas ranging from .86 to .92 with 379 international students and visiting scholars in Germany and the United Kingdom (Krahe, Abraham, Felber, \& Helbig, 2005). The coefficient alpha for the current study was .92. A principal components analysis of the factorial structure of EDS suggested four factors that explaining 54.63\% of the variance (Krahe, Abraham, Felber, \& Helbig, 2005). For the final analysis, four dummy variables were created to represent the four level of perceived discrimination experience using "no experience" as the baseline. 


\section{Chapter Three: Results}

\section{Tests of Assumptions}

Prior to testing the hypotheses, the data was reviewed and cleaned for missing data, univariate and multivariate outliers, normality, and homogeneity of variance. All missing data were converted to value 999 in SPSS 22, which will assure non-usage in further statistical analyses. Participants with missing data seemed to withdraw on the first page of the online survey. In this case, withdrawal was as simple as closing their web browser. Each page of the survey included a single measure and forced response function is added to the survey so that participants could not skip any questions. Therefore, withdrawal resulted complete answers for the measures prior of the withdrawal while no answer for the rest of the measures were stored in the system. In other words, data missing for any variable is either $0 \%$ or $100 \%$. As a result, missing items were not imputed because it is impossible to conduct imputation with a variable with $0 \%$ data.

Normality of the data was determined through the kurtosis and skewness tests in SPSS 22. Data that are normally distribution have a kurtosis and a skewness of 0 , and extreme deviation from 0 indicate that the data may not be normally distributed. The result of the kurtosis and skewness tests suggested that all variables included in the final analysis were normally distributed (all $Z$ scores $<1.73$ ). Box plots and scatter plots were utilized to screen possible outliers. I assessed for homoscedasticity using the scatter plots (i.e., Q-Q-Plot) function in SPSS 22 with the predicted values of the dependent variables against residuals because SPSS does not support any statistical test for homoscedasticity (Statistical Solutions, 2015). The plot of each dependent variable was developed and 
indicated that no tendency in the error terms was found in my final analysis (Kachigan, 1991; UCLA: Statistical Consulting Group, n.d.). Therefore, I concluded the variances of the residuals are constant and the assumption of homoscedasticity is not violated. Two one-way analysis of variance (ANOVA) suggested that there were significant differences with respect to the adult attachment variables by students' romantic relationship status $(F[3,224]=8.901, p<.01)$. Tukey's HSD post hoc comparisons indicated that both attachment avoidance and attachment anxiety scores differed significantly between participants in a committed relationship/married/partnered and other participants. Compared to other participants, international students in a committed relationship (including being married or partnered) for more than 6 months presented with lower attachment anxiety and attachment avoidance. However, considering the small difference between the scores and the fact that $45 \%$ of participants were in a committed relationship, I included this category to the final analysis.

\section{Preliminary Analyses}

I conducted a one-way analysis of variance (ANOVA) to check for variances in the distribution of participants with respect to the main variables of interest based for both the categorical demographic information of gender and English as first language. Table 1 provides a summary of the one-way ANOVA comparisons. The results suggested no significant gender differences of the study variables. However, participants who have English as their first language differed significantly from those do not on heritage culture identification $(F[1,201]=3.995, p=.05)$, acculturation to host culture $(F[1,201]=8.09, p<.01)$, acculturative stress $(F[1,190]=10.94, p<.01)$ and sociocultural adaptation $(F[1,196]=8.47, p<.01)$. Pearson's product-moment 
correlations were conducted to examine the relationship between other demographic information and the study variables (see Tables 2 and 3). The length of stay in the United States was significantly associated with acculturation to the Unites States and self-esteem. English fluency, on the other hand, was significantly associated with adult attachment, adult avoidance, acculturation to the United States, acculturative stress, self-esteem, and sociocultural adaptation. Asian ethnicity was significantly associated with heritage culture identification, acculturative stress, and sociocultural adaptation. Significant associations were found between Caucasian ethnicity and acculturation to host culture, acculturative stress, and sociocultural adaptation. Latino ethnicity was significantly associated with sociocultural adaptation. Considering the result of the preliminary analysis, I decided to use length of stay in the United States, English as the first language, English proficiency, and ethnicity (i.e., Asian, Caucasian, and Latino) as the control variables in the final analysis.

Table 1

One-Way Analysis of Variance Summary Table for Categorical Demographic and Study Variables

\begin{tabular}{llc}
\hline \multicolumn{1}{c}{ Variables } & Gender & $\begin{array}{c}\text { English as } \\
\text { 1st } \\
\text { Language }\end{array}$ \\
\hline 1. Heritage Culture Identification & 0.69 & $3.99^{*}$ \\
2. Acculturation to U.S. & 0.42 & $8.08^{* *}$ \\
3. Psychological Distress & 1.6 & 0.23 \\
4. Self-Esteem & 0.21 & 3.11 \\
5. Acculturative Stress & 0.07 & 10.94 \\
6. Sociocultural Adaptation & 0.06 & $8.47^{* *}$ \\
\hline Note. ${ }^{*} p<.05, * * p<.01$ & &
\end{tabular}


Table 2

Correlations of Demographic, Attachment, Acculturation, and Adaptation Variables

\begin{tabular}{|c|c|c|c|c|c|c|c|c|c|c|c|c|}
\hline Variable & M & SD & 2 & 3 & 4 & 5 & 6 & 7 & 8 & 9 & 10 & 11 \\
\hline $\begin{array}{l}\text { 1. Length of stay in the } \\
\text { U.S. }\end{array}$ & 3.30 & 2.71 & .10 & $.15^{*}$ & -.07 & -.14 & -.14 & $0.17^{*}$ & -.04 & -.12 & $.25 * *$ & .14 \\
\hline $\begin{array}{l}\text { 2. English as } 1 \text { st } \\
\text { Language }\end{array}$ & 0.09 & 0.29 & & $.42^{* *}$ & -.06 & -.09 & $.14^{*}$ & $.2 * *$ & $-.23 * *$ & -.04 & .13 & $.20 * *$ \\
\hline 3. English proficiency & 15.64 & 3.12 & & & $-.16^{*}$ & $-.28 * *$ & .10 & $.24 * *$ & $-.37 * *$ & -.09 & $.37 * *$ & $.52 * *$ \\
\hline 4. Attachment Anxiety & 22.21 & 6.12 & & & & $.37 * *$ & -.02 & -.05 & $.2 * *$ & $.32 * *$ & -.36 & $-.20 * *$ \\
\hline 5. Attachment Avoidance & 17.04 & 6.01 & & & & & -.03 & -.06 & $.26 * *$ & $.25 * *$ & -.28 & $-.26 * *$ \\
\hline $\begin{array}{l}\text { 6. Heritage Culture } \\
\text { Identification }\end{array}$ & 101.32 & 24.54 & & & & & & $.15^{*}$ & .02 & -.05 & .14 & $.14^{*}$ \\
\hline 7. Acculturation to U.S. & 88.97 & 21.80 & & & & & & & -.19 & -.05 & .08 & $.29 * *$ \\
\hline 8. Acculturative Stress & 87.69 & 26.29 & & & & & & & & $.38 * *$ & $-.30 * *$ & $-.20 * *$ \\
\hline 9. Psychological Distress & 10.82 & 10.99 & & & & & & & & & $-.45 * *$ & $.38 * *$ \\
\hline 10. Self-Esteem & 19.68 & 5.86 & & & & & & & & & & $-.30 * *$ \\
\hline $\begin{array}{l}\text { 11. Sociocultural } \\
\text { Adaptation }\end{array}$ & 74.29 & 13.83 & & & & & & & & & & \\
\hline
\end{tabular}


Table 3

Correlations of Ethnicity, Acculturation, and Adaptation Variables

\begin{tabular}{|c|c|c|c|c|c|c|c|c|c|c|}
\hline Variable & $\mathrm{M}$ & SD & 2 & 3 & 4 & 5 & 6 & 7 & 8 & 9 \\
\hline 1. Asian & N/A & N/A & $-.6 * *$ & $-.43 * *$ & $-.18 *$ & -.14 & $.29 * *$ & -.06 & -.07 & $-.3 * *$ \\
\hline 2. Caucasian & N/A & N/A & & $-.17 *$ & .12 & $.25 * *$ & $-.39 * *$ & -.03 & .03 & $.2 * *$ \\
\hline 3. Latino & N/A & N/A & & & .09 & .04 & .03 & .07 & -.05 & $.16^{*}$ \\
\hline $\begin{array}{l}\text { 4. Heritage Culture } \\
\text { Identification }\end{array}$ & 101.32 & 24.54 & & & & $.15^{*}$ & .02 & -.05 & .14 & $.14^{*}$ \\
\hline 5. Acculturation to U.S. & 88.97 & 21.80 & & & & & $-.19 * *$ & -0.05 & 0.08 & $.29 * *$ \\
\hline 6. Acculturative Stress & 87.69 & 26.29 & & & & & & $.38 * *$ & $-.3 * *$ & $-.2 * *$ \\
\hline 7. Depression Symptoms & 10.82 & 10.99 & & & & & & & $-.45^{* *}$ & $.38 * *$ \\
\hline 8. Self-Esteem & 19.68 & 5.86 & & & & & & & & $-.3 * *$ \\
\hline 9. Sociocultural Adaptation & 74.29 & 13.83 & & & & & & & & \\
\hline
\end{tabular}

Note. ${ }^{*} p<.05,{ }^{* *} p<.01$ 


\section{Primary Analyses}

I tested the hypotheses of the study using hierarchical multiple regression. Control variables including length of stay in the U.S., English as the first language, English proficiency, and ethnicity were determined based on the preliminary analysis. I used the block entry function to include the control variables in the first block, and the predictors were entered into the second block. I conducted a total of 11 hierarchical multiple regressions to test the hypotheses of the study.

Hypothesis 1. The result of the Pearson's correlation suggested no significant association between adult attachment (i.e., attachment anxiety and attachment avoidance) and acculturation (i.e., identification with heritage culture and acculturation to U.S. culture). The full model examining the relationship between adult attachment and acculturation to U.S. culture was statistically significant, $F(8,194)=4.46, p<.001, R^{2}$ $=.15$. The full model predicted $15 \%$ of the variance of acculturation to the U.S. However, the results suggest that attachment anxiety and attachment avoidance did not significantly increase the variance explained by the control variables, $R^{2}$ change $=.008, p$ $=.42$. The full model examining the relationship between adult attachment and identification with heritage culture was not statistically significant, $F(8,194)=1.49$, $p$ $=.16, R^{2}=.06$. Attachment anxiety and attachment avoidance did not significantly increase the variance explained by the control variables, $R^{2}$ change $<.01, p=1$. Therefore, I conclude that the result did not support hypothesis $1 \mathrm{a}$ and hypothesis $1 \mathrm{~b}$ (see Table 4). 
Table 4

Hierarchical Regression Analysis of Acculturation

\begin{tabular}{|c|c|c|c|c|c|c|}
\hline Hierarchical Variables & & Change in $R^{2}$ & $\Delta F$ & $B$ & $S E$ & $\beta$ \\
\hline \multicolumn{7}{|c|}{ Heritage Culture Identification } \\
\hline 1. Control Variables & .24 & .06 & & & & \\
\hline 2. Predictors & .24 & .00 & & & & \\
\hline \multicolumn{7}{|l|}{ Control Variables } \\
\hline Length of Stay in U.S. & & & & -1.07 & 0.69 & -0.12 \\
\hline 1st Language & & & & 10.47 & 6.45 & 0.13 \\
\hline English Proficiency & & & & 0.15 & 0.68 & 0.02 \\
\hline Asian & & & & -2.78 & 6.34 & -0.06 \\
\hline Caucasian & & & & 2.94 & 6.79 & 0.05 \\
\hline Latino & & & & 5.45 & 7.88 & 0.07 \\
\hline \multicolumn{7}{|l|}{ Predictors } \\
\hline Attachment Anxiety & & & & 0.004 & 0.29 & 0.001 \\
\hline Attachment Avoidance & & & & 0.003 & 0.33 & 0.001 \\
\hline \multicolumn{7}{|c|}{ Acculturation to U.S. Culture } \\
\hline 1. Control Variables & .38 & $.15 * *$ & $7 * *$ & & & \\
\hline 2. Predictors & .39 & .01 & & & & \\
\hline \multicolumn{7}{|l|}{ Control Variables } \\
\hline Length of Stay in U.S. & & & & 1.35 & 0.58 & $0.17 *$ \\
\hline 1st Language & & & & 7.15 & 5.43 & 0.1 \\
\hline English Proficiency & & & & 1 & 0.57 & 0.15 \\
\hline Asian & & & & 9.37 & 5.33 & 0.21 \\
\hline Caucasian & & & & 20.77 & 5.71 & $0.38 * *$ \\
\hline Latino & & & & 18.03 & 6.63 & $0.25 * *$ \\
\hline
\end{tabular}


Table 4 (Continued)

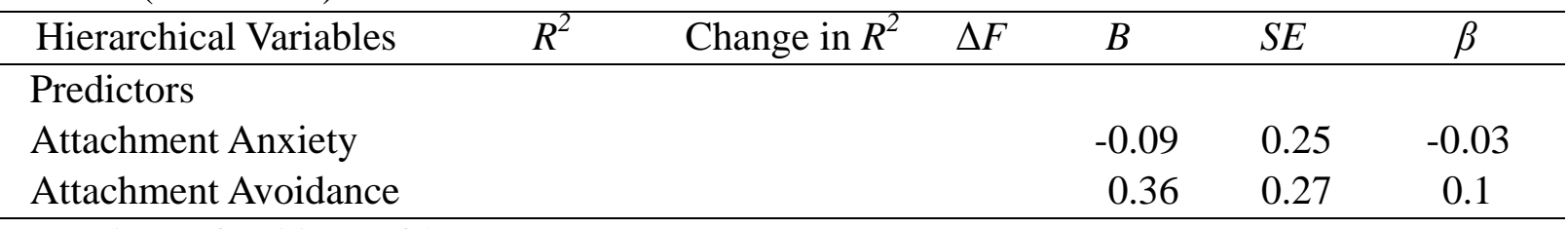

Note. ${ }^{*} p<.05,{ }^{* *} p<.01$ 
Hypothesis 2. The results provided partial support for hypothesis 2 (see Table 5). The two dimensions of adult attachment were both significant predictors of international students' acculturative stress level and psychological adaptation. A positive association existed between each of the two dimensions of adult attachment and international students' acculturative stress level. The full model revealed a statistically significant predictive relationship between adult attachment and acculturative stress, $F(8,183)=$ 7.29, $p<.001, R^{2}=.24$ (see Table 6). Attachment anxiety and attachment avoidance significantly increased the variance explained by the control variables, $R^{2}$ change $=.03, p$ $=.04$. However, attachment anxiety $(\beta=.11, p=.10)$ and attachment avoidance $(\beta=.09$, $p=.21$ ) each were not significant independent predictor of acculturative stress. Thus, this result did not support hypothesis 2a.

A positive association was found between each of the two dimensions of adult attachment and psychological distress (i.e., the negative indicator of psychological adaptation). The full model revealed a statistically significant predictive relationship between adult attachment and psychological distress, $F(8,182)=3.97, p<.001, R^{2}=.15$. Attachment anxiety and attachment avoidance significantly increased the variance of psychological distress explained by the control variables, $R^{2}$ change $=.12, p<.001$. Attachment anxiety $(\beta=.27, p<.001)$ and attachment avoidance $(\beta=.17, p=.04)$ each were significant independent predictor of psychological distress. Therefore, hypothesis $2 \mathrm{~b}$ is supported by the result of this regression model.

A negative association existed between each of the two dimensions of adult attachment and international students' self-esteem (i.e., the positive indicator of psychological adaptation). The full model suggested a statistically significant predictive 
relationship between adult attachment and self-esteem, $F(8,182)=9.66, p<.001, R^{2}=.3$. Attachment anxiety and attachment avoidance significantly increase the variance of selfesteem explained by the control variables, $R^{2}$ change $=.11, p<.001$. Attachment anxiety $(\beta=-.3, p<.001)$ was a significant independent predictor of self-esteem, but attachment avoidance $(\beta=-.1, p=.18)$ was not a significant predictor. Therefore, hypothesis 2c is partially supported by the result of this regression model.

Table 5

Hierarchical Regression Analysis of Psychological Distress, Acculturative Stress, and Sociocultural Adaptation

\begin{tabular}{|c|c|c|c|c|c|c|}
\hline Hierarchical Variables & $R^{2}$ & $\begin{array}{c}\text { Change in } \\
R^{2}\end{array}$ & $\Delta F$ & $B$ & $S E$ & $\beta$ \\
\hline \multicolumn{7}{|c|}{ Psychological Distress } \\
\hline 1. Control Variables & .03 & .03 & 0.88 & & & \\
\hline 2. Predictors & .15 & $.12 * *$ & $3.97 * *$ & & & \\
\hline \multicolumn{7}{|l|}{ Control Variables } \\
\hline Length of Stay in U.S. & & & & -0.17 & 0.3 & -0.04 \\
\hline 1st Language & & & & 1.09 & 2.96 & 0.03 \\
\hline English Proficiency & & & & -0.2 & 0.3 & -0.06 \\
\hline Asian & & & & -2.65 & 2.77 & -0.12 \\
\hline Caucasian & & & & -0.66 & 2.98 & -0.02 \\
\hline Latino & & & & 2.04 & 3.47 & 0.06 \\
\hline \multicolumn{7}{|l|}{ Predictors } \\
\hline Attachment Anxiety & & & & 0.47 & 0.13 & $0.27 * *$ \\
\hline Attachment Avoidance & & & & 0.3 & 0.14 & $0.17 *$ \\
\hline \multicolumn{7}{|c|}{ Self-esteem } \\
\hline 1. Control Variables & .19 & $.19 * *$ & $7.07 * *$ & & & \\
\hline 2. Predictors & .3 & $.11^{* *}$ & $9.66 * *$ & & & \\
\hline \multicolumn{7}{|l|}{ Control Variables } \\
\hline Length of Stay in U.S. & & & & 0.34 & 0.14 & $0.16^{*}$ \\
\hline 1st Language & & & & -1.18 & 1.43 & -0.06 \\
\hline English Proficiency & & & & 0.62 & 0.15 & $0.33 * *$ \\
\hline Asian & & & & -1.17 & 1.34 & -0.1 \\
\hline Caucasian & & & & -2.63 & 1.44 & -0.18 \\
\hline Latino & & & & -2.82 & 1.68 & -0.14 \\
\hline Predictors & & & & & & \\
\hline
\end{tabular}


Table 5 (Continued)

\begin{tabular}{|c|c|c|c|c|c|c|}
\hline Hierarchical Variables & $R^{2}$ & $\begin{array}{c}\text { Change in } \\
R^{2}\end{array}$ & $\Delta F$ & $B$ & $S E$ & $\beta$ \\
\hline Attachment Anxiety & & & & -0.28 & 0.06 & $-0.3^{* *}$ \\
\hline Attachment Avoidance & & & & -0.09 & 0.07 & -0.1 \\
\hline \multicolumn{7}{|c|}{ Sociocultural Adaptation } \\
\hline 1. Control Variables & .29 & $.29 * *$ & $13.25^{* *}$ & & & \\
\hline 2. Predictors & .31 & .02 & $10.56^{* *}$ & & & \\
\hline \multicolumn{7}{|l|}{ Control Variables } \\
\hline Length of Stay in U.S. & & & & 0.5 & 0.33 & $0.1^{*}$ \\
\hline 1st Language & & & & -0.48 & 3.27 & -0.01 \\
\hline English Proficiency & & & & 1.91 & 0.34 & $0.43 * *$ \\
\hline Asian & & & & -1.88 & 3.12 & -0.07 \\
\hline Caucasian & & & & 0.44 & 3.34 & 0.01 \\
\hline Latino & & & & 5.19 & 3.92 & 0.11 \\
\hline \multicolumn{7}{|l|}{ Predictors } \\
\hline Attachment Anxiety & & & & -0.23 & 0.14 & -0.1 \\
\hline Attachment Avoidance & & & & -0.1 & 0.16 & -0.06 \\
\hline \multicolumn{7}{|c|}{ Acculturative Stress } \\
\hline 1. Control Variables & .22 & $.22 * *$ & $8.47 * *$ & & & \\
\hline 2. Predictors & .24 & $.03 *$ & $7.29 * *$ & & & \\
\hline \multicolumn{7}{|l|}{ Control Variables } \\
\hline Length of Stay in U.S. & & & & -0.05 & 0.67 & -0.01 \\
\hline 1st Language & & & & -4.75 & 6.67 & -0.05 \\
\hline English Proficiency & & & & -1.75 & 0.68 & $-0.21^{*}$ \\
\hline Asian & & & & -1.26 & 6.24 & -0.02 \\
\hline Caucasian & & & & -19.18 & 6.72 & $-0.29 * *$ \\
\hline Latino & & & & 0.06 & 7.82 & 0.001 \\
\hline \multicolumn{7}{|l|}{ Predictors } \\
\hline Attachment Anxiety & & & & 0.48 & 0.29 & 0.11 \\
\hline Attachment Avoidance & & & & 0.41 & 0.32 & 0.09 \\
\hline
\end{tabular}

A negative association existed between each of the two dimensions of adult attachment and international students' sociocultural adaptation. The full model suggested a statistically significant predictive relationship between adult attachment and sociocultural adaptation, $F(8,189)=10.56, p<.001, R^{2}=.31$. However, attachment anxiety and attachment avoidance did not significantly increase the variance of 
sociocultural adaptation explained by the control variables, $R^{2}$ change $=.02, p=.13$. Attachment anxiety $(\beta=-.1, p=.12)$ and attachment avoidance $(\beta=-.05, p=.52)$ were not significant independent predictors of sociocultural adaptation. Therefore, hypothesis $2 \mathrm{~d}$ is not supported by the result of this regression model.

Hypothesis 3. To test the moderating relationship between adult attachment (i.e., the moderator) and acculturation (i.e., the predictor) on international students' psychological and sociocultural adaptation (i.e., the dependent variables), four interaction variables of adult attachment (i.e., attachment anxiety and attachment avoidance) and acculturation (i.e., identification to heritage culture and acculturation to the U.S. culture) were calculated to enter into the hierarchical multiple regression model through SPSS. I conducted the calculation by multiplying international students' identification to heritage culture and their acculturation to U.S. culture by the two attachment dimensions. Similar to hypothesis 1 and 2, the control variables are entered as the first block. The four main effect variables were entered as the second block: attachment anxiety, attachment avoidance, identification to heritage culture, and acculturation to the U.S. culture. In addition, the four interaction variables were also entered in the second block: attachment anxiety $\times$ identification to heritage culture, attachment anxiety $\times$ acculturation to the U.S. culture, attachment avoidance $\times$ identification to heritage culture, attachment avoidance $\times$ acculturation to the U.S. culture. When the analysis result suggested a significant moderating effect, the turning point, if one, the moderating relationship was determined using three items (two main effects and one interaction effect) holding all other variables in the model constant: $b_{1} x_{1}+b_{2} x_{2}+b_{3}\left(x_{1} *_{2}\right)$. The turning point was defined as the zero 
coefficient for the anchor variables (either $\mathrm{x}_{1}$ or $\mathrm{x}_{2}$ ) when the other variable is substituted with a specific value.

The result of the final model revealed that the entry of the predictor variables (main effects and interaction effects) accounted for additional significant incremental variance in predicting international students' psychological distress, $F(14,176)=3.49, p$ $<.001, R^{2}=.22, R^{2}$ change $=.19$ (see Table 6$)$. The interaction between attachment avoidance and acculturation to the U.S. culture was a significant independent predictor of psychological distress, $\beta=1.28, p<.001$. Attachment avoidance significantly moderated the effect of acculturation to the U.S. on international students' psychological distress. After conducting some algebraic manipulation (in search for a potential turning point) holding all other coefficients in the model constant, the result indicated that at low levels of attachment avoidance (i.e., < 16.5; ECR-S Attachment Avoidance Subscale Score), acculturation to the U.S. culture was significantly and negatively related to international students’ psychological distress. On the other hand, at high levels of attachment avoidance (i.e., >16.5), acculturation to the U.S. culture is significantly and positively associated with psychological distress. The other three interaction variables (attachment anxiety $\times$ identification to heritage culture, attachment anxiety $\times$ acculturation to the U.S. culture, and attachment avoidance $\times$ identification to heritage culture) were not significant predictors of psychological distress.

The final model in predicting self-esteem (i.e., positive indicator of psychological adaptation) suggested that the entry of the predictor variables (main effects and interaction effects) accounted for additional significant incremental variance in predicting international students' psychological distress, $F(14,176)=6.4, p<.001, R^{2}=.34, R^{2}$ 
change $=.15$. However, none of the four interaction variables were significant independent predictors of self-esteem. Furthermore, none of the four main effect variables were significant independent predictors of self-esteem even though the main effects and interaction effects collectively accounted for additional significant incremental variance (see Table 7).

The results of the final model in predicting sociocultural adaptation suggested that the entry of the predictor variables (main effects and interaction effects) accounted for additional significant incremental variance in predicting international students' sociocultural adaptation, $F(14,183)=7.38, p<.001, R^{2}=.36, R^{2}$ change $=.07$. The interaction between attachment anxiety and acculturation to the U.S. culture was a marginally significant independent predictor of sociocultural adaptation, $\beta=-.64, p$ $=.053$. Similarly, some algebraic manipulation holding all other coefficients in the model constant show that at low levels of attachment anxiety (i.e., $<27$; ECR-S Attachment Anxiety Subscale Score ), acculturation to the United States was significantly and positively associated with international students' sociocultural adaptation. However, at high levels of attachment anxiety (i.e., > 27), acculturation to the United States became significantly and negatively associated with international students’ sociocultural adaptation. However, none of the other three interaction variables were significant independent predictors of sociocultural adaptation (see Table 8).

The result of the final analysis partially supported hypothesis 3d that a moderating effect exists between attachment avoidance and international students' host culture participation (i.e., acculturation to the U.S culture) on international students' depression level (i.e., negative indicator of psychological adaptation). Also, hypothesis $3 g$ was 
supported that a moderating effect exists between attachment anxiety and international students' host culture participation (i.e., acculturation to the U.S. culture). However, the findings did not support other hypotheses on the moderating effect between adult attachment and acculturation on international students’ psychological and sociocultural adaptation.

Hypothesis 4. To test the moderating effect between adult attachment (i.e., the moderator) and perceived discrimination (i.e., the predictor) on international students’ psychological adaptation (i.e., the dependent variables), I calculated eight interaction variables of adult attachment (i.e., attachment anxiety and attachment avoidance) and perceived discrimination to enter into the hierarchical multiple regression models through SPSS. The calculations were conducted by multiply attachment anxiety and attachment avoidance by the four dummy variables of the four level of perceived discrimination experience. Similar to hypothesis 1 and 2, the control variables were entered as the first block. The six main effect variables were entered as the second block: attachment anxiety, attachment avoidance, physical assault, behavioral discrimination, avoidance, and antilocution. In addition, the eight interaction variables were also entered in the second block: attachment anxiety $\times$ physical assault, attachment anxiety $\times$ behavioral discrimination, attachment anxiety $\times$ avoidance, attachment anxiety $\times$ antilocution, attachment avoidance $\times$ physical assault, attachment avoidance $\times$ behavioral discrimination, attachment avoidance $\times$ avoidance, and attachment avoidance $\times$ antilocution. As noted earlier, when the analysis result suggested a significant moderating effect, if one, the turning point of the moderation relationship was determined using three items (two main effects and one interaction effect) holding all 
other variables in the model constant: $b_{1} x_{1}+b_{2} x_{2}+b_{3}\left(x_{1} * x_{2}\right)$. The turning point was defined as the zero coefficient for the anchor variables (either $\mathrm{x}_{1}$ or $\mathrm{x}_{2}$ ) when the other variable is substituted with a specific value.

The results of the final model revealed that the entry of the predictor variables (main effects and interaction effects) accounted for additional significant incremental variance in predicting international students' psychological distress, $F(20,170)=2.27, p$ $=.002, R^{2}=.21, R^{2}$ change $=.18$. However, none of the eight interaction variables were significant independent predictors of psychological distress. Furthermore, none of the six main effect variables were significant independent predictors of psychological distress (see Table 9). The main effects and interaction effects collectively accounted for additional significant incremental variance but no moderation effect were found in this model.

The results of the final model in predicting self-esteem suggested that the entry of the predictor variables (main effects and interaction effects) accounted for additional significant incremental variance, $F(20,170)=4.67, p<.001, R^{2}=.36, R^{2}$ change $=.17$. The interaction between attachment avoidance and experience with physical assault was a marginally significant independent predictor of self-esteem, $\beta=-0.83, p=.05$.

Attachment avoidance significantly moderated the effect of international students’ experience with physical assault on their self-esteem. After conducting some algebraic manipulation (in search for a potential turning point) holding all other coefficients in the model constant, the result indicated that at low levels of attachment avoidance (i.e., $<$ 10.62; ECR-S Attachment Avoidance Subscale Score), experience with physical assault was significantly and positively associated with international students’ self-esteem. 
However, at high levels of attachment avoidance (i.e., > 10.62), experience with physical assault was significantly and negatively associated with international students’ selfesteem. Moreover, the interaction between attachment avoidance and experience with behavioral discrimination was also a significant independent predictor of self-esteem, $\beta=$ -1.06, $p=.01$. Similarly, some algebraic manipulation holding all other coefficients in the model constant indicate at low levels of attachment avoidance (i.e., < 12.09; ECR-S Attachment Avoidance Subscale Score), experience with behavioral discrimination was significantly and positively associated with international students' self-esteem. However, at high levels of attachment avoidance (i.e., > 12.09), experience with behavioral discrimination was significantly and negatively associated with international students’ self-esteem. Given that the two moderating (interaction) effects coexisted, meaning each moderating effect remained significant even after controlling for the other significant moderating effect, these moderating effects can be considered robust and credible. The other three interaction variables were not significant predictors of self-esteem (see Table 10).

The results of the final analysis partially supported hypothesis 4 that a moderating effect exists between attachment avoidance and international students' experiences with physical assault on international students’ self-esteem (i.e., positive indicator of psychological adaptation). Furthermore, I also found a moderating effect between attachment avoidance and international students' experience with behavioral discrimination on international students’ self-esteem (i.e., positive indicator of psychological adaptation). However, the result did not support other hypotheses on the 
moderating effect of adult attachment for the relationship between perceived discrimination and international students' psychological adaptation. 
Table 6

Hierarchical Regression Analysis of Psychological Distress

\begin{tabular}{|c|c|c|c|c|c|c|c|}
\hline Hierarchical Variables & $R^{2}$ & Change in $R^{2}$ & $\Delta F$ & $d f$ & $B$ & $S E$ & $\beta$ \\
\hline 1. Control Variables & .03 & .03 & 0.88 & 6,184 & & & \\
\hline 2. Interactions & .22 & $.19 * *$ & $3.49 * *$ & 14,176 & & & \\
\hline & & & & Final & del & & \\
\hline \multicolumn{8}{|l|}{ Control Variables } \\
\hline Length of Stay in U.S. & & & & & -0.05 & 0.3 & -0.01 \\
\hline 1st Language & & & & & 3.06 & 2.95 & 0.08 \\
\hline English Proficiency & & & & & -0.31 & 0.3 & -0.09 \\
\hline Asian & & & & & -3.19 & 2.74 & -0.14 \\
\hline Caucasian & & & & & -0.89 & 3 & -0.03 \\
\hline Latino & & & & & 1.81 & 3.47 & 0.05 \\
\hline \multicolumn{8}{|l|}{ Main Effect } \\
\hline Attachment Anxiety & & & & & 0.35 & 0.69 & 0.2 \\
\hline Attachment Avoidance & & & & & -0.8 & 0.72 & -0.45 \\
\hline Heritage Culture Identification & & & & & 0.07 & 0.14 & 0.14 \\
\hline Acculturation to U.S. & & & & & -0.33 & 0.15 & $-0.63 *$ \\
\hline \multicolumn{8}{|l|}{ Interactions } \\
\hline $\begin{array}{l}\text { Attachment Anxiety } \times \text { Heritage Culture } \\
\text { Identification }\end{array}$ & & & & & 0.003 & 0.01 & 0.23 \\
\hline Attachment Anxiety $\times$ Acculturation to U.S. & & & & & -0.002 & 0.01 & -0.137 \\
\hline Attachment Avoidance $\times$ Heritage Culture Id & tition & & & & -0.01 & 0.01 & -0.58 \\
\hline Attachment Avoidance $\times$ Acculturation to U.S & & & & & 0.02 & 0.01 & $1.27 * *$ \\
\hline
\end{tabular}

Note. ${ }^{*} p<.05, * * p<.01$ 
Table 7

Hierarchical Regression Analysis of Self-Esteem

\begin{tabular}{|c|c|c|c|c|c|c|c|}
\hline Hierarchical Variables & $R^{2}$ & Change in $R^{2}$ & $\Delta F$ & $d f$ & $B$ & $S E$ & $\beta$ \\
\hline 1. Control Variables & .19 & $.19^{* *}$ & $7.07 * *$ & 6,184 & & & \\
\hline 2. Interactions & .34 & $.15^{* *}$ & $6.4^{* *}$ & 14,176 & & & \\
\hline
\end{tabular}

Control Variables

Length of Stay in U.S.

Final Model

1st Language

English Proficiency

Asian

Caucasian

Latino

$\begin{array}{clc}0.41 & 0.15 & 0.2^{* *} \\ -1.67 & 1.45 & -0.08 \\ 0.63 & 0.15 & 0.34^{* *} \\ -0.7 & 1.35 & -0.06 \\ -2.2 & 1.47 & -0.15 \\ -2.24 & 1.7 & -0.12\end{array}$

Main Effect

Attachment Anxiety

Attachment Avoidance

Heritage Culture Identification

Acculturation to U.S.

Interactions

Attachment Anxiety $\times$ Heritage Culture

$\begin{array}{lll}-0.2 & 0.34 & -0.21\end{array}$

$\begin{array}{lll}0.68 & 0.36 & 0.71\end{array}$

$\begin{array}{lll}0.07 & 0.07 & 0.28\end{array}$

Identification

Attachment Anxiety $\times$ Acculturation to U.S.

Attachment Avoidance $\times$ Heritage Culture Identification

$\begin{array}{lll}0.11 & 0.07 & 0.39\end{array}$

Attachment Avoidance $\times$ Acculturation to U.S. culture

$\begin{array}{ccc}0.001 & 0.003 & 0.15 \\ -0.002 & 0.003 & -0.24 \\ -0.004 & 0.003 & -0.46 \\ -0.004 & 0.003 & -0.49\end{array}$

Note. ${ }^{*} p<.05,{ }^{* *} p<.01$ 
Table 8

Hierarchical Regression Analysis of Sociocultural Adaptation

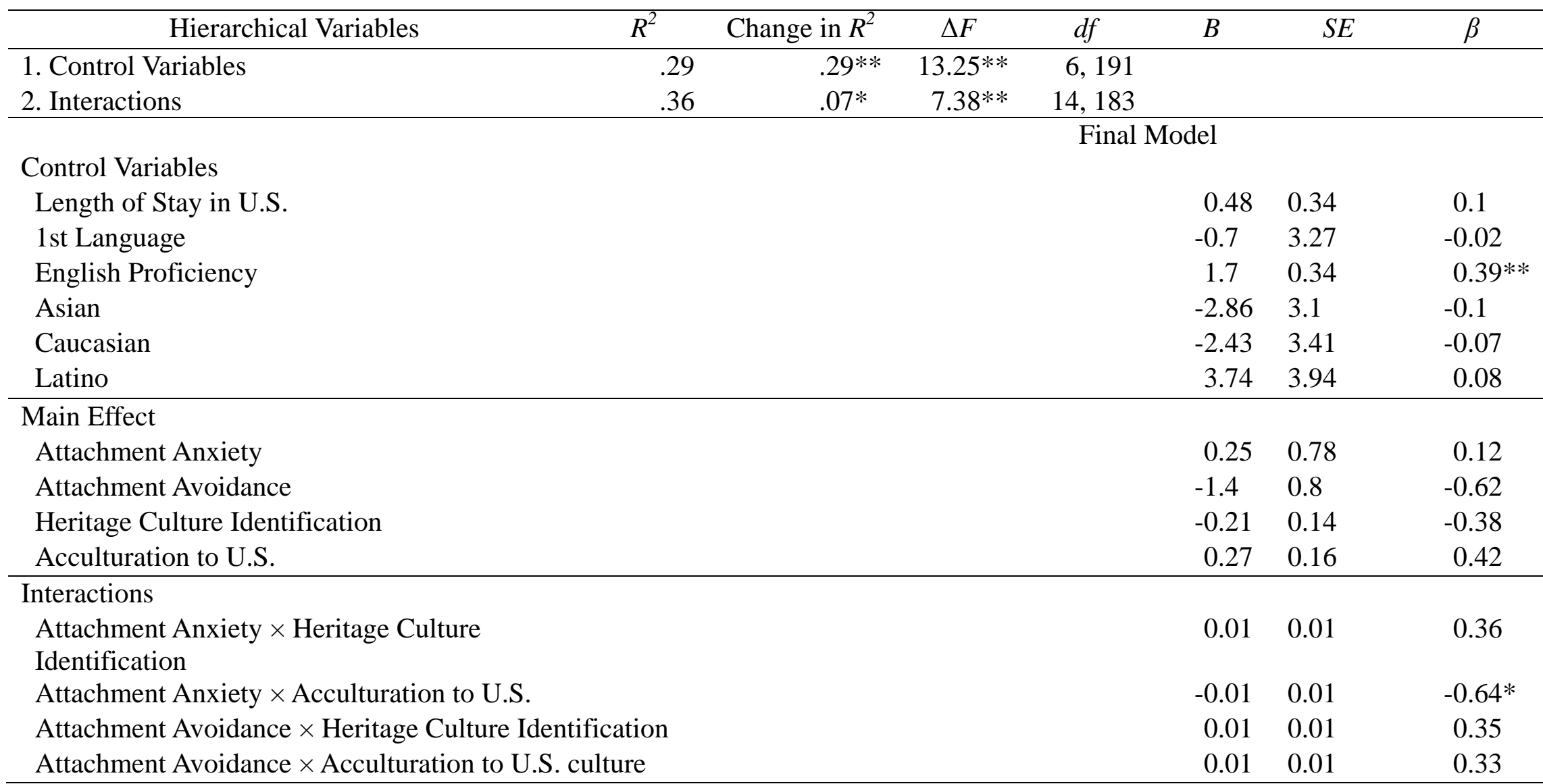

Note. ${ }^{*} p<.05, * * p<.01$ 
Table 9

Moderation Analysis of Psychological Distress

\begin{tabular}{|c|c|c|c|c|c|c|c|}
\hline Hierarchical Variables & $R^{2}$ & Change in $R^{2}$ & $\Delta F$ & $d f$ & $B$ & $S E$ & $\beta$ \\
\hline 1. Control Variables & .03 & .03 & 0.88 & 6,184 & & & \\
\hline 2. Interactions & .21 & $.18 * *$ & $2.27 * *$ & 20,170 & & & \\
\hline
\end{tabular}

Control Variables

Length of Stay in U.S.

Final Model

1st Language

English Proficiency

Asian

Caucasian

Latino

Main Effect

Attachment Anxiety

Attachment Avoidance

Antilocution

Avoidance

Behavioral Discrimination

Physical Assault

Interactions

Attachment Anxiety $\times$ Antilocution

Attachment Anxiety $\times$ Avoidance

Attachment Anxiety $\times$ Behavioral Discrimination

Attachment Anxiety $\times$ Physical Assault

Attachment Avoidance $\times$ Antilocution

$\begin{array}{rrr}-0.28 & 0.31 & -0.07 \\ 2.84 & 3.18 & 0.07 \\ -0.07 & 0.31 & -0.02 \\ -2.24 & 2.95 & -0.1 \\ 1.42 & 3.26 & 0.05 \\ 2.78 & 3.64 & 0.08\end{array}$

$\begin{array}{lll}0.09 & 0.49 & 0.05\end{array}$

$\begin{array}{lll}0.05 & 0.53 \quad 0.03\end{array}$

$\begin{array}{lll}-18.93 & 21.46 & -0.3\end{array}$

$\begin{array}{lll}20.10 & 70.89 & 0.23\end{array}$

$\begin{array}{lll}-6.28 & 9.98 & -0.27\end{array}$

$\begin{array}{lll}-0.05 & 12.31 & -0.002\end{array}$

$\begin{array}{rrr}0.70 & 1.51 & 0.2 \\ -0.14 & 2.21 & -0.03 \\ 0.31 & 0.52 & 0.34 \\ 0.54 & 0.58 & 0.49 \\ 0.35 & 0.88 & 0.1\end{array}$


Table 9 (Continued)

\begin{tabular}{|c|c|c|c|c|c|}
\hline Hierarchical Variables & Change in $R^{2}$ & $\Delta F$ & $B$ & $S E$ & $\beta$ \\
\hline Attachment Avoidance $\times$ Avoidance & & & -1.22 & 3.10 & -0.22 \\
\hline Attachment Avoidance $\times$ Behavioral Discrimination & & & 0.27 & 0.56 & 0.23 \\
\hline Attachment Avoidance $\times$ Physical Assault & & & 0.54 & 0.58 & 0.49 \\
\hline
\end{tabular}
Note. $* p<.05, * * p<.01$ 
Table 10

Moderation Analysis of Self-Esteem

\begin{tabular}{|c|c|c|c|c|c|c|c|}
\hline Hierarchical Variables & $R^{2}$ & Change in $R^{2}$ & $\Delta F$ & $d f$ & $B$ & $S E$ & $\beta$ \\
\hline 1. Control Variables & .19 & $.19 * *$ & $7.07 * *$ & 6,184 & & & \\
\hline 2. Interactions & .36 & $.17^{* *}$ & $4.67 * *$ & 20,170 & & & \\
\hline
\end{tabular}

Final Model

Control Variables

Length of Stay in U.S.

1st Language

English Proficiency

Asian

Caucasian

Latino

Main Effect

Attachment Anxiety

Attachment Avoidance

Antilocution

Avoidance

Behavioral Discrimination

Physical Assault

Interactions

Attachment Anxiety $\times$ Antilocution

Attachment Anxiety $\times$ Avoidance

Attachment Anxiety $\times$ Behavioral Discrimination

Attachment Anxiety $\times$ Physical Assault

Attachment Avoidance $\times$ Antilocution

\begin{tabular}{ccc}
0.35 & 0.15 & $0.07^{*}$ \\
-2.1 & 1.53 & -0.1 \\
0.58 & 0.15 & $0.31^{* *}$ \\
-1.25 & 1.42 & -0.1 \\
3.12 & 1.57 & $-0.21^{*}$ \\
-3.27 & 1.75 & -0.17 \\
\hline & & \\
-0.3 & 0.24 & 0.51 \\
0.49 & 0.25 & 0.36 \\
11.89 & 10.35 & 0.36 \\
14.42 & 34.18 & 0.31 \\
8.1 & 4.81 & 0.66 \\
6.16 & 5.94 & 0.43 \\
\hline & & \\
-0.1 & 0.73 & -0.05 \\
-0.64 & 1.07 & -0.21 \\
0.06 & 0.25 & 0.11 \\
0.02 & 0.28 & 0.04 \\
-0.43 & 0.42 & -0.22
\end{tabular}


Table 10 (Continued)

\begin{tabular}{|c|c|c|c|c|c|c|c|}
\hline Hierarchical Variables & $R^{2}$ & Change in $R^{2}$ & $\Delta F$ & $d f$ & $B$ & SE & $\beta$ \\
\hline Attachment Avoidance $\times$ Avoidance & & & & & -0.38 & 1.49 & -0.13 \\
\hline Attachment Avoidance $\times$ Behavioral Discrimination & & & & & -0.67 & 0.27 & $-1.06 * *$ \\
\hline Attachment Avoidance $\times$ Physical Assault & & & & & -0.58 & 0.3 & $-0.83 *$ \\
\hline
\end{tabular}




\section{Chapter Four: Discussion}

The current study examined how adult attachment contributes to, or influences, international students' adaptation in the United States. Based on the literature reviewed in Chapter 2, I proposed four hypotheses regarding the role of adult attachment in international students' acculturation process. The result provided partial support for three of the four hypotheses.

The results suggest that the two dimensions of adult attachment were not significant predictors of international students' acculturation (i.e., their identification with heritage culture and acculturation to the U.S. culture). However, attachment anxiety was a significant predictor of both the positive indicator (i.e., self-esteem) and negative indicator (i.e., psychological distress) of international students’ psychological adaptation. Attachment avoidance was also a significant predictor of psychological distress among international students. The results of the current study did not indicate a significant predictive relationship between the two dimensions of adult attachment and international students' acculturative stress and sociocultural adaptation. In terms of attachment moderating the relationship between acculturation and psychological adaptation, attachment avoidance significantly moderated the effect of acculturation to the United States on international students' psychological distress. Attachment anxiety was also found to be a marginally significant moderator (i.e., $p=.053$ ) for acculturation to the U.S. culture on international students' sociocultural adaptation. Furthermore, attachment avoidance marginally significantly moderated (i.e., $p=.05$ ) the effect of international students’ experience with physical assault on their self-esteem, and significantly 
moderated the effect of international students' experience with behavioral discrimination on their self-esteem.

The results of the current study also indicate the importance to consider the impact of the control variables on international students' adaptation outcomes. Among the models that were statistically significant, the range of $R^{2}$ for the control variables varied between .19 to .29 . This result suggests that the control variables predicted $19 \%$ to $29 \%$ of the variance of international students' adaptation outcomes. The $R^{2}$ change for the independent variables in the current study, on the other hand, varied between .03 to .19, which means that the independent variables explained between $3 \%$ to $19 \%$ of the variance of international students' adaptation outcomes. The control variables explained higher percent of the variance of the dependent variable comparing to the independent variables. The control variables included in the current study were length of stay in the U.S., English as the first language, English proficiency, and ethnicity (i.e., Caucasian, Asian, and Latino). These variables appeared to play significant roles in international students' acculturation process. Consistent with the existing literature, international students may report different adaptation outcomes due to the influence of these variables. Although the findings were more meager, the current study indicates that adult attachment can also have a significant impact on students' adaptation outcomes in addition to the variables that have been established as important factors in previous studies.

These findings contribute to the literature by examining the role that adult attachment plays in international students' acculturation process. Only a handful of previous studies have explored the link between adult attachment, international students' 
acculturation orientations, and their acculturation outcomes. My study contributes to the development of a better understating of how adult attachment affects acculturation process and adaptation outcomes among international students in the United States. Also, this study is the first one that has investigated how adult attachment influences the effect of perceived discrimination on the psychological adaptation among international students. In addition, I discussed the limitation of the studies over the past two decades using different categorical models of adult attachment even though the field has moved towards a two-dimension model. My study is also the first study to my knowledge that used the two-dimension model of adult attachment after Wang and Mallinckrodt’s (2006a) pioneer study. Finally, this study expands the line of research by using a sample of international students from a diverse background. All of the previous research used the sample from a specific immigrant or international student group (e.g., Chinese international students in United States, Brazilian immigrants in the United Kingdom). The current study included a diverse group of international students in the United States that increased the external validity of the findings and enabled the findings to be applied to a broader sample of international student population.

In the following section, I will discuss the findings of the current study compared to the previous findings of research studies. Secondly, I will highlight implications of the findings that can be applied to the practice of counseling psychology and other personnel working with international students. Thirdly, I will conclude this chapter with a discussion of the strengths and limitations of the present study, and directions for future research. 


\section{Adult Attachment, Acculturation, and Adaptation Outcomes}

The findings of the current study did not suggest a direct predictive relationship between the two dimensions of adult attachment and international students' acculturation (i.e., their identification with heritage culture and acculturation to the U.S. culture). Wang and Mallinckrodt's (2006a) study is the only existing study which found a negative association between attachment anxiety and Chinese international students' acculturation to the U.S. culture. My results contradicted Wang and Mallinckrodt's finding. However, adult attachment was found as a significant predictor for both self-esteem and psychological distress of international students. Specifically, attachment anxiety was a significant independent predictor of psychological distress and self-esteem, while attachment avoidance was a significant independent predictor of psychological distress. International students with higher attachment anxiety experienced higher levels of psychological distress and had lower self-esteem, and those with a higher level of attachment avoidance also experienced higher levels of psychological distress. The results of this study indicated that the two dimensions of adult attachment collectively significantly predicted international students' acculturative stress, but each of the dimensions was not a significant independent predictor of acculturative stress. Overall, international students with high level of attachment anxiety and avoidance were at a higher risk of experiencing psychological distress, low self-esteem, and acculturative stress. These students were more vulnerable to the stress associated with the acculturation process and more likely to report negative psychological adaptation outcomes. This finding is consistent with the results of previous studies that examined the relationship between adult attachment and psychological adaptation (Brisset et al., 
2010; Polek et al., 2010; Sochos \& Diniz, 2011; Wang \& Mallinckrodt, 2006a). The link between adult attachment and sociocultural adaptation varied in previous studies (Brisset et al., 2010; Polek et al., 2010; Sochos \& Diniz, 2011; Wang \& Mallinckrodt, 2006a). These studies used very different conceptualizations and measurement of sociocultural adaptation. Wang and Mallinckrodt found that higher attachment anxiety and attachment avoidance predicted more sociocultural adjustment problems, while Polek et al., (2010) revealed both a positive association between sociocultural adjustment and secure attachment and a negative association between fearful attachment and sociocultural adjustment. Brisset et al. (2010) also claimed that higher levels of co-national identification were associated with higher levels of sociocultural adaptation. Sochos and Diniz (2011), on the other hand, suggested that secure and dismissing attachment styles significantly moderated the effect of sociocultural adaptation difficulties on psychological distress. Given the inconsistency of the adult attachment and sociocultural adaptation measures utilized among these studies, it is difficult to provide a systematic comparison of the previous findings. Even though the current study is most consistent with the conceptualization and measures used in Wang and Mallinckrodt's study, my findings did not support any predictive relationship between adult attachment and sociocultural adaptation.

I also examined the moderation effect of adult attachment on the acculturation process of international students. The two dimensions of adult attachment were also included as moderators in the models of the final analysis. The findings of the few studies that investigated adult attachment as a moderator were contradictory. Some of them provided evidence for the moderating effect of adult attachment on the relationship 
between acculturation and psychological adaptation (e.g., Brisset et al., 2010; Sochos \& Diniz, 2011), others did not support the moderating effect (Polek et al., 2010; Wang \& Mallinckrodt, 2006a). The current study was consistent with studies that supported the moderating effect of adult attachment. Attachment avoidance was a significant moderator of the relationship between acculturation to the United States and international students' psychological distress. When the level of attachment avoidance was lower, international students with higher levels of acculturation to the United States reported lower levels of psychological distress. However, as the level of attachment avoidance increased, this relationship changed to a positive association between acculturation to the United States and psychological distress. In other words, international students with higher levels of attachment avoidance reported higher levels of psychological distress even if they were highly acculturated to the U.S. culture. The turning point (i.e., 16.5; ECR-S Attachment Avoidance Subscale Score) is close to the average score of the sample (17.04; see Table 2). Therefore, international students whose attachment avoidance scores were higher than the average of the current sample were more likely to experience higher levels of psychological distress compared to those whose avoidance level scores were lower than average. According to Fraley and Phillips (2009), attachment avoidance is a factor that is accountable for regulation of attachment behavior associated to attachment-related goals, and individual differences in attachment avoidance determines whether one is willing or unwilling to rely on others as a secure base. Individuals with high attachment avoidance tend to refrain from becoming vulnerable or decline the importance of close relationships. Therefore, international students with high level of acculturation to the U.S. culture may experience a low level of 
psychological distress if they are comfortable with relying on others and establishing close relationships, but those who tend to dismiss the importance of social support and are reluctant to become vulnerable to others are likely to report symptoms of depression. Their discomfort in developing close relationships may lead to limited social support, thus increase the risk of experiencing depressive symptoms.

I also found that attachment anxiety was a marginally significant moderator for the relationship between acculturation to the U.S. culture and international students' sociocultural adaptation. This finding is unique since there is no previous study that has found a similar result. Among international students with lower levels of attachment anxiety, the effect of acculturation to U.S. culture on their sociocultural adaptation was positive (i.e., being highly acculturated to U.S. culture was associated with higher levels of sociocultural adaptation), meanwhile, among international students with high levels of attachment anxiety, the effects of acculturation to the U.S. culture was negative (i.e., being highly acculturated to U.S. culture was associated with lower levels of sociocultural adaptation). Attachment anxiety, as a component in the attachment system, is responsible in monitoring and evaluating experiences for their relevance to attachment related goals, and leads to individual difference in the threshold for identifying threats to security (Fraley \& Phillips, 2009). People who have low thresholds for identifying cues of rejection (i.e., invidious with high attachment anxiety) tend to worry about loveworthiness and rejection from others. Therefore, international students who have a high level of attachment anxiety are more likely to be concerned about their ability of maintaining close relationships compared to those who are less worried with their loveworthiness, and they may experience more difficulty in cultural learning and social skills 
acquisition even if their levels of acculturation to the U.S. culture is high. However, it is important to note that the turning point score was 27 (ECR-S Attachment Anxiety Subscale score) which was much higher than the mean score of the sample (22.21). The standard deviation was 6.12 for this score. Thus, the turning point is close to one standard deviation higher than the mean score of the sample for this study. Therefore, the relationship between acculturation to the U.S. culture and sociocultural adaption was negative if international students' attachment anxiety levels were extremely high. These students were likely to frequently worry about their love-worthiness in relationships and feel insecure about abandonment or rejection. The high level of attachment anxiety may have an antagonistic effect on the relationship between acculturation to the U.S. culture and international students' sociocultural adaptation. With those who reported such a high level of attachment anxiety, even if their identification with the U.S. culture was high, they may still struggle with the social skill acquisition and cultural learning process in the United States.

Besides Wang and Mallinckrodt's study, the current study is the first one to examine the moderating effect of the two dimensions of adult attachment on the relationship between acculturation and adaptation outcomes among international students. Using a larger sample comparing to the previous study, attachment avoidance and attachment anxiety were found as significant moderators respectively in the relationship between acculturation to the U.S. culture and international students' psychological and sociocultural adaptation. This result suggests that adult attachment plays an important role by moderating the link between acculturation to the U.S. culture and international students' adaptation outcomes. 


\section{Adult Attachment, Discrimination, and Psychological Adaptation}

My fourth hypothesis focuses on an exploratory research question: if adult attachment moderates the effect of experience with perceived discrimination on international students’ psychological adaptation. No existing study has examined the relationship between perceived discrimination and adult attachment. The result of the current study indicated that attachment avoidance was a significant moderator between international students' experience with physical assault and their self-esteem. In addition, attachment avoidance also significantly moderated the relationship between international students' experience with behavioral discrimination and their self-esteem. Interestingly, international students with lower levels of attachment avoidance tend to maintain higher self-esteem even if they have experienced physical assault (e.g., physical threats) or behavioral discrimination (e.g., threatened unfairly by people who work in public services). However, when they experience higher levels of attachment avoidance, they tend to have lower self-esteem if they have encountered physical assault or behavioral discrimination.

The direct link between discrimination and self-esteem has not been found consistently in previous studies. Some studies suggest experiencing discrimination negatively impacts self-esteem among immigrant youth (e.g., Diaz, Ayala, Bein, Henne, \& Marin, 2001; Greene, Way, \& Pahl, 2006; Verkuyten, 1998), but others found no relationship between perceived discrimination and self-esteem among African American adults (e.g., Branscombe, Schmitt, \& Harvey, 1999). According to Panchanadeswaran and Dawson (2010), the fact that different individuals do not react the same way to negative experiences such as perceived discrimination may have contributed to the 
contradictory previous findings because they are related to the effects of social environmental, social structural, and personal variables. Furthermore, they argued that whether the individuals as the target of discrimination develop attributions to discrimination and consider the perpetrator as important increase the influence that discriminatory experiences have on self-esteem (Eccleston \& Major, 2006; Major, Quinton, \& Schmader, 2003).

International students' self-esteem may not be negatively affected by perceived discrimination due to their unique experience as sojourners because they do not necessarily plan to stay in the United States after they finish their period of study. In addition, the findings of current study suggested that the impact of perceived discrimination on self-esteem may depend on international students' level of attachment avoidance. Specifically, international students may develop higher self-esteem if they are willing to rely on another individual as a safe haven and secure base, even if they have experienced behavioral discrimination or physical assault. They are likely to seek support when needed and are comfortable to become vulnerable to others, so that they may be able to cope with the experience of physical and behavioral threats effectively and develop resilience towards those negative experiences, which may lead to increased self-esteem. Another significant finding of the current study is the turning point scores for the relationship between both behavioral discrimination and physical assault and international students' self-esteem. The turning point of attachment avoidance for the relationship between physical assault and self-esteem was a score of 10.62, which was more than one standard deviation lower than the average of this study sample ( $M=17.04$, $S D=6.01)$. On the other hand, the turning point score of attachment avoidance for the 
relationship between behavioral discrimination and self-esteem was 12.09 , which is only 1.06 points higher than the score (11.03) that is one standard deviation lower than the average of the sample. International students with this level of attachment avoidance were the minority of the sample population because only $32 \%$ of the participants reported levels of attachment avoidance that were more than one standard deviation lower than the average score. This result suggests that only a limited number of international students were able to maintain their self-esteem if they had experienced behavioral discrimination or physical assault. These international students were likely to be highly resilient, who were very comfortable with being vulnerable, and willing to rely on others as a safe haven. However, those with average levels of attachment avoidance may still suffer from low self-esteem if they experience behavioral discrimination or physical assault. Moreover, $53.7 \%$ of the participants in the current study reported experiences with behavioral discrimination, which is much higher than those who experienced verbal discrimination, avoidance, and physical assault. This result also suggested the prevalence of international students' experience with behavioral discrimination and the difficulty for them to buffer the impact of behavioral discrimination on their self-esteem.

Researchers have also studied coping strategies as protective factors against discrimination for Asian Americans and international student population. For example, high level of suppressive coping was found to be related with a positive association between perceived discrimination and depression symptoms, while students with low self-esteem and who engage in reactive coping were found the most vulnerable to depressive symptoms in the face of discrimination (Wei et al., 2008). Therefore, low self-esteem may also moderate the effect of perceived discrimination on international 
students' depressive symptoms. The relationship between adult attachment and coping strategies need to be examined to develop a better understanding about how international students’ self-esteem is impacted by perceived discrimination.

The findings of the current study provided support for the moderating effect of adult attachment on the relationship between perceived discrimination and international students’ self-esteem. International students with higher levels of attachment avoidance appeared to be at higher risk of developing low self-esteem when they experience

perceived discrimination. However, the relationship is complex and may be influenced by other factors besides adult attachment such as coping strategies and social context. Therefore, it is important for future researchers to examine these factors in order to provide a more comprehensive picture of the relationship between perceived discrimination and international students' adaptation outcomes.

\section{The Effect of Control Variables}

The final analysis of the current study suggested that the control variables accounted for a significant amount of the variance some models. For example, the control variables significantly predicted intentional students' self-esteem in the regression model on adult attachment and international students’ self-esteem. Among the control variables, length of stay in the United States and English proficiency were significant independent predictors of international students' self-esteem. In a few models, the independent variables were not significant predictors for the outcome variables, but the control variables significantly predicted the outcome variables.

It is important to notice that findings of the current study indicated that the control variables played significant roles in international students' adaptation outcomes. The 
control variables I used in the current study included length of stay in the United States, English as the first language, English proficiency, and ethnicity (i.e., Asian, Caucasian, and Latino). Consistent with the existing literature (e.g., Wang and Mallinckrodt, 2006a), these variables appeared to have significantly impacted the acculturation process and adaptation outcomes of international students. Especially length of stay and English proficiency seemed to be factors that influence international students' experience and their acculturative stress level, psychological well-being, and sociocultural adaptation. Future research on the factors that contribute to international students' acculturation process and adaptation outcomes need to include these variables as control variable, and additional studies focusing on how these variables influence international students’ adaptation outcomes may also be beneficial.

\section{Implications of the Findings}

The findings of the current study indicate the importance of considering attachment theory when working with international students. Utilizing what we learned through this study, a wide range of university personnel (e.g., mental health professionals, international student office staff, professors) can promote the well-beings of international students and provide support for their acculturation process. Mental health professionals often work with international students in both clinical and academic settings. First, those who work at university counseling centers have an increased chance to provide psychotherapy to clients who are international students because the number of the international students studying in the United States continues to grow steadily every year (Institute of International Education, 2014). Many mental health professionals are 
engaged in outreach activities on campus that target international students or are in liaison with international student offices.

International students may experience various challenges in the process of adapting to the new environment and meeting academic requirements (Johnson \& Sandhu, 2007). The attachment behavioral system is considered to be most relevant in times of stress (e.g., facing a threat to security), and internal working models are developed through early attachment experience that influence individuals’ thoughts, emotions, and behaviors in interpersonal relationships (Bowlby, 1969/1982, 1988; Cobb \& Davila, 2009). The acculturation process for international students may contribute to acculturative stress and activate their attachment behavioral system. The current study suggested that the two dimensions of adult attachment are predictors of international students’ psychological adaptation, and also moderators of the relationships of acculturation to the U.S. culture and perceived discrimination with international students' psychological distress, self-esteem, and sociocultural adaptation.

Many researchers have explored the clinical utility of attachment theory, and various theoretical orientations have integrated attachment theory into the theoretical models (e.g., Emotionally Focused Therapy, Interpersonal Process Therapy). Cobb and Davila (2009) asserted that therapists may benefit from adopting attachment theory concepts as a new perspective on the goals of chance and mechanisms in psychotherapy. Bowlby (1988) suggested five therapeutic tasks with the specific goal of increasing attachment security, and the first task is to offer a secure base for the client through exploring past and present attachment experiences. Therapists can also utilize an attachment approach to assess, conceptualize, and develop interventions in adult 
psychotherapy (Mallinckrodt, Daly, \& Wang, 2009). For example, therapists can assess a client's attachment style through both observation or administer a brief attachment assessment (e.g., ECR-S), and develop interventions based on the client's level of attachment anxiety and attachment avoidance. Monitoring the therapeutic distance continually, therapists need to notice the optimal distance in the therapeutic relationship that would provide a corrective emotional experience for the client, and make active effort to manage the therapeutic relationship (Daly \& Mallinckrodt, 2008; Mallinckrodt, Daly, \& Wang, 2009). Therapists working with international students with high attachment avoidance may reduce their depressive symptoms and improve their selfesteem by integrating an attachment approach. Through the corrective emotional experience in psychotherapy, international students with high attachment anxiety or attachment avoidance may be able to develop adaptive coping strategies and apply these strategies in managing the threats and stress they experience in the acculturation process.

Attachment theory can be integrated with a variety of clinical approaches, such as Cognitive-Behavioral Therapy, Psychoanalysis, and Interpersonal Therapy (Eagle \& Wolitzky, 2009; Florsheim \& McArthur, 2009; McBride \& Atkinson, 2009). Marmarosh, Markin, and Spiegel (2013) discussed the application of attachment to group practice, and suggested that group therapy can help working through traumatic relationships for members who come to the group with elevated attachment anxiety and avoidance. The increasing research studies on the clinical utility of attachment theory showed the potential of improving international students’ psychological and sociocultural adaptation through both individual and group psychotherapy integrating an attachment approach. 
Mental health professionals who are engaged in outreach activities can reach out to international students by providing information about the resources on campus and explaining the benefits of psychotherapy. Furthermore, prevention work can be conducted by helping international students understand the acculturation process, the impact of their attachment on their psychological well-being, and where they can seek help when they experience depressive symptoms or struggle with low self-esteem. A liaison relationship with the international student office on campus may lead to a better outcome of outreach activities and enable counseling psychologists and other mental health professionals to reach out to more international students who need help. Many international students are unfamiliar with the resources available at university or college counseling centers or are uncomfortable with the idea of receiving psychotherapy. Therefore, they may not seek help or are resistant about participating in psychotherapy even when they are struggling with depression, low self-esteem, and sociocultural adaptation difficulties. Outreach activities towards international students can make a significant difference in terms of informing international students about the services of university counseling centers and reduce the stigma towards psychotherapy. Previous research also revealed an association between high attachment avoidance and less intent to seek help, which was mediated by higher anticipated risks, less positive attitudes toward seeking help, and lower anticipated benefits (Shaffer, Vogel, \& Wei, 2006). Thus, international students with a high level of attachment avoidance are less likely to seek help even though they tend to experience more depressive symptoms, acculturative stress, and low self-esteem comparing to those with low attachment avoidance. Reaching out to 
these students and connecting them to adequate resources may significantly decrease the risk for them to suffer from negative psychological adaptation outcomes.

Furthermore, the results of this study suggested that mental health professionals can address the role of perceived discrimination and international students' self-esteem through the lens of adult attachment. Individuals may differ in their reactions to experience with perceived discrimination depends on their level of attachment avoidance. Those with high levels of attachment avoidance are more likely to struggle with low selfesteem if they have experienced physical threats or behavioral discrimination. Mental health professionals working with international students may benefit from integrating attachment theory into their conceptualization of the clients' reaction to perceived discrimination and using different intervention with international students related to their level of attachment anxiety and avoidance. With a commitment to social justice, mental health professionals can also serve as advocates to reduce discrimination against international students at a systemic/institutional level, therefore reduce the acculturative stress and psychological problems that students may have experienced. Providing psychoeducation on the acculturation process, the impact of adult attachment and experience of discrimination in this process, and individuals' adaptation outcomes may aid international students to obtain a better understanding about their reactions to their experience and reduce the shame associated with "failing” in the United States.

For professors and instructors, they may notice changes of mental health status among the international students they teach or mentor. Taking time to reach out to a student and provide a safe environment for the students to share their struggles or process their acculturation experience can promote students’ psychological well-beings. 
Insecurely attached international students may experience more difficulty connecting with their advisors, professors, instructors, and teaching assistants. They tend to be more vulnerable to psychological distress, low self-esteem, and sociocultural adaptation difficulties. Professors and instructors who observe an interpersonal relationship pattern that indicate high levels of attachment anxiety or avoidance (e.g., discomfort in developing close relationships or excessive anxiety of abandonment) may need to be more sensitive towards the students' needs and changes in mental health. If they recognize any significant need for professional help among international students, they can also make a referral to the university counseling center for the student, or provide information about benefit of counseling and services available at university counseling center. This approach can be applied by other professors, lecturers, or staffs working on campus with international students. The findings of the current study can also be helpful for personnel working in international student offices. They may recognize the benefit of psychotherapy and will be more likely to refer international students to university counseling center if they understand the impact of adult attachment in international students' adaptation outcomes. International students are more likely to consult or seek help from international student office personnel such as international student advisors when they experience difficulties in academic areas or personal life in the United States. Therefore, international student office personnel can support students who need help by discussing the relationship between acculturation, adult attachment (i.e., interpersonal style), and adaptation outcomes. Developing a supportive environment that meet international students' needs and provide comprehensive information regarding visa status and academic requirement may enable more students with high level of attachment 
avoidance to seek help and reduce their acculturative stress. International student office personnel can also refer students to resources such as university or college counseling centers if they recognize the importance for the students to receive help.

Finally, the findings of my study also indicated that higher educational institutions can support international students' acculturation process at a systematic level. For international students with low attachment security (i.e., high attachment anxiety and avoidance), they may experience more difficulties in the process of acculturation, adapting to the new academic environment, and develop a social support system in the U.S. They tend to suffer from depressive symptoms, low self-esteem, and sociocultural adaptation difficulties. Moreover, they are more likely to be impacted by perceived discrimination negatively and are less resilient when they are treated unfairly or being assaulted due to their international student status. Creating an inclusive campus climate may empower international students to develop supportive relationships, adapting to the new environment, and reduce microaggressions and discrimination that students may experience on campus. Administrative personnel at higher educational institutions should increase the resources available for international students on campus and connect them to these resources as the number of international students continues to increase in the United States. These efforts can lead to positive psychological and sociocultural adaptation outcomes among international students studying in higher educational institutions.

The current study also revealed the complexity of international students' acculturation process. University personnel who work with international students need to understand that each international student may vary in their acculturation orientation, 
experience with perceived discrimination, language fluency, and other personal factors (e.g., adult attachment) that impact one's adaptation. The current study focused on the role of adult attachment as one personal factor in international students' acculturation process. Other factors such as coping strategies can also influence and interact with the wide range of aspects that contribute to international students' adaptation outcomes. Therefore, it may also be helpful for university personnel to develop an understanding of each student's unique needs instead assuming their acculturation trajectories, and provide support according to the needs. This approach may also increase attachment security among international students.

\section{Limitations and Future Directions}

The current study is one of the few studies that examined the role of adult attachment in international students' acculturation process using a two dimensional model. Despite the significant findings, several limitations should be acknowledged. First at all, four control variables were included in the final analysis but there may be other external factors that contribute to the adaptation outcomes which were not controlled in the current study. Moreover, all the measures used in the current study were self-report which may have inflated correlations and common response bias due to halo rating effects (Wilcox, 2011). These two factors may have impacted the internal validity of the current study.

Second, I did not find any significant relationships between adult attachment and acculturation orientation. This result may be due to measurement issues. The Cronbach's alpha for the current sample was .67 for the Anxiety subscale of the adult attachment measure (i.e., ECR-S), which fell under the marginal threshold for acceptable 
reliability. This limitation with the reliability of the adult attachment measurement with the current sample may have impacted the findings of the current study. Even though both the adult attachment and acculturation measures have solid evidence of reliability and validity based on prior samples of international students, I found high correlations between the two dimensions of both measures: ECR-S $(r=.37, p<.01)$ and AI $(r=.15, p$ $=.03$ ). As a result, the two attachment dimensions (i.e., attachment anxiety and attachment avoidance) cannot be considered as two orthogonal dimensions in the current study. Some researchers argued that the cross-cultural normativity of attachment security is not supported by previous research studies using the categorical model, and higher rates of preoccupied attachment were found in East Asian cultures comparing to the Western samples (Schmitt, 2008; Schmitt et al., 2004). The current study included a large number of international students who self-identified as Asian (138; 60.3\%), and participants from two East Asian countries China and South Korea comprised 31\% of the final sample. Though recent cross-cultural studies provided a near universal validity for the two-factor structures of adult attachment, it is still arguable if the constructs of the two adult attachment dimensions will carry the same meaning in all the cultures that the participants of this study come from (Fraley \& Phillips, 2009; Wang \& Mallinckrodt, 2006a). In addition, researchers have also debated about the extent to which self-reports of adult attachment are associated to the same constructs that interview-based measures of attachment assessed (e.g., AAI; Fraley \& Phillips, 2009). Therefore, further research of the cross-cultural validity of the two-dimensional model of adult attachment and development of refined measures integrating both self-report and interview may provide a more accurate picture of the influence of adult attachment. This limitation also applies 
to the two dimension model of acculturation. Berry’s model (Berry, 1980, 1997) of acculturation included two dimensions of acculturation: identification to heritage culture and acculturation to host culture. I used AI (Ward \& Kennedy, 1994) which assesses the two fundamental dimensions of acculturation using 21 cognitive and behavioral items by asking respondents to consider how similar their experiences and behaviors to member of their heritage culture and American culture. This instrument was selected because it had the highest number of international students or sojourners sampled in the previous studies when the current study was designed. However, this measure may be overly simplistic to evaluate where respondents are on the continuums of the two dimensions. Furthermore, a meta-analysis of bidimensional acculturation instruments suggested that the ranges of reliability and validity of the instruments across diverse samples vary significantly, and the variability in the estimates was related to gender, scale length, and ethnic composition of sample (Huynh, Howell, \& Benet-Martinez, 2009). Researchers conducting research on bidimensional acculturation should consider the characteristics of sample carefully to decide which instrument will yield the highest reliability and validity with the targeted population.

Another limitation of the current study is that I did not assess other factors associated with the experience of perceived discrimination and contribute to international students' psychological adaptation. This study focused on the moderation role of adult attachment in the relationship between perceived discrimination and psychological adaptation because of the lack of previous research and explorative nature of the hypothesis I proposed. However, the link between perceived discrimination and psychological adaptation may be more complicated and other factors such as coping 
strategies, host culture attitudes, and perceived minority status may be important to consider. The findings about the relationship between perceived discrimination and selfesteem have varied among past studies, and only a small number of them have included international students. Self-esteem may also be considered as a moderator on the relationship between perceived discrimination and depressive symptoms (Wei et al., 2008). Future research should include other factors besides adult attachment in order to develop a comprehensive understanding about the impact of perceived discrimination on international students’ psychological adaptation.

Fourth, the current study only used depressive symptoms as the negative indicator of psychological adaptation. Though depressive symptoms are among the most common concerns presented by international students who are requesting counseling at university counseling centers, other mental health issues (e.g., anxiety, physical symptoms) should be addressed or included in future studies (Nilsson et al., 2004).

Fifth, I intended to examine the influence of campus difference in the current study using hierarchical linear model because the attitudes toward immigrants and international students held by local people and the sociocultural-political atmosphere can be completely different across various geographic locations in the United States (Wang \& Mallinckrodt, 2006a). An international student living in an urban area in the west coast may have a completely different experience with the acculturation process comparing to those living in a small town in the South. Berry (1997) identified the host society’s attitudes as one of the several moderating factors that arise during the acculturation process. International students may have found local American people living in a racially and ethnically diverse region more open toward differences and present with more 
friendly attitudes when interacting with immigrants and international students.

Unfortunately, the number of international students from each institution in my study was too small to utilize hierarchical linear model effectively and examine the campus differences existing among international students' acculturation process. If the data collected in future studies include enough students from more than 10 institutions, researchers should address the factor of campus environment which may be another significant factor that contributes to international students’ psychological and sociocultural adaptation outcomes.

Future research with larger sample sizes may be more sensitive to the interaction effects evaluated. A sufficient sample size was achieved in the current study based on the power analysis for medium effect size when using hierarchical multiple regression analysis. However, considering the number of interaction variables included in the study, power can be increased to capture significant interaction effects by a larger sample size. Further investigation on the relationship between identification with heritage culture and international students' adaptation outcomes may help to develop a better overall picture of international students' acculturation process. Berry's model (1987) suggested that the two acculturation dimensions of identification with heritage culture and acculturation to the host culture are related to four acculturation strategies that are associated with adaptation outcomes. Though the current study did not indicate significant relationships between identification of heritage culture and adaptation outcomes, it is hard to consider this dimension as completely irrelevant with international students' adaptation outcomes. It might also be helpful to address other external factors in the acculturation process such as cultural distance or include other moderators (e.g., coping strategies) to examine how 
these factors interact with attachment variables in impacting international students' adaptation. 


\section{Appendix A}

\section{Recruitment Letter}

Dear fellow students,

Thank you so much for taking time out of your busy schedule to read this short letter. This is an invitation to you, from a fellow international student, to participate in a research study.

I am looking for international students to participate in a study about their experiences with acculturation in the U.S. With your help, we may gain a much better understanding of what it is like for you to adapt to the U.S. culture and what factors influence this experience, given how little research has been conducted in this area.

If you will please grant me 30-45 minutes of your time to fill out an online questionnaire, I would greatly appreciate it! Below is the hyperlink to enter the study:

To participate, you must be a current international student on an F-1, student visa or a J-1, temporary educational exchange visitor visa, be enrolled in a higher education institution in the United States, and be age 18 years or older. Following the link above will give you more information about participating. Rest assured, though, that your responses will be confidential, and that you may withdraw at any time with no penalties.

At the end of the study, you will have the opportunity to enter into a draw to win one iPad Mini if you choose to participate in the raffle. The odds of winning are 1 in approximately 250 . 
This study has received IRB approval from the Office of Research Integrity at University of Kentucky. If you have any questions about this study, please feel free to contact me at miao.li@uky.edu, or my advisor, Dr. Xin Ma, at xin.ma@uky.edu. I am incredibly grateful for your time and candid responses.

Thank you very much for taking time to take part in my research.

I wish you all the best with your studies.

Warm regards,

Miao Li 


\section{Appendix B}

\section{Survey Cover Letter}

To fellow students:

You are being invited to take part in this research study because you are an international student at a higher education institution in the United States. The purpose of this study is to understand how international students' relationships influence their acculturation process, and their short-term and long-term acculturation outcomes.

To participate, you must be a current international student on an F-1, student visa or a J-1, temporary educational exchange visitor visa, be enrolled in a higher education institution in the United States, and be age 18 years or older.

Although you will not get personal benefit from taking part in this research study, your willingness to take part, may, in the future, assist in the process of providing international students at higher education institutions in the United States with beneficial services.

We hope to receive completed questionnaires from about 250 people, so your answers are important to us. Of course, you have a choice about whether or not to complete the survey/questionnaire, but if you do participate, you are free to skip any questions or discontinue at any time.

The survey will take about 30-45 minutes to complete.

At the end of the study, you can choose to be placed into a raffle that may give you the opportunity to win one iPad Mini. The odds of winning are 1 in approximately 250.

To the best of our knowledge there are no known risks to participating in this study.

No names will appear or be used on research documents, or be used in presentations or publications. The research team will not know that any information you provided came from you, nor even whether you participated in the study.

Please be aware, while we make every effort to safeguard your data once received from the online survey/data gathering company, given the nature of online surveys, as with anything involving the Internet, we can never guarantee the confidentiality of the data while still on the survey/data gathering company's servers, or while en route to either them or us. It is also possible the raw data collected for research purposes may be used for marketing or reporting purposes by the survey/data gathering company after the research is concluded, depending on the company's Terms of Service and Privacy policies. 
If you have questions about the study, please feel free to ask; my contact information is given below. If you have complaints, suggestions, or questions about your rights as a research volunteer, contact the staff in the University of Kentucky Office of Research Integrity at 859-257-9428 or toll-free at 1-866-400-9428.

Thank you in advance for your assistance with this important project.

Sincerely,

Miao Li, M.A., Ed.S.

Doctoral Candidate

Department of Educational, School, and Counseling Psychology

University of Kentucky

E-MAIL: miao.li@uky.edu 


\section{Appendix C}

\section{Demographic Questions}

Q1 How old are you? (years)

Q2 What is your gender?

$\square$ Female

$\square$ Male

$\square$ Other

Q3 With which group do you identify?

O Arab/Middle East

O Asian/Pacific Islander

O African/Black

O Caucasian/White

O Hispanic/Latino

O Multiracial

Other

Q4 What is your country of origin?

Q5 What is your religious/spiritual affiliation?

Q6 What is your visa/residency/immigration status?

F1 Visa

O J1 Visa

Other (please specify)

Q7 How long have you lived in the United States? (In Years)

Q8 What type of program are you currently enrolled in?

O Undergraduate

O Masters

O Doctoral

O ESL

Visiting Scholar 
Q9 Which year are you in your program?

1st year

2nd year

3rd year

4th year

5th year

6th year

7th year

$\bigcirc$ More (please specify)

Q10 What is your major/field of study

Q11 What is the name of the institution you are studying at currently?

Q12 What is your first or native language?

Q13 What is your second language?

Q14 Please list any other languages you use:

Q15 Have you been educated in the U.S. previously?

Y Yes

O No

Q16 Do you have ANY relatives in the United States?

O Yes

No

Q17 Please indicate your highest education level.

O High School Diploma

○ Bachelor's degree

O Master's degree

Doctoral degree 
Q18 How good do you think your overall English language ability is?

O Poor

O Fair

O Good

O Excellent/Native-like

Q19 Please rate your ability in English on the following aspects according to the scale provided.

\begin{tabular}{|c|c|c|c|c|}
\hline & Poor & Fair & Good & $\begin{array}{c}\text { Excellent/Native- } \\
\text { like }\end{array}$ \\
\hline $\begin{array}{c}\text { Reading } \\
\text { Proficiency }\end{array}$ & 0 & 0 & 0 & 0 \\
\hline $\begin{array}{c}\text { Writing } \\
\text { Proficiency }\end{array}$ & 0 & 0 & 0 & 0 \\
\hline $\begin{array}{l}\text { Speaking } \\
\text { Fluency }\end{array}$ & 0 & 0 & 0 & 0 \\
\hline $\begin{array}{c}\text { Listening } \\
\text { Ability }\end{array}$ & 0 & 0 & O & 0 \\
\hline
\end{tabular}

Q20 What is your Grade Point Average (GPA)? If you are not sure, please provide the estimate or your most recent GPA. 
Q21 What is your relationship status?

O Single

Dating

In a committed relationship

O Married/Partnered

In a domestic relationship

O Civil Union/Reciprocal Beneficiary

O Widowed

Divorced

Separated

Other(please specify)

Q22 Please Indicate your relationship status by selecting one choice below that best describes your status:

Never had a romantic relationship.

O Have had a romantic relationship, but currently not in one.

Recently started my 1st romantic relationship (within 6 months).

O In a committed romantic relationship (at least 6 months) or married/partnered.

- Q23 Why did you decide to come to the U.S.? Please choose all the options that apply to you.

O Academic Fit

To learn English

O Quality of Education

Financial Resources

O Interest in U.S. culture

Political Issues

Career Advancement

Other (please specify)

- Q24 How many more years do you plan/intend to stay in the U.S.? (If you are not sure, give your best estimate at this point)

- Q25 Do you plan to stay in the U.S. after completing your degree?

O Yes

No 


\section{Appendix D}

\section{Experiences in Close Relationship Scale-Short Form (ECR-S; Wei, Russell, Mallinckrodt, \& Vogel, 2007)}

The following statements concern how you feel in romantic relationships. We are interested in how you generally experience relationships, not just in what is happening in a current relationship. Respond to each statement by indicating how much you agree or disagree with it. If you never had a romantic relationship, please respond to the items based on what you think you would do or feel with your romantic partner.

ECR1 It helps to turn to my romantic partner in times of need.

Strongly disagree

O Disagree

Slightly disagree

O Neutral

Slightly agree

O Agree

Strongly agree

ECR2 I need a lot of reassurance that I am loved by my partner.

O Strongly disagree

O Disagree

O Slightly disagree

O Neutral

O Slightly Agree

Agree

O Strongly agree

ECR3 I want to get close to my partner, but I keep pulling back.

O Strongly disagree

O Disagree

Slightly disagree

O Neutral

O Slightly Agree

O Agree

Strongly agree 
ECR4 I find that my partner(s) don't want to get as close as I would like.

Strongly disagree

Disagree

Slightly disagree

O Neutral

Slightly Agree

O Agree

Strongly agree

ECR5 I turn to my partner for many things, including comfort and reassurance.

Strongly disagree

Disagree

Slightly disagree

O Neutral

Slightly Agree

O Agree

Strongly agree

ECR6 My desire to be very close sometimes scares people away. Strongly disagree

O Disagree

Slightly disagree

O Neutral

Slightly Agree

O Agree

Strongly agree

ECR7 I try to avoid getting too close to my partner.

O Strongly disagree

Disagree

Slightly disagree

O Neutral

O Slightly Agree

O Agree

Strongly agree 
ECR8 I DO NOT often worry about being abandoned.

Strongly disagree

Disagree

Slightly disagree

O Neutral

Slightly Agree

O Agree

Strongly agree

ECR9 I usually discuss my problems and concerns with my partner.

Strongly disagree

O Disagree

Slightly disagree

O Neutral

Slightly Agree

O Agree

Strongly agree

ECR10 I get frustrated if romantic partners are not available when I need them.

O Strongly disagree

Disagree

Slightly disagree

O Neutral

O Slightly Agree

O Agree

Strongly agree

ECR11 I am nervous when partners get too close to me.

O Strongly disagree

Disagree

O Slightly disagree

O Neutral

O Slightly Agree

O Agree

O Strongly agree 
ECR12 I worry that romantic partners won't care about me as much as I care about them. Strongly disagree

Disagree

Slightly disagree

O Neutral

Slightly Agree

O Agree

Strongly agree 


\section{Appendix E}

\section{Acculturation Index (AI; Ward \& Kennedy, 1994)}

This section is concerned with how you see yourself in relation to American culture. You are asked to consider two questions about your current life style. Are your experiences and behaviors similar to members of your culture of origin? Are your experiences and behaviors similar to members of American culture? Use the following scale to indicate how similar your various experiences of daily life are compared to members of your culture of origin and American culture.

\begin{tabular}{|c|c|c|c|c|c|c|c|c|c|c|c|c|c|c|}
\hline & \multicolumn{7}{|c|}{ Culture of Origin } & \multicolumn{7}{|c|}{ American Culture } \\
\hline & $\begin{array}{c}\text { Not at } \\
\text { all } \\
\text { similar } \\
1\end{array}$ & 2 & 3 & 4 & 5 & 6 & $\begin{array}{c}\text { Very } \\
\text { similar } \\
7\end{array}$ & $\begin{array}{c}\text { Not at } \\
\text { all } \\
\text { similar } \\
1\end{array}$ & 2 & 3 & 4 & 5 & 6 & $\begin{array}{c}\text { Very } \\
\text { similar } \\
7\end{array}$ \\
\hline Clothing & $\mathrm{O}$ & $\mathrm{O}$ & $\mathrm{O}$ & $\mathrm{O}$ & 0 & $\mathrm{O}$ & $\mathrm{O}$ & $\mathrm{O}$ & $\mathrm{O}$ & $\mathrm{O}$ & 0 & $\mathrm{O}$ & 0 & $\mathrm{O}$ \\
\hline Pace of life & O & $\mathrm{O}$ & $\mathrm{O}$ & $\mathrm{O}$ & $\mathrm{O}$ & 0 & O & O & $\mathrm{O}$ & $\mathrm{O}$ & 0 & $\mathrm{O}$ & 0 & O \\
\hline General knowledge & O & $\mathrm{O}$ & $\mathrm{O}$ & 0 & 0 & O & O & O & $\mathrm{O}$ & 0 & 0 & $\mathrm{O}$ & 0 & O \\
\hline Food & $\mathrm{O}$ & $\mathrm{O}$ & 0 & 0 & 0 & $\mathrm{O}$ & $\mathrm{O}$ & 0 & $\mathrm{O}$ & $\mathrm{O}$ & 0 & 0 & 0 & $\mathrm{O}$ \\
\hline Religious beliefs & $\mathrm{O}$ & 0 & 0 & 0 & 0 & 0 & O & 0 & 0 & 0 & 0 & 0 & 0 & O \\
\hline $\begin{array}{l}\text { Material comfort } \\
\text { (standard of living) }\end{array}$ & O & 0 & $\mathrm{O}$ & 0 & 0 & $\mathrm{O}$ & O & O & 0 & 0 & 0 & $\mathrm{O}$ & 0 & O \\
\hline Recreational activities & O & $\mathrm{O}$ & O & $\mathrm{O}$ & 0 & 0 & O & O & $\mathrm{O}$ & 0 & 0 & $\mathrm{O}$ & 0 & O \\
\hline Self-identity & 0 & 0 & 0 & 0 & 0 & 0 & O & 0 & 0 & 0 & 0 & 0 & 0 & 0 \\
\hline Family life & O & $\mathrm{O}$ & O & $\mathrm{O}$ & 0 & O & O & O & $\mathrm{O}$ & $\mathrm{O}$ & 0 & $\mathrm{O}$ & 0 & $\mathrm{O}$ \\
\hline Accommodation/residence & O & 0 & $\mathrm{O}$ & 0 & 0 & 0 & O & O & 0 & $\mathrm{O}$ & 0 & 0 & 0 & O \\
\hline Values & $\mathrm{O}$ & $\mathrm{O}$ & $\mathrm{O}$ & $\mathrm{O}$ & $\mathrm{O}$ & $\mathrm{O}$ & $\mathrm{O}$ & $\mathrm{O}$ & $\mathrm{O}$ & $\mathrm{O}$ & 0 & 0 & 0 & $\mathrm{O}$ \\
\hline Friendships & O & $\mathrm{O}$ & $\mathrm{O}$ & 0 & 0 & 0 & O & O & 0 & $\mathrm{O}$ & 0 & $\mathrm{O}$ & 0 & O \\
\hline Communication styles & $\mathrm{O}$ & $\mathrm{O}$ & $\mathrm{O}$ & $\mathrm{O}$ & 0 & $\mathrm{O}$ & O & $\mathrm{O}$ & $\mathrm{O}$ & $\mathrm{O}$ & 0 & 0 & 0 & $\mathrm{O}$ \\
\hline Cultural activities & O & $\mathrm{O}$ & $\mathrm{O}$ & $\mathrm{O}$ & 0 & 0 & O & $\mathrm{O}$ & 0 & $\mathrm{O}$ & 0 & 0 & 0 & $\mathrm{O}$ \\
\hline Language & O & $\mathrm{O}$ & O & $\mathrm{O}$ & $\mathrm{O}$ & $\mathrm{O}$ & 0 & O & $\mathrm{O}$ & $\mathrm{O}$ & 0 & $\mathrm{O}$ & 0 & O \\
\hline $\begin{array}{l}\text { Perceptions of co- } \\
\text { nationals/compatriot }\end{array}$ & 0 & $\bigcirc$ & O & $\mathrm{O}$ & $\mathrm{O}$ & 0 & O & $\mathrm{O}$ & $\mathrm{O}$ & $\bigcirc$ & 0 & $\mathrm{O}$ & 0 & $\mathrm{O}$ \\
\hline $\begin{array}{l}\text { Perceptions of host } \\
\text { nationals }\end{array}$ & 0 & $\mathrm{O}$ & 0 & $\mathrm{O}$ & $\mathrm{O}$ & $\mathrm{O}$ & O & 0 & $\mathrm{O}$ & $\mathrm{O}$ & 0 & $\mathrm{O}$ & 0 & O \\
\hline Political ideology & O & $\mathrm{O}$ & O & 0 & 0 & 0 & 0 & O & $\mathrm{O}$ & 0 & 0 & 0 & 0 & 0 \\
\hline World view & O & $\mathrm{O}$ & O & $\mathrm{O}$ & 0 & O & O & O & $\mathrm{O}$ & 0 & 0 & $\mathrm{O}$ & 0 & O \\
\hline Social customs & $\mathrm{O}$ & 0 & 0 & 0 & 0 & 0 & $\mathrm{O}$ & $\mathrm{O}$ & 0 & $\mathrm{O}$ & 0 & 0 & 0 & $\mathrm{O}$ \\
\hline Employment activities & 0 & $\mathrm{O}$ & O & $\mathrm{O}$ & 0 & 0 & 0 & 0 & $\mathrm{O}$ & $\mathrm{O}$ & 0 & $\mathrm{O}$ & 0 & O \\
\hline
\end{tabular}




\section{Appendix F}

\section{Revised Sociocultural Adaptation Scale (Ward \& Kennedy, 1999)}

Living in a different culture often involves learning new skills and behaviors. Thinking about life in the United States, please rate your competence at each the following behaviors.

\begin{tabular}{|c|c|c|c|c|c|}
\hline & $\begin{array}{l}\text { Not at all } \\
\text { competent }\end{array}$ & $\begin{array}{l}\text { Slightly } \\
\text { competent }\end{array}$ & $\begin{array}{l}\text { Moderately } \\
\text { competent }\end{array}$ & $\begin{array}{c}\text { Very } \\
\text { competent }\end{array}$ & $\begin{array}{l}\text { Extremely } \\
\text { competent }\end{array}$ \\
\hline Making friends & $\mathrm{O}$ & $\mathrm{O}$ & $\mathrm{O}$ & O & O \\
\hline $\begin{array}{l}\text { Using the transport } \\
\text { system }\end{array}$ & $\mathrm{O}$ & $\mathrm{O}$ & $\mathrm{O}$ & $\mathrm{O}$ & $\mathrm{O}$ \\
\hline $\begin{array}{l}\text { Making yourself } \\
\text { understood }\end{array}$ & $\mathrm{O}$ & $\mathrm{O}$ & 0 & $\mathrm{O}$ & $\mathrm{O}$ \\
\hline $\begin{array}{l}\text { Getting used to the pace } \\
\text { of life }\end{array}$ & $\mathrm{O}$ & $\mathrm{O}$ & $\mathrm{O}$ & O & $\mathrm{O}$ \\
\hline Going shopping & $\mathrm{O}$ & $\mathrm{O}$ & $\mathrm{O}$ & $\mathrm{O}$ & $\mathrm{O}$ \\
\hline $\begin{array}{c}\text { Going to social } \\
\text { events/gatherings/functio } \\
\text { ns }\end{array}$ & $\mathrm{O}$ & O & $\mathrm{O}$ & O & $\mathrm{O}$ \\
\hline $\begin{array}{l}\text { Worshiping in your usual } \\
\text { way }\end{array}$ & $\mathrm{O}$ & O & 0 & O & O \\
\hline $\begin{array}{l}\text { Talking about yourself } \\
\text { with others }\end{array}$ & $\mathrm{O}$ & $\mathrm{O}$ & O & O & O \\
\hline $\begin{array}{l}\text { Understanding jokes and } \\
\text { humor }\end{array}$ & $\mathrm{O}$ & $\mathrm{O}$ & $\mathrm{O}$ & $\mathrm{O}$ & $\mathrm{O}$ \\
\hline $\begin{array}{l}\text { Dealing with someone } \\
\text { who is } \\
\text { unpleasant/cross/aggressi } \\
\text { ve }\end{array}$ & 0 & 0 & 0 & 0 & O \\
\hline $\begin{array}{l}\text { Getting used to the local } \\
\text { food/finding food you } \\
\text { enjoy }\end{array}$ & 0 & 0 & 0 & 0 & 0 \\
\hline $\begin{array}{l}\text { Following rules and } \\
\text { regulations }\end{array}$ & 0 & O & 0 & 0 & 0 \\
\hline $\begin{array}{l}\text { Dealing with people in } \\
\text { authority }\end{array}$ & $\mathrm{O}$ & O & 0 & O & O \\
\hline $\begin{array}{l}\text { Dealing with the } \\
\text { bureaucracy }\end{array}$ & 0 & O & O & O & O \\
\hline $\begin{array}{l}\text { Adapting to local } \\
\text { accommodation }\end{array}$ & $\mathrm{O}$ & O & O & O & $\mathrm{O}$ \\
\hline
\end{tabular}




\begin{tabular}{|c|c|c|c|c|c|}
\hline $\begin{array}{l}\text { Communicating with } \\
\text { people of a different } \\
\text { ethnic group }\end{array}$ & $\mathrm{O}$ & 0 & 0 & $\mathrm{O}$ & $\mathrm{O}$ \\
\hline $\begin{array}{l}\text { Relating to members of } \\
\text { the opposite sex }\end{array}$ & $\mathrm{O}$ & $\mathrm{O}$ & $\mathrm{O}$ & O & O \\
\hline $\begin{array}{l}\text { Dealing with } \\
\text { unsatisfactory service }\end{array}$ & $\mathrm{O}$ & $\mathrm{O}$ & $\mathrm{O}$ & O & O \\
\hline Finding your way around & $\mathrm{O}$ & $\mathrm{O}$ & $\mathrm{O}$ & $\mathrm{O}$ & $\mathrm{O}$ \\
\hline Dealing with the climate & $\mathrm{O}$ & $\mathrm{O}$ & $\mathrm{O}$ & $\mathrm{O}$ & $\mathrm{O}$ \\
\hline $\begin{array}{l}\text { Dealing with people } \\
\text { staring at you }\end{array}$ & $\mathrm{O}$ & O & O & O & O \\
\hline $\begin{array}{l}\text { Going to coffee shops/ } \\
\text { food } \\
\text { stalls/restaurants/fast } \\
\text { food outlets }\end{array}$ & $\mathrm{O}$ & O & O & O & O \\
\hline $\begin{array}{l}\text { Understanding the local } \\
\text { accent/language }\end{array}$ & $\mathrm{O}$ & $\mathrm{O}$ & $\mathrm{O}$ & O & O \\
\hline $\begin{array}{l}\text { Living away from family } \\
\text { members } \\
\text { overseas/independently } \\
\text { from your parents }\end{array}$ & $\mathrm{O}$ & 0 & O & O & O \\
\hline $\begin{array}{l}\text { Adapting to local } \\
\text { etiquette }\end{array}$ & $\mathrm{O}$ & 0 & O & O & O \\
\hline $\begin{array}{l}\text { Getting used to the } \\
\text { population density }\end{array}$ & $\mathrm{O}$ & O & 0 & $\mathrm{O}$ & 0 \\
\hline Relating to older people & $\mathrm{O}$ & $\mathrm{O}$ & $\mathrm{O}$ & $\mathrm{O}$ & O \\
\hline $\begin{array}{l}\text { Dealing with people of } \\
\text { higher status }\end{array}$ & $\mathrm{O}$ & $\mathrm{O}$ & $\mathrm{O}$ & $\mathrm{O}$ & $\mathrm{O}$ \\
\hline $\begin{array}{l}\text { Understanding what is } \\
\text { required of you at } \\
\text { university }\end{array}$ & $\mathrm{O}$ & O & O & O & O \\
\hline $\begin{array}{l}\text { Coping with academic } \\
\text { work }\end{array}$ & $\mathrm{O}$ & 0 & O & O & O \\
\hline $\begin{array}{l}\text { Dealing with foreign staff } \\
\text { at the university }\end{array}$ & $\mathrm{O}$ & $\mathrm{O}$ & $\mathrm{O}$ & O & $\mathrm{O}$ \\
\hline $\begin{array}{l}\text { Expressing your ideas in } \\
\text { class }\end{array}$ & $\mathrm{O}$ & 0 & 0 & O & $\mathrm{O}$ \\
\hline $\begin{array}{l}\text { Living with your host } \\
\text { family }\end{array}$ & $\mathrm{O}$ & O & O & O & O \\
\hline Accepting /understanding & 0 & 0 & 0 & 0 & $\mathrm{O}$ \\
\hline
\end{tabular}




\begin{tabular}{|c|c|c|c|c|c|}
\hline the local political system & & & & & \\
\hline $\begin{array}{l}\text { Understanding the locals' } \\
\text { world view }\end{array}$ & $\mathrm{O}$ & $\mathrm{O}$ & $\mathrm{O}$ & O & $\mathrm{O}$ \\
\hline $\begin{array}{l}\text { Taking a local } \\
\text { perspective on the culture }\end{array}$ & $\mathrm{O}$ & $\mathrm{O}$ & $\mathrm{O}$ & O & $\mathrm{O}$ \\
\hline $\begin{array}{l}\text { Understanding the local } \\
\text { value system }\end{array}$ & $\mathrm{O}$ & ○ & $\mathrm{O}$ & ○ & $\mathrm{O}$ \\
\hline $\begin{array}{l}\text { Seeing things from the } \\
\text { locals' point of view }\end{array}$ & $\mathrm{O}$ & $\mathrm{O}$ & $\mathrm{O}$ & O & $\mathrm{O}$ \\
\hline $\begin{array}{l}\text { Understanding cultural } \\
\text { differences }\end{array}$ & $\mathrm{O}$ & O & $\mathrm{O}$ & ○ & $\mathrm{O}$ \\
\hline $\begin{array}{l}\text { Being able to see two } \\
\text { sides of an intercultural } \\
\text { issue }\end{array}$ & O & $\mathrm{O}$ & $\mathrm{O}$ & $\mathrm{O}$ & $\mathrm{O}$ \\
\hline
\end{tabular}




\section{Appendix G}

Acculturative Stress Scale for International Students (ASSIS; Sandhu \& Asrabadi, 1994)

Please indicate your degree of agreement or disagreement to the following statements.

\begin{tabular}{|c|c|c|c|c|c|}
\hline & $\begin{array}{l}\text { Strongly } \\
\text { Disagree }\end{array}$ & Disagree & Undecided & Agree & $\begin{array}{c}\text { Strongly } \\
\text { Agree }\end{array}$ \\
\hline $\begin{array}{c}1 . \\
\text { Homesickness } \\
\text { bothers me. }\end{array}$ & $\mathrm{O}$ & $\mathrm{O}$ & $\mathrm{O}$ & $\mathrm{O}$ & $\mathrm{O}$ \\
\hline $\begin{array}{l}\text { 2. I feel } \\
\text { uncomfortable } \\
\text { to adjust to } \\
\text { new foods. }\end{array}$ & $\mathrm{O}$ & $\mathrm{O}$ & $\mathrm{O}$ & $\mathrm{O}$ & $\mathrm{O}$ \\
\hline $\begin{array}{l}\text { 3. I am treated } \\
\text { differently in } \\
\text { social } \\
\text { situations. }\end{array}$ & 0 & 0 & O & $\mathrm{O}$ & 0 \\
\hline $\begin{array}{l}\text { 4. Others are } \\
\text { sarcastic } \\
\text { toward my } \\
\text { cultural } \\
\text { values. }\end{array}$ & $\mathrm{O}$ & O & O & 0 & 0 \\
\hline $\begin{array}{c}\text { 5. I feel } \\
\text { nervous to } \\
\text { communicate } \\
\text { in English.* }\end{array}$ & $\mathrm{O}$ & $\mathrm{O}$ & $\mathrm{O}$ & $\mathrm{O}$ & 0 \\
\hline $\begin{array}{l}\text { 6. I feel sad } \\
\text { living in } \\
\text { unfamiliar } \\
\text { surroundings. }\end{array}$ & $\mathrm{O}$ & O & 0 & 0 & 0 \\
\hline $\begin{array}{l}\text { 7. I fear for my } \\
\text { personal } \\
\text { safety } \\
\text { because of my } \\
\text { different } \\
\text { cultural } \\
\text { background. }\end{array}$ & O & $\mathrm{O}$ & $\mathrm{O}$ & $\mathrm{O}$ & $\mathrm{O}$ \\
\hline $\begin{array}{c}\text { 8. I feel } \\
\text { intimidated to } \\
\text { participate in } \\
\text { social } \\
\text { activities. }\end{array}$ & 0 & O & 0 & 0 & 0 \\
\hline
\end{tabular}




\begin{tabular}{|c|c|c|c|c|c|}
\hline $\begin{array}{c}\text { 9. Others are } \\
\text { biased toward } \\
\text { me. }\end{array}$ & 0 & 0 & 0 & 0 & 0 \\
\hline $\begin{array}{l}\text { 10. I feel guilty } \\
\text { to leave my } \\
\text { family and } \\
\text { friends } \\
\text { behind. }\end{array}$ & O & 0 & 0 & 0 & 0 \\
\hline $\begin{array}{c}\text { 11. Many } \\
\text { opportunities } \\
\text { are denied to } \\
\text { me. }\end{array}$ & 0 & 0 & 0 & 0 & 0 \\
\hline $\begin{array}{l}\text { 12. I feel } \\
\text { angry that my } \\
\text { people are } \\
\text { considered } \\
\text { inferior here. }\end{array}$ & 0 & 0 & 0 & 0 & 0 \\
\hline $\begin{array}{l}\text { 13. Multiple } \\
\text { pressures are } \\
\text { placed upon } \\
\text { me after } \\
\text { migration. }\end{array}$ & 0 & 0 & 0 & 0 & 0 \\
\hline $\begin{array}{l}\text { 14. I feel that I } \\
\text { receive } \\
\text { unequal } \\
\text { treatment. }\end{array}$ & O & 0 & 0 & 0 & 0 \\
\hline $\begin{array}{l}\text { 15. People } \\
\text { show hatred } \\
\text { toward me } \\
\text { non-verbally. }\end{array}$ & 0 & 0 & 0 & 0 & 0 \\
\hline $\begin{array}{l}\text { 16. It hurts } \\
\text { when people } \\
\text { don't } \\
\text { understand } \\
\text { my cultural } \\
\text { values. }\end{array}$ & 0 & 0 & 0 & 0 & 0 \\
\hline $\begin{array}{c}\text { 17. I am } \\
\text { denied what I } \\
\text { deserve. }\end{array}$ & 0 & 0 & 0 & 0 & 0 \\
\hline $\begin{array}{c}18 . \text { I } \\
\text { frequently } \\
\text { relocate for } \\
\text { fear of others. }\end{array}$ & 0 & 0 & 0 & 0 & 0 \\
\hline
\end{tabular}




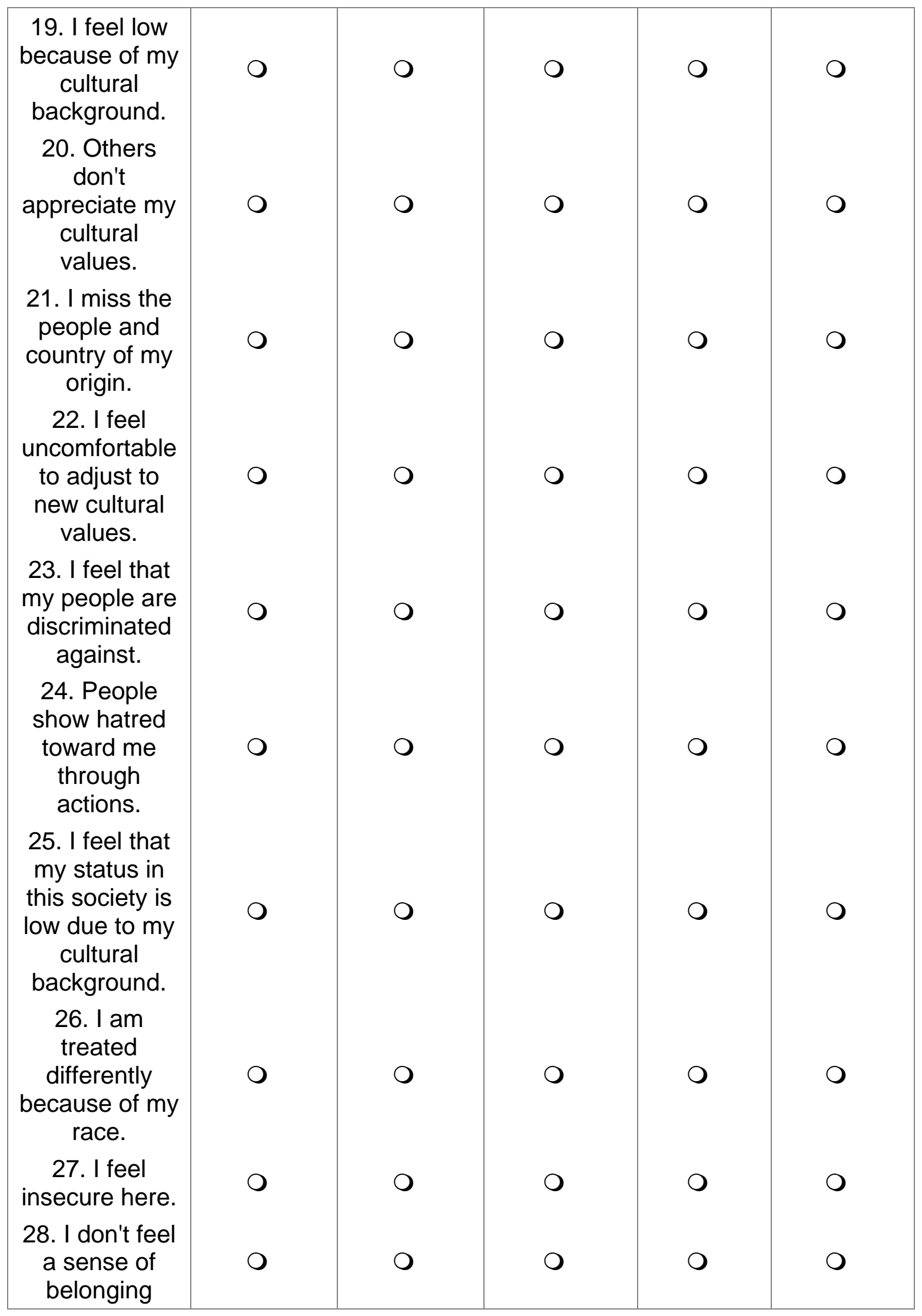




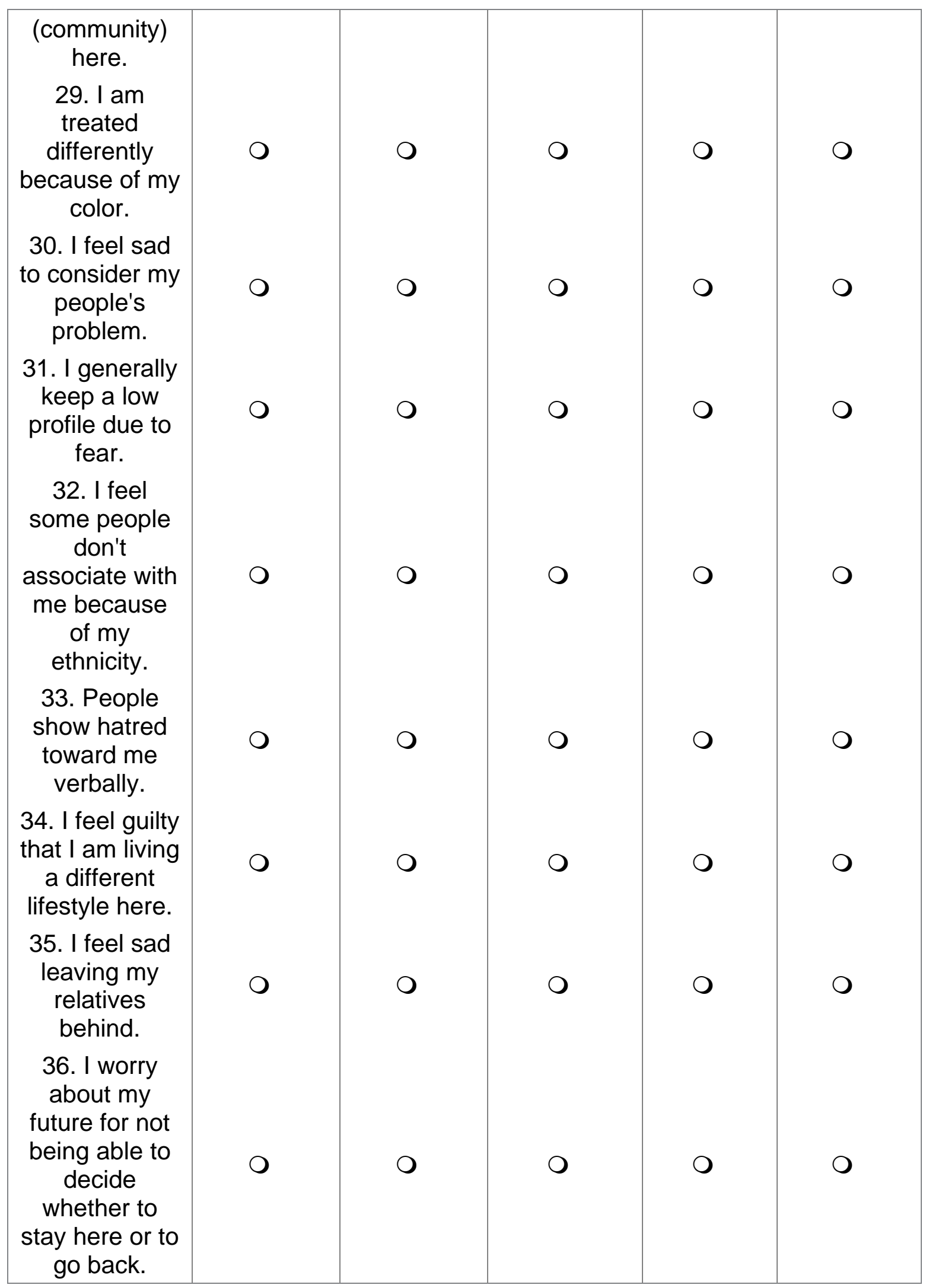




\section{Appendix H}

Center for Epidemiologic Studies Depression scale revised (CESD-R; Radloff, 1977)

Choose from the following options you most agree with.

CESD1 My appetite was poor.

Not at all or less than 1 day last week.

One or two days last week.

Three to four days last week.

Five to seven days last week.

Nearly everyday for two weeks.

CESD2 I could not shake off the blues.

Not at all or less than 1 day last week.

One or two days last week.

Three to four days last week.

Five to seven days last week.

Nearly everyday for two weeks.

CESD3 I had trouble keeping my mind on what I was doing.

Not at all or less than 1 day last week.

One or two days last week.

Three to four days last week.

Five to seven days last week.

O Nearly everyday for two weeks.

CESD4 I felt depressed.

Not at all or less than 1 day last week.

One or two days last week.

Three to four days last week.

Five to seven days last week.

O Nearly everyday for two weeks.

CESD5 My sleep was restless.

Not at all or less than 1 day last week.

One or two days last week.

Three to four days last week.

Five to seven days last week.

O Nearly everyday for two weeks. 
CESD6 I felt sad.

O Not at all or less than 1 day last week.

O One or two days last week.

O Three to four days last week.

O Five to seven days last week.

O Nearly everyday for two weeks.

CESD7 I could not get going.

O Not at all or less than 1 day last week.

O One or two days last week.

Three to four days last week.

O Five to seven days last week.

O Nearly everyday for two weeks.

CESD8 Nothing made me happy.

O Not at all or less than 1 day last week.

O One or two days last week.

O Three to four days last week.

O Five to seven days last week.

O Nearly everyday for two weeks.

CESD9 I felt like a bad person.

O Not at all or less than 1 day last week.

O One or two days last week.

O Three to four days last week.

O Five to seven days last week.

O Nearly everyday for two weeks.

CESD10 I lost interest in my usual activities.

O Not at all or less than 1 day last week.

O One or two days last week.

O Three to four days last week.

O Five to seven days last week.

O Nearly everyday for two weeks. 
CESD11 I slept much more than usual.

Not at all or less than 1 day last week.

One or two days last week.

Three to four days last week.

Five to seven days last week.

O Nearly everyday for two weeks.

CESD12 I felt like I was moving too slowly.

Not at all or less than 1 day last week.

One or two days last week.

Three to four days last week.

Five to seven days last week.

Nearly everyday for two weeks.

CESD13 I felt fidgety.

Not at all or less than 1 day last week.

One or two days last week.

O Three to four days last week.

Five to seven days last week.

O Nearly everyday for two weeks.

CESD14 I wished I were dead.

Not at all or less than 1 day last week.

One or two days last week.

Three to four days last week.

Five to seven days last week.

Nearly everyday for two weeks.

CESD15 I wanted to hurt myself.

Not at all or less than 1 day last week.

One or two days last week.

Three to four days last week.

Five to seven days last week.

Nearly everyday for two weeks. 
CESD16 I was tired all the time.

Not at all or less than 1 day last week.

One or two days last week.

Three to four days last week.

Five to seven days last week.

O Nearly everyday for two weeks.

CESD17 I did not like myself.

Not at all or less than 1 day last week.

One or two days last week.

Three to four days last week.

Five to seven days last week.

Nearly everyday for two weeks.

CESD18 I lost a lot of weight without trying to.

Not at all or less than 1 day last week.

One or two days last week.

Three to four days last week.

Five to seven days last week.

O Nearly everyday for two weeks.

CESD19 I had a lot of trouble getting to sleep.

Not at all or less than 1 day last week.

One or two days last week.

Three to four days last week.

Five to seven days last week.

Nearly everyday for two weeks.

CESD20 I could not focus on the important things.

Not at all or less than 1 day last week.

One or two days last week.

Three to four days last week.

Five to seven days last week.

Nearly everyday for two weeks. 


\section{Appendix I}

ROSENBERG SELF-ESTEEM SCALE (Rosenberg, 1965)

Below is a list of statements dealing with your general feelings about yourself. Please indicate how strongly you agree or disagree with each statement.

\begin{tabular}{|c|c|c|c|c|}
\hline & $\begin{array}{c}\text { Strongly } \\
\text { Agree }\end{array}$ & Agree & Disagree & $\begin{array}{l}\text { Strongly } \\
\text { Disagree }\end{array}$ \\
\hline $\begin{array}{c}\text { 1. On the } \\
\text { whole, I am } \\
\text { satisfied with } \\
\text { myself. }\end{array}$ & 0 & 0 & 0 & 0 \\
\hline $\begin{array}{l}\text { 2. At times I } \\
\text { think I am no } \\
\text { good at all. }\end{array}$ & 0 & 0 & 0 & 0 \\
\hline $\begin{array}{l}\text { 3. I feel that I } \\
\text { have a } \\
\text { number of } \\
\text { good qualities. }\end{array}$ & 0 & O & O & 0 \\
\hline $\begin{array}{l}\text { 4. I am able } \\
\text { to do things } \\
\text { as well as } \\
\text { most other } \\
\text { people. }\end{array}$ & 0 & 0 & 0 & 0 \\
\hline $\begin{array}{l}\text { 5. I feel I do } \\
\text { not have } \\
\text { much to be } \\
\text { proud of. }\end{array}$ & 0 & 0 & 0 & 0 \\
\hline $\begin{array}{l}\text { 6. I certainly } \\
\text { feel useless at } \\
\text { times. }\end{array}$ & 0 & 0 & 0 & 0 \\
\hline $\begin{array}{l}\text { 7. I feel that } \\
\text { I'm a person } \\
\text { of worth, at } \\
\text { least on an } \\
\text { equal plane } \\
\text { with others. }\end{array}$ & 0 & 0 & 0 & 0 \\
\hline $\begin{array}{l}\text { 8. I wish I } \\
\text { could have } \\
\text { more respect } \\
\text { for myself. }\end{array}$ & 0 & 0 & 0 & 0 \\
\hline $\begin{array}{l}\text { 9. All in all, I } \\
\text { am inclined to } \\
\text { feel that I am }\end{array}$ & O & O & 0 & 0 \\
\hline
\end{tabular}




\begin{tabular}{|c|c|c|c|c|}
\hline $\begin{array}{c}\text { a failure. } \\
\text { 10. I take a } \\
\text { positive } \\
\text { attitude } \\
\text { toward myself. }\end{array}$ & $\bigcirc$ & 0 & 0 & 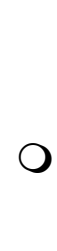 \\
\hline
\end{tabular}




\section{Appendix $\mathbf{J}$}

Items of the Experience of Discrimination Scale (EDS; Krahe, Abraham, Felber, \& Helbig, 2005)

ASS1 How often have you felt afraid in the U.S. because you are not American?

O Never

O Rarely

O Sometimes

$\bigcirc$ Frequently

Very Often

ASS2 How often have you been verbally threatened because you are not American?

O Never

O Rarely

O Sometimes

Frequently

Very Often

ASS3 How often have you been physically threatened because you are not American?

O Never

O Rarely

O Sometimes

O Frequently

Very Often

ASS4 How often have you been physically attacked because you are not American?

O Never

O Rarely

O Sometimes

O Frequently

Very Often

ASS5 Are there areas where you are living that you avoid because you are in fear of an attack?

O None

O Little

Some

O Frequently

Many 
DIS6 When looking for a place to live I have never had any problems that I think were caused by not being American.

Strongly Disagree

Disagree

Neither Agree nor Disagree

O Agree

O Strongly Agree

DIS7 At the university, how often have you felt that you were treated unfairly because you are not American?

O Never

O Rarely

O Sometimes

Frequently

Very Often

DIS8 I feel I have to achieve more than an American person in order to receive the same recognition because I am not American.

Strongly Disagree

O Disagree

Neither Agree nor Disagree

O Agree

Strongly Agree

DIS9 I do not feel that my mistakes are judged more harshly than the mistakes of American people.

Strongly Disagree

Disagree

Neither Agree nor Disagree

O Agree

Strongly Agree

DIS10 I do not think that the law favors American people over non-American people.

O Strongly Disagree

O Disagree

Neither Agree nor Disagree

O Agree

Strongly Agree 
DIS11 How often have you felt you were treated unfairly by people who work in public services because you are not American?

O Never

Rarely

O Sometimes

Frequently

Very often

AVO12 How often have you felt that people are less interested in you because you are not American?

O Never

Rarely

O Sometimes

Frequently

Very Often

AVO13 How often have you felt that you were treated with indifference (a lack of concern) because you are not American?

O Never

O Rarely

O Sometimes

Frequently

Very Often

AVO14 How often have you felt that American people kept you at distance because you are not American?

O Never

Rarely

O Sometimes

Frequently

Very Often

AVO15 How often have you felt that American people have avoided eye contact with you because you are not American?

O Never

O Rarely

O Sometimes

Frequently

Very Often 
AOV16 How often have you experienced American people keeping a physical distance from you because you are not American?

O Never

O Rarely

O Sometimes

O Frequently

O Very Often

AOV17 How often have you experienced people losing interest in you or turning away from you when they discovered that you are not American?

O Never

O Rarely

O Sometimes

O Frequently

O Very Often

AOV18 How often have you experienced someone not recognizing your work or performance or not giving you the credit you deserved because you are not American?

O Never

O Rarely

O Sometimes

O Frequently

O Very Often

ANT19 How often has someone made a discriminating or negative remark to you during your stay in the U.S.?

O Never

O Rarely

O Sometimes

O Frequently

O Very Often

ANT20 How often has someone made a discriminating or negative remark about nonAmerican people in your presence?

O Never

O Rarely

O Sometimes

O Frequently

O Very Often 
ANT21 How often has someone expressed prejudice against non-American people in your presence?

O Never

Rarely

O Sometimes

Frequently

Very Often

ANT22 How often has it happened to you that an American person expressed disapproval because you did not behave in the way American people would have expected you to (i.e. 'that is not how we do it in U.S.')?

O Never

Rarely

O Sometimes

Frequently

V Very Often 


\section{References}

Ainsworth, M. D. S. (1963). Infancy in Uganda: Infant care and the growth of attachment. Baltimore, MD: Johns Hopkins University Press.

Ainsworth, M. D. S. (1967). Infancy in Uganda: Infant care and the growth of love. Baltimore, MD: Johns Hopkins University Press.

Ainsworth, M. D. S., \& Bell, S. M. (1969). Some contemporary patterns in the feeding situation. In A. Ambrose (Ed.), Stimulation in early infancy (pp. 133- 170). London, UK: Academic Press.

Ainsworth, M. D. S., \& Bell, S. M. (1969). Some contemporary patterns in the feeding situation. In A. Ambrose (Ed.), Stimulation in early infancy (pp. 133- 170). London, UK: Academic Press.

Ainsworth, M. D. S., Blehar, M. C., Waters, E., \& Wall, S. (1978). Patterns of attachment: A psychological study of the Strange Situation. Hillsdale, NJ: Erlbaum.

Alonso-Arbiol, I., Balleurka, N., \& Shaver, P. R. (2007). A Spanish version of the Experiences in Close Relationships adult attachment questionnaire. Personal Relationships, 14, 45-63. doi: 10.1111/j.1475-6811.2006.00141.x

Arends-Tóth, J., \& van de Vijver, F. J. R. (2006). Assessment of psychological acculturation. In J. W. Berry, \& D. L. Sam, The Cambridge Handbook of Acculturation Psychology (pp. 142-162). Cambridge, UK: Cambridge University Press.

Atri, A., Sharma, M., \& Cottrell, R. (2006). Role of social support, hardiness, and acculturation as predictors of mental health among international students of Asian Indian origin. International Quarterly of Community Health Education, 27, 59-73. 
Bakker, W., van Oudenhoven, J. P., \& van der Zee, K. I. (2004). Attachment styles, personality and Dutch emigrants’ intercultural adjustment. European Journal of Personality, 18, 387-404. doi: 10.1002/per.515

Barratt, M. F., \& Huba, M. E. (1994). Factors related to international undergraduate student adjustment in an American community. College Student Journal, 28, 422436.

Bartholomew, K. (1990). Avoidance of intimacy: An attachment perspective. Journal of Social and Personal Relationships, 7, 147-178. doi: 10.1177/0265407590072001

Bartholomew, K., \& Horowitz, L. M. (1991). Attachment styles among young adults: A test of a four-category model. Journal of Personality and Social Psychology, 61, 226-244. doi:10.1037//0022-3514.61.2.226

Belsky, J., Steinberg, L., \& Draper, P. (1991). Childhood experience, interpersonal development, and reproductive strategy: An evolutionary theory of socialization. Child Development, 62, 647-670. doi: 10.2307/1131166

Berry, J. W. (1970). Marginality, stress, and ethnic identification in an acculturated Aboriginal community. Journal of Cross-Cultural Psychology, 1, 239-252. doi: $10.1177 / 135910457000100303$

Berry, J. W. (1974). Psychological aspects of cultural pluralism: Unity and identity reconsidered. Topics in Culture learning, 2, 17-22.

Berry, J. W. (1980). Acculturation as varieties of adaptation. In A. M. Padilla (Ed.), Acculturation: Theory, Models, and Some New Findings (pp. 9-25). Boulder, CO: Westview. 
Berry, J. W. (1997). Immigration, acculturation, and adaptation. Applied psychology: An International Review, 46, 5-68. doi: 10.1111/j.1464-0597.1997.tb01087.x

Berry, J. W. (1998). Acculturation and health: Theory and research. In S. Karazian \& D. Evans (Eds.), Cultural clinical psychology: Theory, research, and practice (pp. 3957). New York: Oxford University Press.

Berry, J. W. (2003). Conceptual approaches to acculturation. In K. M. Chun, P.B. Organista, \& G. Martin (Eds.), Acculturation: Advances in theory, measurement and applied research (pp. 17-37). Washington, DC: American Psychological Association.

Berry, J. W. (2006a). Contexts of acculturation. In J. W. Berry, \& D. L. Sam, The Cambridge Handbook of Acculturation Psychology (pp. 27-42). Cambridge, UK: Cambridge University Press.

Berry, J. W. (2006b). Stress perspectives on acculturation. In J. W. Berry, \& D. L. Sam, The Cambridge Handbook of Acculturation Psychology (pp. 43-57). Cambridge, UK: Cambridge University Press.

Berry, J. W., \& Kim, U. (1988). Acculturation and mental health. In P. R. Dasen, J. W. Berry, \& N, Sartorius (Eds.), Health and cross-cultural psychology (pp. 207-236). Newbury Park, CA: Sage.

Berry, J. W., Kim, U., Minde, T., \& Mok, D. (1987). Comparative studies of acculturative stress. International Migration Review, 21, 490-511. doi: 10.2307/2546607

Berry, J. W., Phinney, J. S., Sam, D. L., \& Vedder, P. (2006). Immigrant youth in cultural transition: Acculturation, identity and adaptation across national contexts. Mahwah, NJ: Lawrence Erlbaum Associates. 
Berry, J. W. \& Sam, D. (1997). Acculturation and adaptation. In J. W. Berry, M. H. Segall \& C. Kağitçibaşi (Eds.), Handbook of cross-cultural psychology, Vol. III: Social behavior and applications (pp. 291-326). Boston, MA: Allyn \& Bacon.

Bowlby, J. (1956). The growth of independence in the young child. Royal Society of Health Journal, 76, 587-591.

Bowlby, J. (1969/1982). Attachment and loss: Vol. I. Attachment. New York: Basic Books.

Bowlby, J. (1973). Attachment and loss: Vol. 2. Separation: Anxiety and anger. New York: Basic Books.

Bowlby, J. (1979). The making and breaking of affectional bonds. London, UK:

Tavistock.

Bowlby, J. (1988). A secure base: Parent-child attachment and healthy human development. New York: Basic Books.

Branscombe, N. R., Schmitt, M. T., \& Harvey, R. D. (1999). Perceiving pervasive discrimination among African-Americans: Implications for group identification and well-being. Journal of Personality and Social Psychology, 77, 135-149.

Brennan, K. A., Clark, C. L., \& Shaver, P. R. (1998). Self-report measurement of adult romantic attachment: An integrative overview. In J. A. Simpson \& W. S. Rholes (Eds.), Attachment theory and close relationships (pp. 46-76). New York: Guilford Press.

Bretherton, I., \& Munholland, K. A. (2008). Internal working modelsin attachment relationships: Elaborating a central construct in attachment theory. In J. Cassidy, 
P. R. Shaver (Eds.), Handbook of attachment: Theory, research, and clinical applications ( $2^{\text {nd }}$ ed., pp. 102-130). New York, NY: The Guilford Press.

Brisset, C., Safdar, S., Lewis, J. R. \& Sabatier, C. (2010). Psychological and sociocultural adaptation of university students in France: The case of Vietnamese international students. International Journal of Intercultural Relations, 34, 413-426. doi:

10.1016/j.ijintrel.2010.02.009

Cassidy, J. (2008). The nature of the child's tie. In J. Cassidy, P. R. Shaver (Eds.), Handbook of attachment: Theory, research, and clinical applications $\left(2^{\text {nd }}\right.$ ed., pp. 3-22). New York, NY: The Guilford Press.

Chataway, C. J., \& Berry, J. W. (1989). Acculturation experiences, appraisal, coping, and adaptation: A comparison of Hong Kong Chinese, French, and English students in Canada. Canadian Journal of behavioral Science/ Revue Candienne des Sciences du Comportement, 21, 295-309. doi: 10.1037/h0079820

Chavajay, P., \& Skowronek, J. (2008). Aspects of acculturation stress among international students attending a university in the USA. Psychological Reports, 103, 827-835. doi: 10.2466/PR0.103.7.827-835

Chen, H.-J., Mallinckrodt, B., \& Mobley, M. (2003). Attachment patterns of East Asian international students and sources of social support as moderators of the impact of U.S. racism and cultural distress. Asian Journal of Counseling, 9, 27-48.

Cobb, R. J., \& Davila, J. (2009). Internal working models and change. In J. H. Obegi \& E. Berant (Eds.), Attachment theory and research in clinical work (pp. 209-233). New York, NY: The Guilford Press.

Cohen, J. (1992). Quantitative methods in psychology: A power primer. Psychological 
Bulletin, 112, 155-159.

Collins, N. L., \& Read, S. J. (1990). Adult attachment, working models, and relationship quality in dating couples. Journal of Personality and Social Psychology, 58, 644-663. doi: 10.1037/0022-3514.58.4.644

Conradi, H., Gerlsma, C., van Duijn, M., \& de Jonge, P. (2006). Internal and external validity of the Experiences in Close Relationships questionnaire in an American and two Dutch samples. European Journal of Psychiatry, 20, 258269.

Constantine, M. G., Kindaichi, M., Okazaki, S., Gainor, K. A., \& Baden, A. L. (2005). A qualitative investigation of the cultural adjustment experiences of Asian international college women. Cultural Diversity and Ethnic Minority Psychology, 11, 162-175. doi: 10.1037/1099-9809.11.2.162

Constantine, M. G., Okazaki, S., \& Utsey, S. O. (2004). Self-concealment, social selfefficacy, acculturative stress, and depression in African, Asian, and Latin American international college students. American Journal of Orthopsychiatry, 74, 230-241. doi: 10.1037/0002-9432.74.3.230

Crowell, J. A., Fraley, R. C., Shaver, P. R. (2008). Measurement of individual differences in adolescent and adult attachment. In J. Cassidy, P. R. Shaver (Eds.), Handbook of attachment: Theory, research, and clinical applications $\left(2^{\text {nd }}\right.$ ed., pp. 599-634). New York, NY: The Guilford Press.

Csóka, S., Szabó, G., Sáfrány, E., Rochlitz, R., \& Bódizs, R. (2007). An attempt to measure adult attachment: The Hugarian version of the relationship scale questionnaire [Abstract]. Pszichológia: Az MTA Pszichológiai Intézéenek 
folyóirata, 27, 333-355.

Daly, K. D., \& Mallinckrodt, B. (2008). Experienced therapists’ approaches o psychotherapy for adults with attachment avoidance or attachment anxiety. Journal of Counseling Psychology, 56, 549-563. doi: 10.1037/a0016695

Diaz, R. M., Ayala, G., Bein, E., Henne, J., \& Marin, B. V. (2001). The impact of homophobia, poverty, and racism on the mental health of gay and bisexual Latino men; findings from 3 U.S. cities. American Journal of Public Health, 91, 927932.

Duru, E., \& Poyrazli, S. (2011). Perceived discrimination, social connectedness, and other predictors of adjustment difficulties among Turkish international students. International Journal of Psychology, 46, 446-454. doi: $10.1080 / 00207594.2011 .585158$

Eagle, M., \& Wolitzky, D. L. (2009). Adult psychotherapy from the perspectives of attachment theory and psychoanalysis. In J. H. Obegi \& E. Berant (Eds.), Attachment theory and research in clinical work (pp. 351-378). New York, NY: The Guilford Press.

Eccleston, C., \& Major, B. (2006). Attributions to discrimination and self-esteem: The role of group identification and appraisals. Group Processes \& Intergroup Relations, 9(2), 147-162. doi: 10.1177/1368430206062074

Feeney, J. A. (1995). Adult attachment and emotional control. Personal Relationships, 1, 333-348. doi: 10.1111/j.1475-6811.1995.tb00082.x

Florsheim, P., \& McArthur, L. (2009). An interpersonal approach to attachment and change. In J. H. Obegi \& E. Berant (Eds.), Attachment theory and research in 
clinical work (pp. 379-409). New York, NY: The Guilford Press.

Fraley, R. C., Brumbaugh, C. C., \& Marks, M. (2005). The evolution and function of adult attachment: A comparative and phylogenetic analysis. Journal of Personality and Social Psychology, 89,731-746. doi: 10.1037/0022-3514.89.5.751

Fraley, R. C., \& Phillips, R. L. (2009). Self-report measures of adult attachment in Clinical practice. In J. H. Obegi \& E. Berant (Eds.), Attachment theory and research in clinical work (pp. 153-180). New York, NY: The Guilford Press.

Fraley, R. C., \& Waller, N. G. (1998). Adult attachment patterns: A test of the typological model. In J. A. Simpson \& W. S. Rholes (Eds.), Attachment theory and close relationships (pp. 77-114). New York: Guilford Press.

Freud, S. (1957). Five lectures on psycho-analysis. In J. Strachey (Ed. \& Trans.), The standard edition of the complete psychological works of Sigmund Freud (Vol. 11, pp. 3-56). London: Hogarth Press. (Original work published 1910)

Furnham, A., \& Bochner, S. (1982). Social difficulty in a foreign culture: An empirical analysis of culture shock. In S. Bochner (Ed.), Cultures in contact: Studies in cross-cultural interaction (pp. 161-198). Oxford: Pergamon Press.

Graves, T. (1967). Acculturation, access and alcohol in a tri-ethnic community. American Anthropologist, 69, 306-321. doi: 10.1525/aa.1967.69.3-4.02a00030

Greene, M. L., Way, N., \& Pahl, K. (2006). Trajectories of perceived adult and peer discrimination among Black, Latino, and Asian American Adolescents: Patterns and psychological correlates. Developmental Psychology, 42, 218-238.

Hazen, C., \& Shaver, P. R. (1987). Conceptualizing romantic love as an attachment process. Journal of Personality and Social Psychology, 52, 511-524. 
doi:10.1037//0022-3514.52.6.1061

Huynh, Q.-L., Howell, R. T., \& Benet-Martinez, V. (2013). Reliability of bidimensional acculturation scores. Journal of Cross-cultural Psychogloy, 40, 256-274. doi: $10.1177 / 0022022108328919$

Huynh, Q-L., Howell, R. T., \& Benet-Martinez, Veronica. (2009). Reliability of bidimensional acculturation scores: A meta-analysis. Journal of Cross-Cultural Psychology, 40, 256-274. doi: 0.1177/0022022108328919

Institute of International Education. (2014). Open Doors Report on International Educational Exchange. Retrieved from http://www.iie.org/opendoors

Johnson, L. R., \& Sandhu, D. S. (2007). Isolation, adjustment, and acculturation issues of international students: Intervention strategies for counselors. In H. D. Singaravelu, \& M. Pope (Eds.), A handbook for counseling International students in the United States (pp. 13-35). Alexandria, VA: American Counseling Association.

Jung, E., Hecht, M. L., \& Wadsworth, B. C. (2007). The role of identity in international students' psychological well-being in the United States: A model of depression level, identity gaps, discrimination, and acculturation. International Journal of Intercultural Relations, 31, 605-624. doi:10.1016/j.ijintrel.2007.04.001

Kachigan, S. M. (1991). Multivariate statistical analysis: a conceptual introduction ( $2^{\text {nd }}$ ed.). New York, NY: Radius Press.

Klonoff, E. A., Landrine, H., \& Ullman, J. B. (1999). Racial discrimination and psychiatric symptoms among Black. Cultural Diversity \& Ethnic Minority 
Psychology, 5, 329-339. doi: 10.1037/1099-9809.5.4.329

Krahe, B., Abraham, C., Felber, J., \& Helbig, M. K. (2005). Perceived discrimination of international visitors to universities in Germany and the UK. British Journal of Psychology, 96, 263-281. doi: 10.1348/000712605X4829

LaFramboise, T., Coleman, H., \& Gerton, J. (1993). Psychological impact of biculturalism: Evidence and theory. Psychological Bulletin, 114, 395-412. doi: 10.1037//0033-2909.114.3.395

Lee, D.-L. (2003). A cluster analysis of procrastination and coping. Unpublished doctoral dissertation, University of Missouri, Columbia.

Lee, R. M. (2005). Resilience against discrimination: Ethnic identity and other-group orientation as protective factors for Korean Americans. Journal of Counseling Psychology, 52, 36-44. doi: 10.1037/0022-0167.52.1.36

Levy, M. B., \& Davis, K. E. (1988). Lovestyles and attachment styles compared: Their relations to each other and to various relationship characteristics. Journal of Social and Personal Relaitonships, 5, 439-471. doi:

$10.1177 / 0265407588054004$

Lin, S. (2010). Adult attachment patterns and their consequences in romantic relationships: A comparison between China and the United States. In Erdman, P., \& Ng, Kok-mun (Ed.), Attachment: expanding the cultural connections. (pp. 259-277). New York: Talor \& Grancis Group.

Lopez, F. G., Mauricio, A. M. Gormley, B., Simko, \& T., Berger, E. (2001). Adult attachment orientations and college student distress: The mediating role of problem coping styles. Journal of Counseling \& Development, 79, 459-464. 
doi: 10.1002/j.1556-6676.2001.tb01993.x

Lyons-Ruth, K., \& Jacobvitz, D. (2008) Attachment disorganization: Genetic factors, parenting contexts, and developmental transformation from infancy to adulthood. In J. Cassidy, P. R. Shaver (Eds.), Handbook of attachment: Theory, research, and clinical applications ( $2^{\text {nd }}$ ed., pp. 666-698). New York, NY: The Guilford Press.

Main, M., \& Solomon, J. (1986). Discovery of an insecure-disorganized/disoriented attachment pattern. In T. B. Brazelton \& M. W. Yogman (Eds.), Affective Development in Infancy (pp. 95-124). Norwood, NJ: Ablex.

Major, B., Quinton, W. J., \& Schmader, T. (2003). Attributions to discrimination and self-esteem: Impact of group identification and situational ambiguity. Journal of Experimental Social Psychology, 39, 220-231. doi:10.1016/S00221031(02)00547-4

Mallinckrodt, B., Daly, K., \& Wang, C. (2009). An attachment approach to adult psychotherapy. In J. H. Obegi \& E. Berant (Eds.), Attachment theory and research in clinical work (pp. 234-268). New York, NY: The Guilford Press.

Mallinckrodt, B., \& Wang, C. (2004). Quantitative methods for verifying semantic equivalence of translated research instruments: A Chinese version of the Experiences in Close Relationships scale. Journal of Counseling Psychology, 51, 368-379. doi: 10.1037/0022-0167.51.3.368

Mallinckrodt, B., \& Wei, M. (2005). Attachment, social competencies, social support, and psychological distress. Journal of Counseling Psychology, 52, 358-367. doi: 10.1037/0022-0167.52.3.358 
Marmarosh, C. L., Markin, R. D., and Spiegel, E. B. (2013). Attachment in group psychotherapy. Washington, DC: American Psychological Association.

McBride, C., \& Atkinson, L. (2009). Attachment theory and cognitive-behavioral therapy. In J. H. Obegi \& E. Berant (Eds.), Attachment theory and research in clinical work (pp. 434-458). New York, NY: The Guilford Press.

Mikulincer, M., \& Shaver, P. R. (2001). Attachment theory and intergroup bias: Evidence that priming the secure base schema attenuates negative reactions to out-groups. Journal of personality and Social Psychology, 81, 97-115. doi: 10.1037//0022-3514.81.1.97

Mikulincer, M., \& Shaver, P. R. (2007). Attachment in adulthood: Structure, dynamics, and change. New York: Guilford Press.

Mikulincer, M., \& Shaver, P. R. (2008). Adult attachment and affect regulation. In J. Cassidy, P. R. Shaver (Eds.), Handbook of attachment: Theory, research, and clinical applications ( $2^{\text {nd }}$ ed., pp. 503-531). New York, NY: The Guilford Press.

Mikulincer, M., Shaver, P. R., Sapir-Lavid, Y., \& Avihou-Kanza, N. (2009). What's inside the minds of securely and insecurely attached people? The secure-base script and its associations with attachment-style dimensions. Journal of personality and Social Psychology, 97, 615-633. doi: 10.1037/a0015649

Mori, S. (2000). Addressing the mental health concerns of international students. Journal of Counseling \& Development, 78, 137-145. doi: 10.1002/j.15566676.2000.tb02571.x

Nguyen, H. H. (2006). Acculturation in the United States. In J. W. Berry, \& D. L. Sam, The Cambridge Handbook of Acculturation Psychology (pp. 311-330). 
Cambridge, UK: Cambridge University Press.

Nilsson, J. E., Berkel, L. A., Flores, L. Y., \& Lucas, M. S. (2004).Utilization rate and presenting concerns of international students at a university counseling center: Implications for outreach programming. Journal of College Student Psychotherapy, 19, 49-59

Panchanadeswaran, S., \& Dawson, B. A. (2010). How discrimination and stress affect self-esteem among Dominican immigrant women: An exploratory study. Social Work in Public Health, 26, 60-77. doi: 10.1080/10911350903341069

Polek, E. (2007). Attachment in cultural context: Differences in attachment between Easter and Western Europeans (Doctoral dissertation, University of Groningen, Netherlands). Retrieved from http://dissertations.ub.rug.nl/faculties/gmw/2008/e.polek/

Polek, E., van Oudenhoven, J. P., \& ten Berge, J. (2008). Attachment styles and demographic factors as predictors of sociocultural and psychological adjustment of Eastern European immigrants in the Netherlands. International Journal of Psychology, 43, 919-928.

Polek, E., Wöhrle, J., \& van Oudenhoven, J. P. (2010). The role of attachment styles, perceived discrimination, and culture distance in adjustment of German and Eastern European immigrants in the Netherlands. Cross-cultural Research, 44, 60-88. doi: 10.1177/1069397109352779

Radloff, L. S. (1977). The CES-D scale: a self-report depression scale for research in the general population. Applied Psychological Measurement,1, 385-401.

Rahman, O., \& Rollock, D. (2004). Acculturation, competence, and mental health 
among South Asian students in the United States. Journal of Multicultural Counseling \& Development, 32, 130-142.

Redfield, R., Linton, R., \& Herskovits, M. J. (1936). Memorandum on the study of acculturation. American Anthropologist, 38, 149-152. doi:

10.1525/aa.1936.38.1.02a00330

Rosenberg, M. (1965). Society and adolescent self-image. Princeton, NJ: Princeton University Press.

Ryder, A. G., Alden, L. E., \& Paulhus, D. L. (2000). Is acculturation unidimensional or bidimendional? A head-to-head comparison in the prediction of personality, self-identity, and adjustment. Journal of Personality and Social Psychology, 79, 49-65. doi: 10.1037//0022-3514.1.49

Safdar, S. F., Lay, C., \& Struthers, W. (2003). The process of acculturation and basic goals: Testing a multidimensional individual difference acculturation model with Iranian immigrants in Canada. Applied Psychology: An International Review, 52 (4), 555-579. doi: 10.1111/1464-0597.00151

Sam, D. L. (2006). Acculturation: conceptual background and core components. In J. W. Berry, \& D. L. Sam, The Cambridge Handbook of Acculturation Psychology, pp. 11-26. Cambridge, UK: Cambridge University Press.

Sanchez, J., \& Fernandez, D. (1993). Acculturative stress among Hispanics: A bidimensional model of ethnic identification. Journal of Applied Social Psychology, 23, 654-668. doi: 10.1111/j.1559-1816.1993.tb01107.x

Sandhu, D. S., \& Asrabadi, B. R. (1994). Development of an acculturative stress scale for International students: Preliminary findings. Psychological Reports, 75, 
435-448. doi: 10.2466/pr0.1994.75.1.435

Searle, W. \& Ward, C. (1990). The prediction of psychological and sociocultural adjustment during across-cultural transitions. International Journal of Intercultural Relations, 14, 449-464. doi: 10.1016/0147-1767(90)90030-Z

Schmitt, D. P. (2008). Attachment matters: Patterns of romantic attachment across gender, geography, and cultural forms. In J. Forgas \& J. Fitness (Eds.), Social relationships: Cognitive, affective, and motivational processes (pp. 75-97). New York: Psychology Press.

Schmitt, D. P. (2010). Romantic attachment from Argentina to Zimbabwe: Patterns of adaptive variation across contexts, cultures, and local ecologies. In Erdman, P., \& Ng, Kok-mun (Ed.), Attachment: expanding the cultural connections. (pp. 211-226). New York: Talor \& Grancis Group.

Schmitt, D. P., \& Allik, J. (2005). Simultaneous administration of the Rosenberg SelfEsteeem Scale in 53 nations: Exploring the universal and culture-specific features of global self-esteem. Journal of Personality and Social Psychology, 89, 623-642. doi: 10.1037/0022-3514.89.4.623

Schmitt, D. P., Alcalay, L., Allensworth, M., Allik, J., Alut, I., Austers, I., ... Zupanèiè, A. (2004). Patterns and universals of adult romantic attachment across 62 cultural regions: Are models of self and of other pancultural constructs? Journal of Cross-Cultural Psychology, 35, 367-402. doi: $10.1177 / 0022022104266105$

Shaffer, P., Vogel, D. L., \& Wei, M. (2006). The mediating roles of anticipated risks, anticipated benefits, and attitudes on the decision to seek professional help: An 
attachment perspective. Journal of Counseling Psychology, 53, 442-452. doi: 10.1037/0022-0167.53.4.442

Simpson, J. A. (1990). The influence of attachment styles on romantic relationships. Journal of Personality and Social Psychology, 59, 971-980. doi: 10.1037/0022-3514.59.5.971

Smith, R. A., \& Khawaja, N. G. (2011). A review of the acculturation experiences of international students. International Journal of Intercultural Relations, 35, 699-713. doi :10.1016/j.ijintrel.2011.08.004

Sochos, A., \& Diniz, M. (2011). The role of attachment in immigrant sociocultural adaptation and psychological distress. Journal of Community \& Applied Social Psychology, 22, 75-91. doi: 10. 1002/casp.1102

Sroufe, L. A. (1990). The role of training in attachment assessment. Society for Research in Child Development Newsletter, pp. 1-2.

Statistics Solutions. (2015). The multiple linear regression analysis in SPSS. [Online article]. Retrieved from http://www.statisticssolutions.com/the-multiple-linearregression-analysis-in-spss/

Suomi, S. (2008). Attachment in Rhesus monkeys. In J. Cassidy, P. R. Shaver (Eds.), Handbook of attachment: Theory, research, and clinical applications $\left(2^{\text {nd }}\right.$ ed., pp. 173-191). New York, NY: The Guilford Press.

UCLA: Statistical Consulting Group. (n.d.). Regression diagnostics. In SPSS web books: regression with SPSS. Retrieved from http://www.ats.ucla.edu/stat/spss/webbooks/reg/chapter2/spssreg2.htm van Ijzendoorn, M. H., \& Sagi-Schwartz, A. (2008). Cross-cultural patterns of 
attachment: Universal and contextual dimensions. In J. Cassidy \& P. R. Shaver (Eds.), Handbook of attachment: Theory, research, and clinical applications ( $2^{\text {nd }}$ ed., pp. 880-905). New York: Guilford Press.

van Oudenhoven, J. P., \& Hofstra, J. (2006). Personal reactions to ‘strange’ situations: Attachment styles and acculturation attitudes of immigrants and majority members. International Journal of Intercultural Relations, 30, 783-798. doi: 10.1016/j.ijintrel.2006.05.005

Verkuyten, M. (1998). Perceived discrimination and self-esteem among ethnic minority adults. Journal of Social Psychology, 138, 479-493.

Wang, C., \& Mallinckrodt, B. (2006a). Acculturation, attachment, and psychosocial adjustment of Chinese/Taiwanese international students. Journal of Counseling Psychology, 53, 422-433. doi: 10. 1037/0022-0167.53.4.422

Wang, C., \& Mallinckrodt, B. (2006b). Differences between Taiwanese and U. S. Cultural beliefs about ideal adult attachment. Journal of Counseling Psychology, 53, 192-204. doi: 10. 1037/0022-0167.53.2.192

Wang, K. T., Slaney, R. B., \& Rice, K. G. (2007). Perfectionism in Chinese university students from Taiwan: A study of psychological well-being and achievement motivation. Personality and Individual Differences, 42, 1279-1290.

Ward, C. (1996). Acculturation. In D. Landis \& Bhagat (Eds.), Handbook of intercultural training (pp. 124-147). Newbury Park: Sage Publications.

Ward, C. (2001). The ABCs of acculturation. In D. Matsumoto (ed.), Handbook of culture and psychology (pp. 411-455). New York: Oxford University Press.

Ward, C., Bochner, S. \& Furnham, A. (2001). The psychology of culture shock. Sussex: 
Routledge.

Ward, C., \& Kennedy, A. (1993). Psychological and socio-cultural adjustment during cross-cultural transitions: a comparison of secondary students at home and abroad. International Journal of Psychology, 28, 129-147. doi:

$10.1080 / 00207599308247181$

Ward, C., \& Kennedy, A. (1994). Acculturation strategies, psychological adjustment and sociocultural competence during cross-cultural transitions. International Journal of Intercultural Relations, 18, 329-343. doi: 10.1016/01471767(94)90036-1

Ward, C., \& Kennedy, A. (1999). The measurement of sociocultural adaptation. International Journal of Intercultural Relations, 23, 659-677. doi: 10.1016/0147-1767(99)00014-0

Ward, C., \& Rana-Deuba, A. (1999). Acculturation and Adaptation Revisited. Journal of Cross-Cultural Psychology, 30, 422-442. doi:

$10.1177 / 0022022199030004003$

Wei, M., Ku, T., Russell, D. W., Mallinckrodt, B., \& Liao, K. Y. (2008). Moderating effects of three coping strategies and self-esteem on perceived discrimination and depressive symptoms: A minority stress model for Asian international students. Journal of Counseling Psychology, 55, 451-462. doi: $10.1037 / \mathrm{a} 0012511$

Wei, M., Russell, D. W., Mallinckrodt, B., \& Vogel, D. L. (2007). The experiences in Close Relationship Scale (ECR)-Short Form: Reliability, validity, and factor structure. Journal of Personality Assessment, 88, 187-204. 
Wei, M., Vogel, D. L., Ku, T.-Y., \& Zakalik, R. A. (2005). Adult attachment, affect regulation, negative mood, and interpersonal problems: The mediating roles of emotional reactivity and emotional cutoff. Journal of Counseling Psychology, 52, 14-24. doi: 10.1037/0022-0167.52.1.14

Weinfield, N. S., Sroufe, L. A., Egeland, B., \& Carlson, E. (2008) Individual differences in infant-caregiver attachment: Conceptual and empirical aspects of security. In J. Cassidy, P. R. Shaver (Eds.), Handbook of attachment: Theory, research, and clinical applications ( ${ }^{\text {nd }}$ ed., pp. 78-101). New York, NY: The Guilford Press.

Weiss, R. S. (1982). Attachment in adult life. In C. M. Parkes \& J. Stevenson-Hinde (Eds.), The place of attachment in human behavior (pp. 171-184). New York: Basic Books.

Weiss, R. S. (1986). Continuities and transformations in social relationships from childhood to adulthood. In W.W. Hartup \& Z. Rubin (Eds.), Relationships and development (pp. 95-110). Hillsdale, NJ: Erlbaum.

Wilcox, R. R. (2011). Introduction to robust estimation and hypothesis Testing ( ${ }^{\text {rd }}$ ed.). Waltham, MA: Academic Press

Yakunina, E. S., Weigold, I. K., Weigold, A., Hercegovac, S., \& Elsayed, N. (2013). International students’ personal and multicultural strengths: Reducing acculturative stress and promoting adjustment. Journal of Counseling \& Development, 91, 216-223. doi:10.1002/j.1556-6676.2013.00088.x

Yeh, C. J., \& Inose, M. (2003). International students’ reported English fluency, social support satisfaction, and social connectedness as predictors of acculturative 
stress. Counseling Psychology Quarterly, 16, 15-28. doi:

$10.1080 / 0951507031000114058$

You, H. S., \& Malley-Morrison, K. (2000). Young adult attachment styles and intimate relationships with close friends: A cross-cultural study of Koreans and Caucasian Americans. Journal of Cross-Cultural Psychology, 31, 528-534. doi: $10.1177 / 0022022100031004006$

Zhang, J. \& Goodson, P. (2011). Predictors of international students’ psychosocial adjustment to life in the United States: A systematic review. International Journal of Intercultural Relations, 35, 139-162.

doi:10.1016/j.ijintrel.2010.11.011

Zheng, X. \& Berry, J. W. (1991). Psychological adaptation of Chinese sojourners in Canada. International Journal of Psychology, 26, 451-470. doi: $10.1080 / 00207599108247134$

Zung, W. W. K. (1965). A self-rating depression scale. Archives of General Psychiatry, 12, 63-70. 


\section{Vita}

\section{Miao Li}

Date of Birth: October $18^{\text {th }}, 1985$

Place of Birth: Changsha, China

\section{Education}

University of Kentucky

Doctor of Philosophy in Counseling Psychology |4.00 GPA
Lexington, $K Y$

Expected August 2016

Dissertation title: The Role of Adult Attachment in International Students' Acculturation Process

(Defended November 2015)

Committee Chair: Dr. Jeff Reese

Boston College

Master of Arts in Mental Health Counseling | 3.94 GPA

Waseda University

Bachelor of Arts in International Liberal Studies | 3.96 GPA | Top 10\%

University College London

Study Abroad Affiliate student in the Department of Psychology

\section{Counseling-Related Experience}

University of California, Irvine Counseling Center Intern

Supervisors: Frances Diaz, Psy.D., Dianna Gonzalez, Ph.D., Jessica

Ortega, Ph.D., Amy La, Ph.D., Diana Chan, Psy.D.

\section{Eastern State Hospital Counselor}

Supervisors: David Susman, Ph.D., John Scanish, Psy.D., Sean

Reilley, Ph.D., Rebecca Asher, Psy.D., and Maria Haugen, Ph.D.

University of Kentucky Supervision and Assessment Practicum

Supervisor: Michael McClellan, Ph.D.

Eastern Kentucky University Counseling Center Counselor

Supervisors: Tara Hart, Ph.D., Kevin Stanley, Ph.D.

University of Kentucky Counseling Center Counselor

Supervisor: Nathan Miles, Ph.D., Aesha Tyler, Psy.D., Tina Bryant, Ph.D.

University of Kentucky Supervision Practicum

Supervisor: Jeff Reese, Ph.D.

Integrated Substance-Informed Survivor Therapy Research Team

Supervisors: Pamela Remer, Ph.D., and Kim Waldheim, M.S.
Chestnut Hill, MA

May 2011

Tokyo

Mar. 2009

London

Sep. 2006 - Jun. 2007

Irvine, CA

Aug. 2015- present

Lexington, KY

Aug. 2014- Jun. 2015

Lexington, $\mathrm{KY}$

Feb. 2015 - Jun. 2015

Richmond, KY

Aug. 2013 - May 2014

Lexington, $\mathrm{KY}$

Aug. 2012 - Jun. 2014

Lexington, $\mathrm{KY}$

Jan. 2013 - May 2013

Lexington, KY

Jul. 2012 - May 2013 
Ally Development Workshop

Lexington, $\mathrm{KY}$

Supervisors: Pamela Remer, Ph.D., and Rory Remer, Ph.D.

Aug. 2012

Chrysalis House Counselor

Supervisors: Carmella Yates, Ph.D., and Shannon Waters, CADC.

Lexington, $\mathrm{KY}$

Jan. 2012 - May 2012

Boston Area Rape Crisis Center (BARCC) Counselor

Cambridge, MA

Supervisors: Sharon Imperato, LMHC, and Vanessa Seibald, LICSW.

Sep. 2010 - May 2011

Reaching Out About Depression (ROAD) Advocate

Cambridge, MA

Supervisor: Lisa Goodman, Ph.D., Cara Feldberg, Psy.D.

Sep. 2009 - May 2010

\section{Teaching Experience}

EDP 650 Psychopathology Teaching Assistant

Supervisor: Michael McClellan, Ph.D.

GCS 199 Career Counseling Seminar

Instructor
University of Kentucky-Lexington, KY

Aug. 2014 - Dec. 2014

Eastern Kentucky University-Richmond, KY Jan. 2014 - May 2014

Supervisor: Michalle Rice, M.S., L.P.P, Jen Walker, Ph.D.

EDP 202 Human Development and Learning (Undergraduate Course) Teaching Assistant

Supervisor: Kenneth Tyler, Ph.D.

HHS 453 Cultural Competence in Health Care (Undergraduate Course) Teaching Assistant Supervisor: Randa Remer, Ph.D.
University of Kentucky-Lexington, KY

Aug. 2013 - Jun. 2014

University of Kentucky-Lexington, KY Jan. 2013 - May 2014 \& Feb. 2015

\section{Awards and Scholarships}

Lyman T. Johnson Academic Fellowship

merit-based fellowship for students contribute to UK's

compelling interest in diversity

Gillis Award

merit-based scholarship

Counseling Psychology Award

merit-based scholarship

Community Student Scholarship

merit-based scholarship

Dean's List
University of Kentucky

Aug. 2012-Present

University of Kentucky

Aug. 2011-May 2012

Boston College

Aug. 2009- May 2011

Waseda University

Apr. 2006- Mar. 2007

Waseda University

Jun. 2005 - Mar. 2009 


\section{Professional Affiliations and Leadership Roles}

American Psychological Association, Graduate Student Member,

Aug. 2010 -Present

American Psychological Association, International Section of

Aug. 2014 -Present

Division 17 Counseling Psychology, Student Member

Boston College, Chinese Students and Scholars Association,

Aug. 2010 -Jul. 2011

Financial Director

\section{Research Experience}

Diversity Training Research Team

Advisor: Michael McClellan, Ph.D., Randa Remer, Ph.D.

Integrating Attachment Theory and Acculturation

Theory in Group Therapy Research Team

Advisor: Keisha Love, Ph. D.

Attachment Styles, Diversity, and Career

Development Lab

Advisor: Keisha Love, Ph.D.

International Students Acculturation, Attachment Style, and Psychological Well-being Research Team Advisor: Marie A. Sossou, Ph.D.

P20 Motivation and Learning Lab

Advisor: Ellen Usher, Ph.D.

Race and the Effects of Racial Discrimination

Research Team

Advisor: Usha Tummala-Narra, Ph.D.

Mentoring and Relational Health Research Team

Advisor: Belle Liang, Ph.D.

Gender Roles Research Team

Advisor: James Mahalik, Ph.D.
University of Kentucky-Lexington, KY

Jan. 2015 - Present

University of Kentucky-Lexington, KY

Aug. 2013- Present

University of Kentucky-Lexington, KY Aug. 2012 - May 2013

University of Kentucky-Lexington, KY

Aug. 2012 - Present

University of Kentucky-Lexington, KY

Sep. 2011 - Aug. 2012

Boston College-Chestnut Hill, MA Aug. 2012 - Jun. 2014

Boston College-Chestnut Hill, MA Sep. 2009 - Jun. 2011

Boston College-Chestnut Hill, MA

Jun. 2010 - Sep. 2010

\section{Peer-Reviewed Manuscripts Under Review}

Li, M., \& Love, K. (Manuscript Submitted). Attachment relationships as a predictive variable for adjustment outcomes of middle school students. Journal of Adolescence.

Sundaram, S., Li, M., \& Kim, E. (Manuscript Submitted). Clinical supervision experiences of international graduate students in psychology. Teaching and Education in Professional Psychology. 


\section{Presentations}

Li, M. (2015, August). The Role of Adult Attachment in International Student's Acculturation process. J. Helms (Chair). In International Students and Immigrants' Acculturation, Identity and Mental Health. Symposium session presented at the American Psychological Association Annual Convention, Toronto, Canada.

Li, M., Mason, D. (2014, August). International Students: The Relationship between Acculturation and Adjustment Outcomes. Poster session presented at the American Psychological Association Conference, Washington, DC.

Li, M., Mason, D., Sossou, M. A., \& Love, K. (2013, August). The Role of Attachment Style and Acculturation in International Student's Psychological Well-being. Poster session presented at the American Psychological Association Conference, Honolulu, HI.

Li, M., \& Love, K. (2012, October). Attachment Relationships as a Predictive Variable for Adjustment Outcomes of Middle School Students. Poster session presented at the Society for Research in Child Development Themed Meeting, Tampa, FL.

Li, M., Kim, E., Sundaram, S., \& Tummala-Narra, P. (2012, August). International students' supervision experiences in counseling and clinical psychology programs. Poster session presented at the American Psychological Association Conference, Orlando, FL.

Li, Z., Li, M., Salgado, A., Toland, M. D., \& Usher, E. L. (2012, March). Development of middle level students' self-efficacy for self-regulation in mathematics. Poster session presented at the Kentucky Psychological Association Foundation Spring Academic Conference, Lexington, KY.

Sundaram, S., Kim, E., Li, M., \& Balci, I. (2010, October). Supervision experiences of international students in counseling and clinical programs. Individual presentation at the $10^{\text {th }}$ annual Diversity Challenge of the Institute for the Study and Promotion of Race and Culture at Boston College, Chestnut Hill, MA.

Nam, J. S., Duffy, N. M., Singer, R. R., Reid, A., Lee, H. J., Li, M., \& Liang, B. (2010, August). Postcards for Peace: Evaluation of a Youth Organizing Program. Poster session presented at the American Psychological Association Conference, San Diego, CA.

\section{Other Professional Experience}

H\&A Noto Legal Office Office Assistant

Tokyo

Feb. 2009 - Jul. 2009

Isetan Department Store Sales Assistant

Tokyo

Aug. 2007 - Jun. 2008

\section{Volunteer Experience}


- Japanese Tutor to International students (English Speaking)

Tokyo Sep. 2005 - Jul. 2008 